\title{
The AquaVIT-1 intercomparison of atmospheric water vapor measurement techniques
}

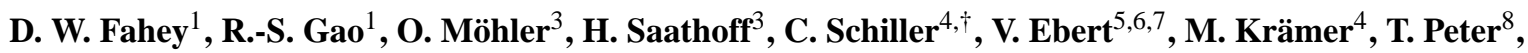 \\ N. Amarouche ${ }^{9}$, L. M. Avallone ${ }^{10,{ }^{*}}$, R. Bauer ${ }^{4}$, Z. Bozóki ${ }^{11}$, L. E. Christensen ${ }^{12}$, S. M. Davis ${ }^{1,2}$, G. Durry ${ }^{13}$, \\ C. Dyroff ${ }^{14}$, R. L. Herman ${ }^{12}$, S. Hunsmann ${ }^{5}$, S. M. Khaykin ${ }^{15}$,*** , P. Mackrodt ${ }^{5}$, J. Meyer ${ }^{4}$, J. B. Smith ${ }^{16}$, N. Spelten ${ }^{4}$, \\ R. F. Troy ${ }^{12}$, H. Vömel ${ }^{1,2, * *}$, S. Wagner ${ }^{5,7}$, and F. G. Wienhold ${ }^{8}$
}

${ }^{1}$ National Oceanic and Atmospheric Administration, Earth System Research Laboratory, Boulder, CO, USA

${ }^{2}$ Cooperative Institute for Research in Environmental Sciences, University of Colorado, Boulder, CO, USA

${ }^{3}$ Karlsruhe Institute of Technology, Institute for Meteorology and Climate Research, Atmospheric Aerosol Research (IMK-AAF), Karlsruhe, Germany

${ }^{4}$ Institute for Energy and Climate Research, Stratosphere (IEK-7), Forschungszentrum Jülich, Jülich, Germany

${ }^{5}$ University of Heidelberg, Physikalisch-Chemisches Institut (PCI), Heidelberg, Germany

${ }^{6}$ Physikalisch-Technische Bundesanstalt (PTB, National Metrology Institute of Germany), Bundesallee 100,

Brunswick, Germany

${ }^{7}$ Technical University Darmstadt, Center of Smart Interfaces (CSI), Darmstadt, Germany

${ }^{8}$ Institute for Atmospheric and Climate Science, ETH Zurich, 8092 Zurich, Switzerland

${ }^{9}$ Division Technique de l'Institut National des Sciences de l'Univers, UPS 855 CNRS, Meudon, France

${ }^{10}$ Department of Atmospheric and Oceanic Sciences, University of Colorado, Boulder, CO, USA

${ }^{11}$ MTA-SZTE Research Group on Photoacoustic Spectroscopy, University of Szeged, Szeged, Hungary

${ }^{12}$ Jet Propulsion Laboratory, California Institute of Technology, Pasadena, CA, USA

${ }^{13}$ Groupe de Spectrométrie Moléculaire et Atmosphérique, UMR CNRS 7331, Université de Reims-Champagne-Ardenne, Reims, France

${ }^{14}$ Karlsruhe Institute of Technology (KIT), Institute for Meteorology and Climate Research, Atmospheric Trace Gases and Remote Sensing (IMK-ASF), Karlsruhe, Germany

${ }^{15}$ Central Aerological Observatory, Moscow, Russia

${ }^{16}$ School of Engineering and Applied Sciences, Harvard University, Cambridge, MA, USA

*now at: the National Science Foundation, Washington DC, USA

** now at: Meteorologisches Observatorium Lindenberg, Lindenberg, Germany

**** now at: CNRS/INSU, LATMOS, IPSL, Université de Versailles St. Quentin, Guyancourt, France

$\dagger$ deceased

Correspondence to: D. W. Fahey (david.w.fahey@noaa.gov)

Received: 5 January 2014 - Published in Atmos. Meas. Tech. Discuss.: 1 April 2014

Revised: 16 August 2014 - Accepted: 27 August 2014 - Published: 26 September 2014

\begin{abstract}
The AquaVIT-1 intercomparison of atmospheric water vapor measurement techniques was conducted at the aerosol and cloud simulation chamber AIDA (Aerosol Interaction and Dynamics in the Atmosphere) at the Karlsruhe Institute of Technology, Germany, in October 2007. The overall objective was to intercompare state-of-the-art and prototype atmospheric hygrometers with each other and with
\end{abstract}

independent humidity standards under controlled conditions. This activity was conducted as a blind intercomparison with coordination by selected referees. The effort was motivated by persistent discrepancies found in atmospheric measurements involving multiple instruments operating on research aircraft and balloon platforms, particularly in the upper troposphere and lower stratosphere, where water vapor reaches 
its lowest atmospheric values (less than $10 \mathrm{ppm}$ ). With the AIDA chamber volume of $84 \mathrm{~m}^{3}$, multiple instruments analyzed air with a common water vapor mixing ratio, by extracting air into instrument flow systems, by locating instruments inside the chamber, or by sampling the chamber volume optically. The intercomparison was successfully conducted over 10 days during which pressure, temperature, and mixing ratio were systematically varied $(50$ to $500 \mathrm{hPa}, 185$ to $243 \mathrm{~K}$, and 0.3 to $152 \mathrm{ppm}$ ). In the absence of an accepted reference instrument, the absolute accuracy of the instruments was not established. To evaluate the intercomparison, the reference value was taken to be the ensemble mean of a core subset of the measurements. For these core instruments, the agreement between 10 and $150 \mathrm{ppm}$ of water vapor is considered good with variation about the reference value of about $\pm 10 \%( \pm 1 \sigma)$. In the region of most interest between 1 and $10 \mathrm{ppm}$, the core subset agreement is fair with variation about the reference value of $\pm 20 \%( \pm 1 \sigma)$. The upper limit of precision was also derived for each instrument from the reported data. The implication for atmospheric measurements is that the substantially larger differences observed during in-flight intercomparisons stem from other factors associated with the moving platforms or the non-laboratory environment. The success of AquaVIT-1 provides a template for future intercomparison efforts with water vapor or other species that are focused on improving the analytical quality of atmospheric measurements on moving platforms.

\section{Introduction}

Water vapor is the most important greenhouse gas in the atmosphere, representing a major feedback to warming and other changes in the climate system (Trenberth et al., 2007). Knowledge of the distribution of water vapor and how it is changing as climate changes is especially important in the upper troposphere and lower stratosphere (UT-LS), where water vapor plays a critical role in determining atmospheric radiative balance, cirrus cloud formation, and photochemistry. Trends in UT-LS water vapor have the potential to alter surface radiative forcing (Solomon et al., 2010; Dessler, 2013). The dehydration process reduces water vapor amounts to part per million (ppm) values in the tropical UT air before it enters the LS. Ice microphysics and cirrus cloud nucleation that characterize the dehydration process are not fully understood at present, limiting our ability to accurately model the dehydration process and, hence, our ability to fully describe the interaction of the UT-LS water vapor distribution with climate change.

Our understanding of water vapor processes in the UTLS has been limited, in part, by large uncertainties in available water measurements. The 2000 Assessment of Upper Tropospheric and Stratospheric Water Vapor (SPARC, 2000) is the most recent comprehensive assessment of water vapor observations. It includes intercomparisons of satellite, aircraft, balloon-borne, and ground-based water vapor instrumentation that show discrepancies in the critical range of 1 to $10 \mathrm{ppm}$. Since the SPARC report, discrepancies have remained between key data sets. An example of tropical profile measurements that reveal substantial disagreements is shown in Fig. 1 (Vömel et al., 2007a; Jensen et al., 2008; Weinstock et al., 2009; Rollins et al., 2014). One important consequence of these systematic differences is that in some cases large values of the relative humidity with respect to ice are inferred in the UT-LS, with the largest being over $200 \%$ (Jensen et al., 2005; Peter et al., 2006). Such values are unexpected based on our understanding of the fundamental microphysics of ice formation. In contrast, in other aircraft and balloon measurements, liquid water supersaturation was not observed (Krämer et al., 2009).

The AquaVIT-1 intercomparison campaign of water vapor measurement techniques was undertaken at the AIDA (Aerosol Interaction and Dynamics in the Atmosphere) chamber at the Karlsruhe Institute of Technology (KIT) as an effort to clarify uncertainties in UT-LS water vapor measurements and help identify the cause(s) of the discrepancies, such as instrument calibration and artifacts. The campaign did not include an evaluation of instrument sampling issues related to platform configuration, the ambient environment, or inlets, all of which can affect in-flight performance and inherently are more difficult to evaluate - nor an evaluation of instrument calibration procedures.

AquaVIT-1 was a controlled, refereed, and blind intercomparison of a large group of water vapor instruments using the AIDA chamber. The ranges of pressure, temperature, and water vapor in the chamber included those found in the tropical UT-LS. The principal objective of AquaVIT-1 was to compare instruments in a controlled ground-based facility with the expectation that systematic measurement problems and perhaps their causes could be identified more readily and with less expense and effort than in airborne campaigns. In addition, the campaign included instruments that were relatively new to atmospheric studies or still under development in order to accelerate their progress in becoming reliable and accurate instruments for use in future field measurement campaigns.

The AquaVIT- 1 experiments were initially planned as part of a SPARC workshop on upper tropospheric humidity in June 2007 (Peter et al., 2008) and subsequently occurred in two one-week phases in October 2007 in Karlsruhe, Germany. The first phase was devoted to static intercomparisons with a separate experiment each day (15-19 October) at nearconstant temperature conditions and several fixed pressure levels. The second phase was a week of dynamic intercomparisons, with several experiments each day (22-26 October) under varying pressure, temperature, and humidity conditions and with or without ice clouds present. In this paper, only the static experiments and their results are described. 

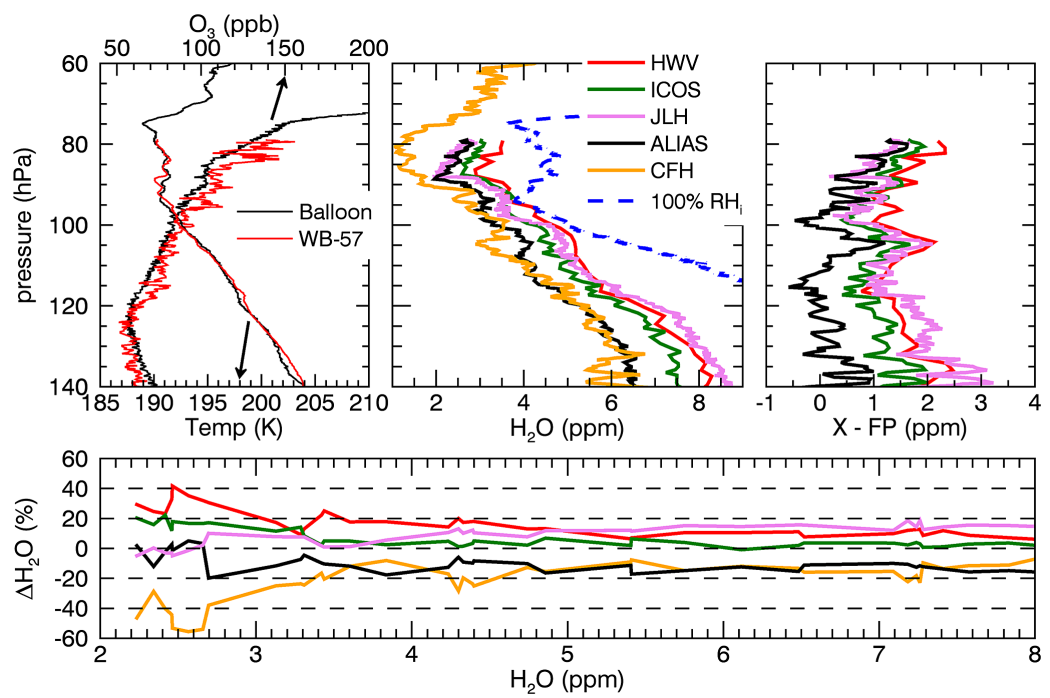

Figure 1. Profiles of water vapor mixing ratios from three core instruments included in the AquaVIT-1 intercomparison (CFH, HWV, and JLH), the Aircraft Laser Infrared Absorption Spectrometer (ALIAS; Webster et al., 1994), and the Integrated Cavity Output Spectroscopy (ICOS) instrument (Sayres et al., 2009). All measurements were made in situ near San Jose, Costa Rica, on 1 February 2006. The CFH measurements were made from a small balloon launched near the San Jose airport. The other measurements were made onboard the NASA WB-57F high-altitude research aircraft on descent into the San Jose airport. Top left panel: profiles of temperature (bottom axis) and $\mathrm{O}_{3}$ (top axis) versus ambient pressure measured from the WB-57F (red) and balloon (black) showing good correspondence between air masses sampled from these different platforms. Top middle panel: water vapor mixing ratios measured by the balloon and aircraft instruments. Saturation mixing ratios (blue dashed line) were calculated using balloon temperature and pressure. Top right panel: vertical profiles showing differences between each of the WB-57F instruments and the FP $(\mathrm{CFH})$ balloon instrument. Bottom panel: deviations from a mean profile (mean profile consists of equally weighted HWV, ICOS, JLH, ALIAS, and CFH) for HWV (red), ICOS (green), JLH (violet), ALIAS (black), and CFH (gold)). From Rollins et al. (2014).

\section{AIDA chamber}

The Aerosol Interaction and Dynamics in the Atmosphere (AIDA) chamber is located at KIT. The chamber is an aluminum vessel of $84 \mathrm{~m}^{3}$ volume, with a facility to control pressure from $1 \mathrm{~atm}$ to as low as $0.01 \mathrm{hPa}$ and temperature from $313 \mathrm{~K}$ to as low as $183 \mathrm{~K}$ (Möhler et al., 2003). This range of conditions allows for simulating atmospheric aerosol and cloud formation processes under tropospheric and lower stratospheric conditions on short (minutes) to long (hours) timescales. Important features of the AIDA chamber for AquaVIT-1 were, first, that the operation of the chamber allowed for conditions of near-constant pressure $( \pm 1 \mathrm{hPa})$ and temperature $( \pm 0.3 \mathrm{~K})$. Under these conditions, water vapor amounts were constant or slowly changing for periods of many minutes, thereby allowing adequate time for all instruments to sample chamber air and make multiple determinations of water vapor content. Second, the water vapor mixing ratio and humidity could be altered by the addition of water vapor or dry air, or the partial removal of chamber air by pumping. Third, the large chamber volume has a small wall-to-volume ratio and allows multiple instruments to be located inside the chamber or to sample air from outside the chamber without significantly disturbing internal conditions. To this end, customized, extractive sampling probes were implemented for AquaVIT-1 to deliver chamber air to instruments located outside the chamber. The probes were made of stainless steel and heated to avoid water adsorption on the probe inner walls at low chamber temperatures.

\section{Data protocol}

All investigators signed the data protocol adopted for AquaVIT-1. The protocol encouraged rapid assessment and use of the results from the AquaVIT-1 tests while upholding the rights of the individual scientists and treating all participants equitably. Key features of the protocol are as follows:

- Quick-look data. Preliminary or quick-look data obtained during the AquaVIT-1 campaign were made available to the referees as soon as possible following each day's experiments $(<24 \mathrm{~h})$. In the event of obvious difficulties, this allowed the referees to suggest that corrections or amendments to data processing, instrument configuration, or instrument operation be made as soon as possible, thereby improving the overall outcome of the intercomparison. All water vapor mixing ratio values were archived as molar fractions in units of ppm (i.e., $\mu \mathrm{mol} \mathrm{mol}^{-1}$ ) unless otherwise noted. 
- Blind intercomparison. A blind intercomparison was established so that preliminary data submitted during the campaign (typically within $48 \mathrm{~h}$ ) and the short evaluation period immediately following the campaign were available only to the referees (O. Möhler, D. W. Fahey, and R. S. Gao) who were not affiliated with any participating instrument team.

- Final data. After the end of the short evaluation period (4 December 2007) the submitted data sets were released to all participants. Any further changes to a submitted data set required documentation from an instrument's investigator and approval by the referees. All data sets were considered final on 10 January 2008.

A dedicated wiki page with password protection enabled archiving and interchange of data sets among the participants and access to other AquaVIT-1 documents and information.

\section{Instruments}

AquaVIT-1 included more than 20 instruments utilizing either state-of-the-art or newly developed techniques and, thereby, represented a large fraction of the international UTLS water vapor community. A subset of 15 instruments divided into core and non-core groups in Table 1 is the focus of this paper. This subset participated in the formal, blind, refereed intercomparison. The remaining instruments did not participate in the formal intercomparison or acquired insufficient science-quality data for analysis.

The core instrument subgroup includes APicT, CFH, FISH-1, FISH-2, FLASH-B1, FLASH-B2, HWV, and JLH (see Appendix A). The APicT, as an AIDA facility instrument, has been involved in many AIDA chamber experiments. The other instruments have a long history of field measurements and intercomparisons on balloon and aircraft platforms operating in the upper troposphere and stratosphere. The mixing ratio discrepancies noted at low values in these regions derive from a number of data sets from these instruments. Establishing the accuracy of the core instruments under controlled laboratory conditions was one primary objective of AquaVIT-1. The reported uncertainty for each of the core instruments is listed in Table 2.

The non-core instrument subgroup includes MBW373LX, SnowWhite, ISOWAT, OJSTER, PicoSDLA, WaSul-Hygro2, and CLH. This group includes mature instruments that have also been used in field measurements as well as instruments that were in the initial to later stages of development.

Following extensive discussion among the organizers and investigators, the decision was made that no AquaVIT-1 instrument would serve as the reference instrument. No participating instrument had played this role previously for a multi-instrument intercomparison in a chamber configuration, and no sufficiently objective and analytical basis could be developed by the group prior to or following the campaign to determine which instrument(s) would qualify as a reference. See Sect. 6.5 for further discussion of reference choices. As a consequence, only relative quantitative evaluations were conducted of the chamber experiments.

The intercomparison results are expressed in units of water vapor molar mixing ratio. The instrument suite measures different aspects of water vapor. For example, while Lyman$\alpha$ instruments measure mixing ratio (HWV and FISH), the CFH measures partial pressure and tunable diode laser (TDL) instruments measure column number density (JLH and APicT). Mixing ratio is preferred because it is easily derived from all measurement techniques and is conserved in the atmosphere and within extractive instrument systems (in the absence of the condensed phase). As a consequence, mixing ratio is a customary unit found in scientific interpretation and modeling studies.

Brief descriptions of the intercompared instruments, their configuration in the AIDA chamber, their performance during the static experiments, and lessons learned from AquaVIT-1 are included in Appendix A as provided by the respective instrument teams. Fundamental differences exist between the laboratory and flight environments (e.g., ambient pressure, temperature, flow rates, solar environment, and inlet sampling strategy) that generally represent some limit in the relevance of the laboratory results to instrument operation on moving platforms under ambient conditions. The nature of these differences and their impact on the measurements are different for each instrument. All flight instruments were modified or reconfigured to adapt to the laboratory setting, and, in some cases, sources of error or uncertainty associated with the laboratory implementation degraded instrument performance. While the AIDA configuration is not ideal in this regard, the value of a systematic laboratory intercomparison was clear in advance of AquaVIT-1 given the large discrepancies found in field observations.

\section{AIDA chamber instrument configuration}

The overall configuration of instruments in the AIDA chamber facility is shown in Fig. 2. The instrument sampling techniques used in AquaVIT-1 can be classified into two distinct types. The first type is extractive sampling, which requires gas to be removed through a probe located inside the chamber that connects to a sample line that passes through the chamber and/or thermal enclosure walls. Most of the core instruments used extractive sampling with heated probes (Fig. 3). Three instruments were located outside the chamber but inside the chamber thermal enclosure.

The second type is internal or non-extractive sampling. Three core instruments and one non-core instrument used non-extractive sampling. APicT and JLH used openpath optical absorption spectroscopy inside the chamber (Fig. 3). FLASH-B1 (FLuorescent Advanced Stratospheric 
Table 1. AquaVIT-1 instruments, participants, and institutes.

\begin{tabular}{|c|c|c|c|}
\hline Instrument (acronym) (technique) ${ }^{\mathrm{a}}$ & Type $^{\mathrm{b}}$ & Participants & Institute \\
\hline \multicolumn{4}{|l|}{ Core instruments } \\
\hline $\begin{array}{l}\text { AIDA-PCI-in-cloud-TDL (APicT) } \\
\text { (tunable diode laser technique }(T D L) \text { ) }\end{array}$ & NE & $\begin{array}{l}\text { Volker Ebert }{ }^{1, *} \text {, Christian Lauer }{ }^{1}, \text { Stefan Hunsmann } \\
\end{array}$ & $\begin{array}{l}\text { PCI, University of Heidelberg }{ }^{1} \text {, } \\
\text { now: PTB*, Karlsruhe Institute of Technology (KIT), } \\
\text { Germany }{ }^{2} \text {, } \\
\text { now: Technical University Darmstadt** }\end{array}$ \\
\hline $\begin{array}{l}\text { Cryogenic Frost-point Hygrometer }(\mathrm{CFH}) \\
\text { (frost-point) }\end{array}$ & $\mathrm{E}$ & Holger Vömel & $\begin{array}{l}\text { NOAA Earth System Research Laboratory and Univer- } \\
\text { sity of Colorado, Boulder, CO, USA (now at Deutscher } \\
\text { Wetterdienst, Lindenberg, Germany) }\end{array}$ \\
\hline $\begin{array}{l}\text { Fast In situ Stratospheric Hygrometer } \\
(\text { FISH-1 and FISH-2) } \\
(\text { Lyman- } \alpha)\end{array}$ & $\mathrm{E}$ & $\begin{array}{l}\text { Martina Krämer, Cornelius Schiller, Armin Afchine, } \\
\text { Reimar Bauer, Jessica Meyer, Nicole Spelten, Andres } \\
\text { Thiel, Miriam Kübbeler }\end{array}$ & Forschungszentrum Jülich, Jülich, Germany \\
\hline $\begin{array}{l}\text { FLuorescent Advanced Stratospheric Hygrom- } \\
\text { eter for Balloon (FLASH-B1 and FLASH-B2) } \\
(\text { Lyman- } \alpha)\end{array}$ & $\mathrm{NE}$ & Sergey Khaykin, Leonid Korshunov & Central Aerological Observatory, Moscow, Russia \\
\hline $\begin{array}{l}\text { Harvard Water Vapor }(\mathrm{HWV}) \\
(\text { Lyman- } \alpha)\end{array}$ & $\mathrm{E}$ & Jessica Smith, Elliot Weinstock & Harvard University, Cambridge, MA, USA \\
\hline $\begin{array}{l}\text { JPL Laser Hygrometer }(\mathrm{JLH}) \\
(T D L)\end{array}$ & $\mathrm{NE}$ & Robert Herman, Robert Troy, Lance Christensen & $\begin{array}{l}\text { Jet Propulsion Laboratory, California Institute of Tech- } \\
\text { nology, Pasadena, CA, USA }\end{array}$ \\
\hline \multicolumn{4}{|l|}{ Non-core instruments } \\
\hline $\begin{array}{l}\text { MBW-373LX } \\
\text { (frost point) }\end{array}$ & $\mathrm{E}$ & Harald Saathoff, Robert Wagner & KIT, Karlsruhe, Germany \\
\hline $\begin{array}{l}\text { SnowWhite } \\
\text { (frost point) }\end{array}$ & $\mathrm{NE}$ & Frank Wienhold, Ulrich Krieger, Martin Brabec & $\begin{array}{l}\text { Eidgenössische Technische Hochschule-ETH, Zürich, } \\
\text { Zurich, Switzerland }\end{array}$ \\
\hline $\begin{array}{l}\text { ISOWAT } \\
(T D L)\end{array}$ & $\mathrm{E}$ & Christoph Dyroff & KIT, Karlsruhe, Germany \\
\hline $\begin{array}{l}\text { Open-path Jülich Stratospheric TDL } \\
\text { Experiment (OJSTER) } \\
(T D L)\end{array}$ & $\mathrm{E}$ & $\begin{array}{l}\text { Martina Krämer, Cornelius Schiller, Armin Afchine, } \\
\text { Reimar Bauer, Jessica Meyer, Nicole Spelten, Andres } \\
\text { Thiel, Miriam Kübbeler }\end{array}$ & Forschungszentrum Jülich, Jülich, Germany \\
\hline $\begin{array}{l}\text { PicoSDLA } \\
(T D L)\end{array}$ & $\mathrm{NE}$ & $\begin{array}{l}\text { Georges Durry, Nadir Amarouche, Jacques Deleglise, } \\
\text { Fabien Frerot }\end{array}$ & $\begin{array}{l}\text { University of Reims, Champagne-Ardenne and Institut } \\
\text { National des Sciences de l'Univers/Centre National de } \\
\text { la Recherche Scientifique (INSU/CNRS), France }\end{array}$ \\
\hline $\begin{array}{l}\text { WaSul-Hygro2 } \\
\text { (photoacoustic) }\end{array}$ & $\mathrm{E}$ & Zoltan Bozóki, Árpád Mohácsi & University of Szeged, Hilase Ltd., Szeged, Hungary \\
\hline Closed-path Laser Hygrometer (CLH) (TDL) & $\mathrm{E}$ & Linnea Avallone, Sean Davis & University of Colorado, Boulder, CO, USA \\
\hline
\end{tabular}

${ }^{a}$ Instrument descriptions in Appendix A. ${ }^{\text {b }}$ Instrument type based on standard use configuration in atmospheric or laboratory measurements: extractive sampling (E) and non-extractive sampling (NE).

Hygrometer for Balloon) used a chamber window to measure Lyman- $\alpha$ fluorescence produced directly inside the chamber walls. Principal optical components of APicT and FLASHB1 were mounted outside the chamber but inside the thermal enclosure. The JLH laser, detector, and open-path mirrors were mounted entirely inside the chamber (Fig. 3), as was the SnowWhite instrument sensor. For these two instruments, the associated control and data-recording electronics remained outside the thermal enclosure. The open-path white cell used by APicT was mounted completely inside the AIDA chamber. By folding its optical path between the inner chamber walls, APicT was the only instrument that provided a measurement of the water vapor abundance averaged over the full diameter of the chamber.

\section{AquaVIT-1 static experiments}

\subsection{AIDA chamber conditions}

The chamber pressures and temperatures for the static experiments are shown in Fig. 4. Also shown are the nominal domains from approximately a decade of Harvard Water Vapor (HWV) observations in the tropics and midlatitudes (Weinstock et al., 2009) that show substantial overlap with the AquaVIT-1 experimental domains. In the experiments, temperature was reduced in daily steps from $\sim 240 \mathrm{~K}$ on the first day to $\sim 185 \mathrm{~K}$ on the last day. The transient temperature changes in Fig. $4 \mathrm{a}$ are the quasi-adiabatic responses to the pressure changes in Fig. $4 \mathrm{~b}$ that occur while the chamber walls and enclosure remain at a constant temperature. The 
Table 2. Core and non-core instrument uncertainty values.

\begin{tabular}{|c|c|}
\hline $\begin{array}{l}\text { Instrument name } \\
\text { (technique })^{1}\end{array}$ & Uncertainty in final data ${ }^{2}$ \\
\hline \multicolumn{2}{|l|}{ Core instruments } \\
\hline $\begin{array}{l}\text { APicT } \\
\text { (tunable diode laser technique (TDL)) }\end{array}$ & $\begin{array}{l}\text { Accuracy: }<5 \% \text {; precision: from } \approx 10 \% \text { at } 0.25 \mathrm{ppm} \mathrm{H}_{2} \mathrm{O} \text { to } 1-0.1 \% \\
\text { at }>20 \mathrm{ppm} \mathrm{H}_{2} \mathrm{O} \text {; for } \mathrm{H}_{2} \mathrm{O}<20 \mathrm{ppm} \text { : noise level ca. } 0.025 \mathrm{ppm}(1 \sigma \text { at } \\
\Delta t=2 \mathrm{~s}) \text { at } 80 \mathrm{~m} \text { path }\end{array}$ \\
\hline $\mathrm{CFH}$ & $10 \% @ \mathrm{H}_{2} \mathrm{O} \leq 5 \mathrm{ppm}$ \\
\hline (frost point) & $4 \% @ \mathrm{H}_{2} \mathrm{O}>5 \mathrm{ppm}$ \\
\hline FISH-1 \& FISH-2 & $\mathrm{H}_{2} \mathrm{O} \leq 20 \mathrm{ppm}, P>80 \mathrm{hPa}:$ \\
\hline$($ Lyman- $\alpha)$ & $6 \%+0.1 \mathrm{ppm}(\mathrm{FISH}-2)$ \\
\hline & $6-8 \%+0.15$ ppm (FISH-1) \\
\hline FLASH-B1 \& FLASH-B2 & $\pm(10 \%+0.1 \mathrm{ppm}) @ 10 \mathrm{hPa}<P<300 \mathrm{hPa}, \mathrm{H}_{2} \mathrm{O}>3 \mathrm{ppm}$ \\
\hline$($ Lyman- $\alpha)$ & $\pm(20 \%+0.1 \mathrm{ppm}) @ \mathrm{H}_{2} \mathrm{O}<3 \mathrm{ppm}$ \\
\hline $\mathrm{HWV}^{2}$ & $\pm 5 \%+0.53 /-0.28 \mathrm{ppm} @ P>100 \mathrm{hPa}$ \\
\hline$($ Lyman- $\alpha)$ & $\pm 10 \%+0.53 /-0.28 \mathrm{ppm} @ P \leq 100 \mathrm{hPa}$ \\
\hline JLH & $10 \%+0.15 \mathrm{ppm}(1 \mathrm{~s})$ \\
\hline$(T D L)$ & $10 \%+0.05 \mathrm{ppm}(10 \mathrm{~s})$ \\
\hline \multicolumn{2}{|l|}{ Non-core instruments } \\
\hline MBW-373LX (frost point) & $\begin{array}{l}\text { Accuracy } \pm 3 \% \text { and precision } \pm 1.5 \%\left( \pm 0.1^{\circ} \mathrm{C} \text { frost-point temperature }\right) \\
\text { at pressures }>150 \mathrm{hPa} \text { and frost-point temperatures }>-70^{\circ} \mathrm{C} \text {; unknown } \\
\text { systematic errors at lower pressures and temperatures }\end{array}$ \\
\hline SnowWhite (frost point) & $5 \%$ accuracy for mixing ratios $>10 \mathrm{ppm}$ \\
\hline ISOWAT & $4 \%$ precision for $\mathrm{H}_{2}^{16} \mathrm{O}$ \\
\hline$(T D L)$ & Accuracy suffered from instabilities of the optical alignment \\
\hline OJSTER & $2 \%$ accuracy for $\mathrm{H}_{2} \mathrm{O}>100 \mathrm{ppmv}$ \\
\hline$(T D L)$ & $\begin{array}{l}5 \% \text { accuracy for } \mathrm{H}_{2} \mathrm{O}<100 \mathrm{ppmv} \text {, } \\
2 \% \text { precision for } 1 \mathrm{~s}, 4 \% \text { for } 100 \mathrm{~Hz} \\
\text { (Due to a contamination problem, the detection limit varied during the } \\
\text { experiments) }\end{array}$ \\
\hline $\begin{array}{l}\text { PicoSDLA } \\
(T D L)\end{array}$ & 5 to $10 \%$ accuracy (measurement time of $800 \mathrm{~ms}$ ) \\
\hline $\begin{array}{l}\text { WaSul-Hygro } 2 \\
\text { (photoacoustic) }\end{array}$ & Approaches $1 \%$ above $100 \mathrm{ppm}$, lower accuracy at lower mixing ratios \\
\hline Closed-path Laser Hygrometer (CLH) $(T D L)$ & $15 \%$ above $15 \mathrm{ppm}$ \\
\hline
\end{tabular}

${ }^{1}$ Precision and accuracy values $( \pm 1 \sigma)$ provided by instrument investigators. See Table 4 for precision values derived from AquaVIT-1 data sets. ${ }^{2}$ These values reflect instrument performance specific to the AIDA facility and may differ from values reported in the literature for atmospheric measurements.

reported value was stable to $\pm 0.2 \mathrm{~K}(1 \sigma)$ during the measurement segments. Transient temperature excursions in the time series of up to $10 \mathrm{~K}$ are the adiabatic responses to the occasional rapid addition or removal of air from the chamber. Chamber pressure was held constant to $\pm 1 \mathrm{hPa}$ in $0.5-$ $1 \mathrm{~h}$ intervals or segments (between five and eight) during each day. Water vapor mixing ratio values varied depending on the amount of water added directly to the chamber at the beginning of each day's experiment and on the subsequent changes in chamber conditions.

For the static intercomparisons, data segments were selected that provided nearly constant pressures and temperatures. Table 3 shows the average pressure, temperature, and water vapor mixing ratio values for the segments used in the accuracy and precision analyses presented below. During each segment, the total extractive sampling flow in the range 50 to 140 standard $\mathrm{L} \mathrm{min}^{-1}$ depending on the instrument configuration and chamber pressure corresponds to a removal of 0.05 to $0.16 \%$ of the total chamber volume $\left(84 \mathrm{~m}^{3}\right)$ each minute. To maintain the AIDA pressure constant within $\pm 1 \mathrm{hPa}$, a servo control system added dry air $\left(<3 \mathrm{ppm} \mathrm{H}_{2} \mathrm{O}\right)$ as needed. During the static segments with constant pressure, the gas temperatures measured at various chamber locations deviated by less than $0.3 \mathrm{~K}$ from the average AIDA air temperature. A large vane-axial fan inside the chamber was used routinely to promote uniform mixing ratio and temperature conditions throughout the chamber (Möhler et al., 2003). With the use of the fan and extractive sampling points away from the chamber walls (Fig. 3), mixing ratio gradients are 
Table 3. Details of AquaVIT-1 static segments used in the accuracy and precision evaluations.

\begin{tabular}{|c|c|c|c|c|c|c|c|}
\hline Oct 2007 & $\#^{\mathrm{a}}$ & $\begin{array}{l}\text { Press. } \\
(\mathrm{hPa})^{\mathrm{b}}\end{array}$ & $\begin{array}{l}\text { Temp } \\
(\mathrm{K})^{\mathrm{b}}\end{array}$ & $\begin{array}{r}\text { Water vapor } \\
(\mathrm{ppm})^{\mathrm{c}}\end{array}$ & $\begin{array}{r}\text { Start time } \\
\text { (UTs) }\end{array}$ & $\begin{array}{r}\text { Stop time } \\
\text { (UTs) }\end{array}$ & $\begin{array}{r}\text { Length } \\
(\mathrm{s})\end{array}$ \\
\hline \multirow[t]{6}{*}{15 th } & 1 & 100 & 243 & 12.22 & 28500 & 30300 & 1800 \\
\hline & 2 & 200 & 243 & 5.16 & 32400 & 34200 & 1800 \\
\hline & 3 & 500 & 243 & 1.91 & 36000 & 39600 & 3600 \\
\hline & 4 & 200 & 243 & 3.58 & 43500 & 45300 & 1800 \\
\hline & 5 & 100 & 242 & 6.05 & 47100 & 48900 & 1800 \\
\hline & 6 & 50 & 242 & 10.41 & 50700 & 52500 & 1800 \\
\hline \multirow[t]{5}{*}{ 16th } & 7 & 200 & 225 & 33.87 & 30900 & 32700 & 1800 \\
\hline & 8 & 500 & 224 & 12.8 & 35700 & 38400 & 2700 \\
\hline & 9 & 200 & 223 & 15.59 & 41880 & 43080 & 1200 \\
\hline & 10 & 100 & 223 & 21.11 & 44880 & 46680 & 1800 \\
\hline & 11 & 50 & 223 & 31.09 & 48600 & 50400 & 1800 \\
\hline \multirow[t]{6}{*}{17 th } & 12 & 100 & 214 & 88.99 & 26880 & 28680 & 1800 \\
\hline & 13 & 200 & 214 & 46.79 & 29880 & 31380 & 1500 \\
\hline & 14 & 300 & 214 & 31.96 & 34200 & 37800 & 3600 \\
\hline & 15 & 200 & 213 & 44.44 & 41280 & 43080 & 1800 \\
\hline & 16 & 100 & 213 & 79.42 & 45480 & 47280 & 1800 \\
\hline & 17 & 50 & 213 & 151.57 & 49500 & 51300 & 1800 \\
\hline \multirow[t]{6}{*}{ 18th } & 18 & 120 & 197 & 1.62 & 28800 & 30600 & 1800 \\
\hline & 19 & 200 & 197 & 0.97 & 31980 & 33780 & 1800 \\
\hline & 20 & 300 & 197 & 0.64 & 36300 & 38100 & 1800 \\
\hline & 21 & 200 & 196 & 0.87 & 40080 & 41880 & 1800 \\
\hline & 22 & 80 & 196 & 1.77 & 45000 & 48600 & 3600 \\
\hline & 23 & 50 & 196 & 2.59 & 50400 & 52200 & 1800 \\
\hline \multirow[t]{8}{*}{ 19th } & 24 & 80 & 186 & 1.64 & 23400 & 25200 & 1800 \\
\hline & 25 & 120 & 186 & 1.03 & 27480 & 29280 & 1800 \\
\hline & 26 & 200 & 186 & 0.64 & 30300 & 31800 & 1500 \\
\hline & 27 & 300 & 186 & 0.44 & 33900 & 35700 & 1800 \\
\hline & 28 & 500 & 186 & 0.25 & 38100 & 39900 & 1800 \\
\hline & 29 & 200 & 185 & 0.8 & 43500 & 44700 & 1200 \\
\hline & 30 & 80 & 185 & 1.59 & 47850 & 49080 & 1500 \\
\hline & 31 & 50 & 185 & 2.34 & 50400 & 51300 & 900 \\
\hline
\end{tabular}

a Segment number. Segments not in italics were used in both accuracy and precision evaluations. Segments in italics were used only in the accuracy evaluation. ${ }^{b}$ Average measured chamber conditions over the segment. See Fig. 5 for example segments. ${ }^{c}$ Reference value derived from the linear fits to the core instrument time series (see Sect. 6.2(c) for details).

expected to be negligible for the purposes of this intercomparison.

Overnight between experiments the chamber was evacuated to less than $0.01 \mathrm{hPa}$. Each morning, an amount of pure water vapor (not disclosed to the instrument investigator teams) was added to the chamber and then subsequently mixed with dry synthetic air $(22.5 \%$ oxygen in nitrogen; low hydrocarbon grade, $<3 \mathrm{ppm} \mathrm{H}_{2} \mathrm{O}$ ) as the pressure was increased stepwise to $500 \mathrm{hPa}$. The resulting water vapor mixing ratios in the static measurement segments varied from 0.2 to $150 \mathrm{ppm}$ as shown in Table 3. Values were kept below ice saturation except on the last two experiment days. Particle number concentrations in the AIDA chamber after humidification and filling with synthetic air are typically below
$1 \mathrm{~cm}^{-3}$. These particles are typically smaller than $100 \mathrm{~nm}$ in diameter.

In certain situations the gas-phase water vapor mixing ratio is not conserved in the AIDA chamber. The first situation occurs when the water vapor mixing ratio of the synthetic air that is added for constant pressure regulation during sampling periods or for increasing the chamber total pressure differs from the water vapor mixing ratio present in the chamber air. Generally the added air is drier than the chamber air, causing the mixing ratio to decrease. The second situation occurs when the chamber walls are at least partially coated with ice. As chamber pressure changes, wall ice acts as a source or sink of water vapor to keep the number concentration of water vapor in the chamber at saturation values. 


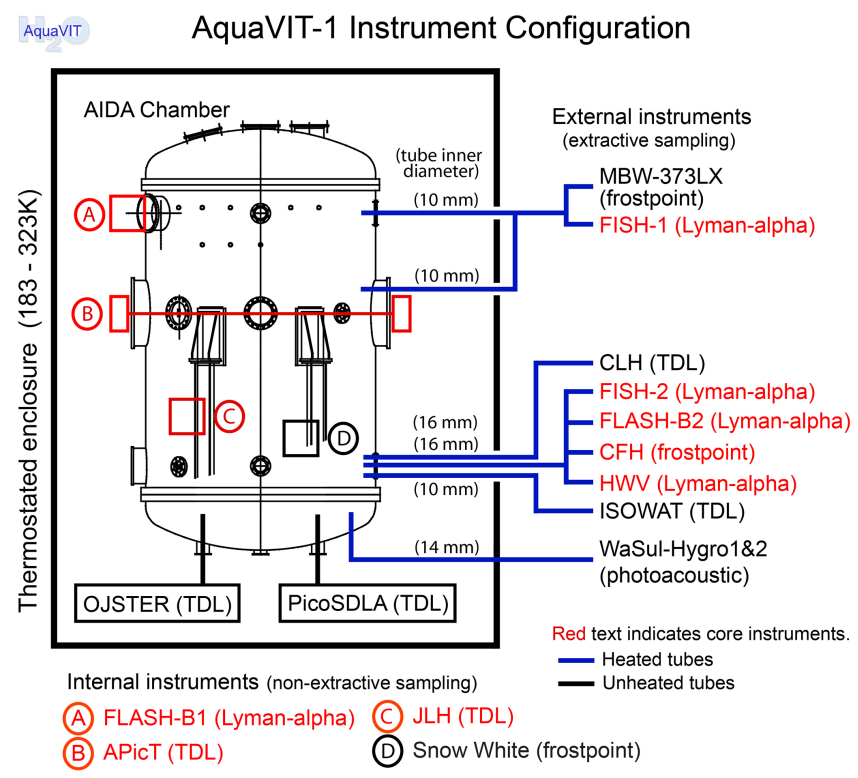

Figure 2. AIDA chamber configuration of the AquaVIT-1 instruments in Table 1.

Non-conservation was also observed to a lesser extent in the ice-free static experiments due to the adsorption and desorption of water on the walls and other chamber internal components. Examples of this are shown by the time series in Fig. 5 in which the water vapor mixing ratio increases when the chamber pressure is reduced in the second half of the day's experiment. If there are no other sources of water vapor, then the mixing ratio should remain constant as air is pumped from the chamber. However, non-conservation of water vapor does not interfere fundamentally with the AquaVIT-1 results because the water vapor mixing ratios always changed slowly with time within an intercomparison segment and the stirring fan forced complete internal mixing within about $1 \mathrm{~min}$ (see discussion below).

\subsection{Data processing}

For each day of the static experiment series, the instrument teams submitted a data file reporting water vapor mixing ratios vs. UT time. The measurement interval for most instruments was $1 \mathrm{~s}$. As an example, the $1 \mathrm{~s}$ data sets for 15 October are plotted in Fig. 5.

The data processing steps taken for the combined data set were the following:

a. Define segments. The time series were divided into constant pressure and near-constant temperature segments for statistical analysis. Not all segments were used in the intercomparison analysis. The criteria for selecting a segment were near-constant or slowly and linearly varying water vapor mixing ratios within the segment and the availability of water vapor data for the segment from a majority of the core instruments. The first criterion ensured uniform mixing ratio conditions in the chamber and, hence, each sample line. Data gaps between segments generally correspond to rapidly changing chamber pressure (Fig. 4). Constant or linearly varying water vapor values in a segment were also required for the precision analysis described below. Segment lengths in the range 900-3600 s were chosen to provide good statistical confidence in the subsequent analysis steps. The times and lengths of the segments used in the analysis along with average pressure, temperature, and water vapor mixing ratios are provided in Table 3 .

b. Calculate linear fits for each instrument segment. Core instrument linear fits to water vapor mixing ratios as a function of time were calculated from the respective time series data for each segment, thereby defining the mean values and their rates of change.

c. Calculate reference water vapor mixing ratios. The reference water vapor mixing ratio for each segment was obtained using only the core instrument data. The exception was that data from the FLASH instruments were excluded because of offsets discovered during the data evaluation (see Appendix). A two-step process was adopted to provide a consistent basis of comparison across and within segments. First, a single linear fit was performed on the complete set of core instrument linear fits. This combined fit was chosen over a simple unweighted average of all core instrument data in order to give the same weight to each core instrument in deriving the reference value. This combined fit defines the reference function for the segment, which in turn defines the time evolution of values within the segment. Second, the reference water vapor mixing ratio for the segment was defined to be the average of the reference function over the segment. These reference mixing ratios as listed in Table 3 are used throughout the analysis and plots presented here. Note that the number of instruments reporting data for each segment generally influences the reference value. Also note that it would be incorrect to use the reference values to infer the absolute accuracy of any instrument averages (see Sect. 6.5).

d. Calculate 1 s probability distribution functions (PDFs) for each segment. For each instrument the differences between the instrument time series of $1 \mathrm{~s}$ mixing ratios and the reference function were used to form a PDF for each segment time series. A Gaussian function was fit to each PDF. The difference between the Gaussian mean and the reference value was assigned to be the average difference for the segment. These values appear for each instrument segment as separate symbols in Figs. 6 and 7. 

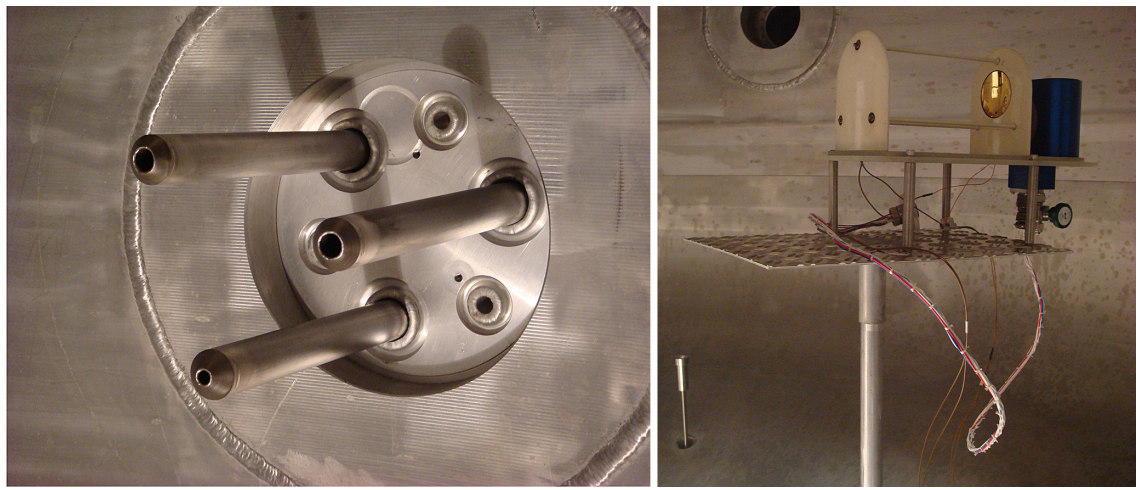

Figure 3. Left: customized extractive sampling probes inside the chamber. This cluster of three probes was located on the lower right-hand chamber wall (lower right hand in Fig. 2) and provided chamber airflow to several instruments. These probes are either 10 or $16 \mathrm{~mm}$ insidediameter stainless-steel tubes surrounded by a sealed heating mantle and extending $35 \mathrm{~cm}$ into the chamber. Right: the JPL TDL open-path instrument mounted inside the chamber. The instrument electronic module remained outside the chamber.
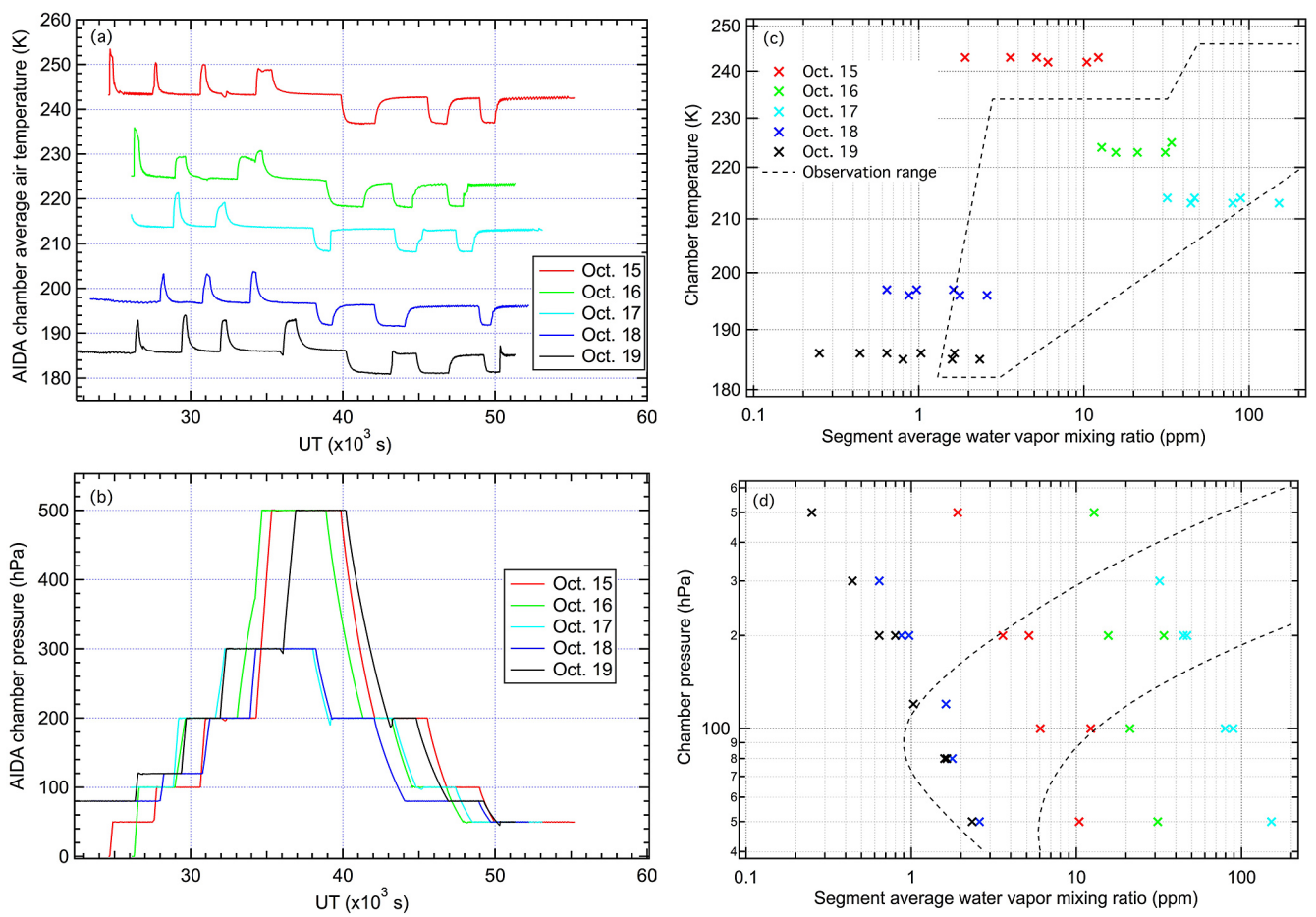

Figure 4. Time series of temperatures (a), pressures (b), and the relationship of chamber pressure and temperature with water vapor mixing ratios (c and $\mathbf{d}$ ) for all segments during the experiments (also see Table 3). The dashed lines indicate the nominal range of conditions observed by the HWV instrument in tropical and midlatitude flights during the last decade. During the two lowest-temperature experiments (18 and 19 October), humidity in the chamber was controlled by ice cover on the chamber walls.

e. Calculate instrument precision. The standard deviation $( \pm 1 \sigma)$ of each Gaussian fit to differences from the reference function is defined to be the instrument precision for a segment. Values represent an upper limit since $\sigma$ includes error in the reference function and nonlinear variation of water vapor in the chamber over the segment period. Examples of instrument precision values are shown in Table 4 for core and non-core instruments.

\subsection{Core instrument results}

\subsubsection{Reference value comparisons}

A summary of the instrument intercomparison results for the five-day static experiment series is shown in the plots in Figs. 6 and 7. The symbols represent the average difference within a segment from the reference water vapor value for that segment. Summary points for the core instruments are 
Table 4. Experimental upper limits of instrument precision derived from the AquaVIT-1 intercomparison data for selected segments during the static experiments ${ }^{\mathrm{a}}$.

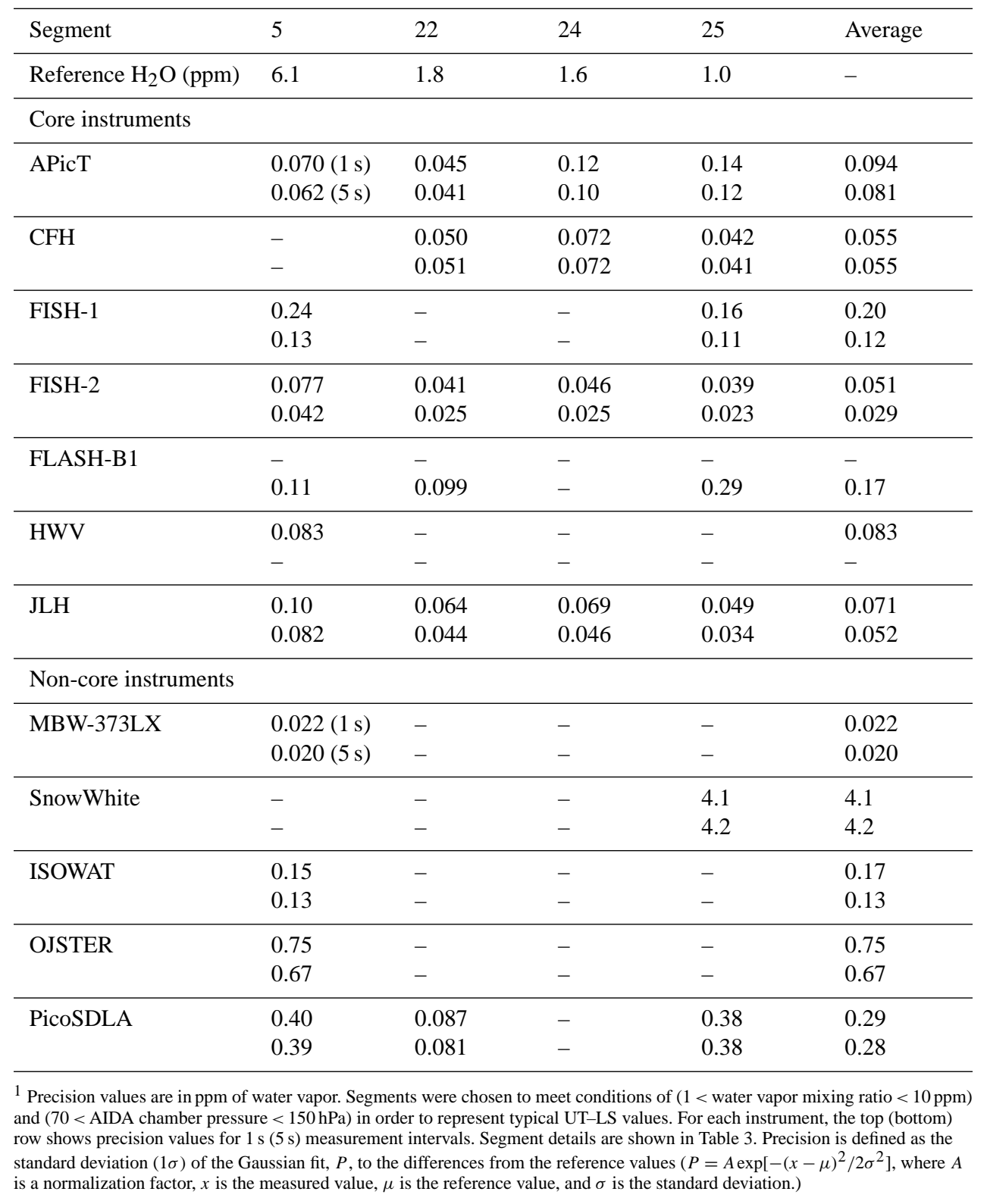

- 10-150 ppm $\mathrm{H}_{2} \mathrm{O}$. Good agreement occurs in this range. Except for a few segments, all the segment values and the all-segment averages (circle/plus symbols in Fig. 6) for each instrument agree with the reference within $\pm 10 \%$. The FLASH-B instrument shows the greatest segment-to-segment variability and the largest differences due to experimental setup issues described in Appendix A4. The instruments other than FLASH$\mathrm{B}(1) / \mathrm{B}(2)$ show a small segment-to-segment variability $(\sim 5 \%)$, indicating good instrument stability and systematic uncertainties that are constant throughout these experiments. There is some tendency of the largest differences to occur for the lowest pressure range $(<70 \mathrm{hPa})$. A good linear correlation with APicT values was found (not shown) in this range for all instruments.

$-1 \leq \mathrm{H}_{2} \mathrm{O} \leq 10 \mathrm{ppm}$. Fair agreement occurs in this range. All the segment values and the all-segment averages for each instrument agree with the reference within about $\pm 20 \%$. The segment-to-segment variability for each instrument is about $10 \%$ or greater, indicating, in comparison to the results for $10-150 \mathrm{ppm} \mathrm{H}_{2} \mathrm{O}$, instrument stability issues and systematic uncertainties that are more important. A good linear correlation with APicT values was found (not shown) in this range for all instruments. 

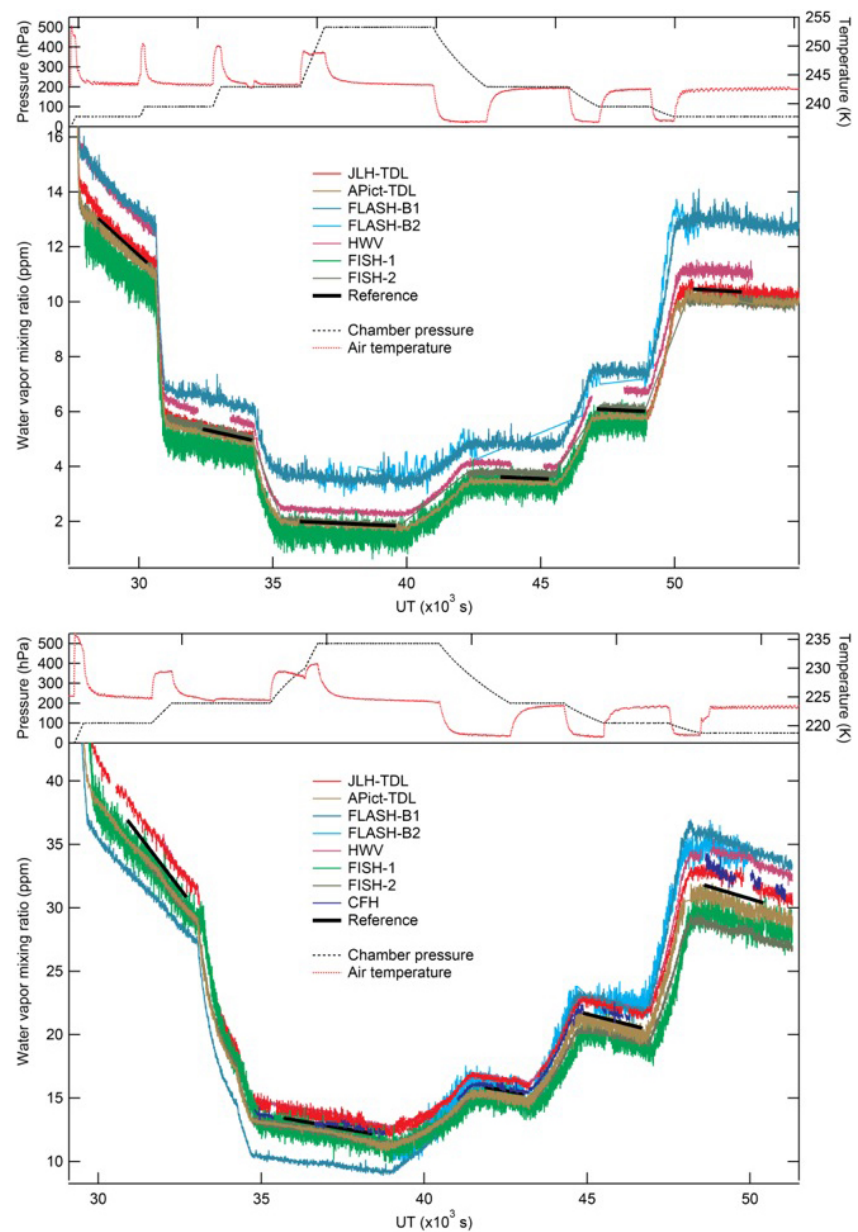

Figure 5. Example time series of AIDA water vapor mixing ratios ( $1 \mathrm{~s}$ averages) as reported by the core instruments during the static experiments on 15 October (top) and 16 October (bottom). Data from the FLASH instruments are not included in the reference value (see text). The chamber pressures and temperatures are given in the top panel of each graph. The black lines are the reference functions for each segment and indicate the time intervals used in the intercomparison. The average of each reference function yields the reference value for each segment, all of which are given in Table 3 .

- $0.2 \leq \mathrm{H}_{2} \mathrm{O} \leq 1 \mathrm{ppm}$. Poor agreement occurs in this range. Mixing ratios in this range occur rarely in the UT-LS. Fewer instruments reported data for these segments than for the other two mixing ratio ranges. In this range more so than in the two higher ranges, the reference value is influenced more strongly by the FISH results since the FISH-1 and FISH-2 data are essentially equal and fewer instruments contribute to the reference value calculation. All core instrument segment values agree with the reference and with each other within a range of about -100 to $+150 \%$, with absolute differences less than $0.4 \mathrm{ppm}$. All segments have pressures $>150 \mathrm{hPa}$. Although mixing ratios in this range occur rarely in the UT-LS, these measurements help to identify potential sources of uncertainties.

\subsubsection{Uncertainties}

The uncertainties of the core instruments as provided by the investigators are listed in Table 2 and further documented in Appendix A. Since no absolute reference value was established for AquaVIT-1, no independent conclusion can be drawn concerning whether the individual uncertainty ranges include the correct value for each segment. Since the core instrument uncertainties are derived with independent calibration procedures, there is an expectation of agreement within the combined uncertainties of the measurements. With the accuracy values given in Table 2 and data in Fig. 7, agreement can be expected within $\pm 20 \%$ for the $1-150$ ppm range and about $\pm 100 \%$ for values $<1$ ppm.

The precision upper limits calculated for the core instrument measurements for several example segments are shown in Table 4. PDFs of FISH-2 data for all segments are shown as an example in Fig. 8. Precision is not routinely reported for all instruments, in part, because precision, in contrast to accuracy, depends more on conditions of the measurements and treatment of the raw data. Most of the segment PDFs show a good Gaussian fit, indicating good stochastic behavior of the detection module in each instrument. The magnitude of the precision limits is typically in the range of 0.1 to $0.2 \mathrm{ppm}$, which suggests that the $1 \mathrm{~s}$ measurement precision is not a large component of the uncertainty in the $1-150 \mathrm{ppm}$ range when averaging over segment lengths of 1800-3600 s. A comparison of precision derived from 1 and $5 \mathrm{~s}$ time series measurements is also shown in Table 4. If the measurement variability is truly random, then the PDF of $5 \mathrm{~s}$ measurements should be a factor of $5^{0.5}=2.2$ smaller than the $1 \mathrm{~s}$ precision values. Table 4 shows that this is not the case for most of the core and non-core instruments. The largest ratios of about 1.7 are found for the FISH instruments. This suggests that the measurement variability is not completely random on the 1-to-5 s timescale for most of the instruments and may contain significant contributions from instrument drift and varying conditions of instrument components. Rollins et al. (2014) further discuss precision and accuracy issues related to a suite of water vapor instruments that includes some AquaVIT-1 core instruments.

\subsection{Non-core instrument results}

Figure 6 includes results for the non-core instruments for the same segments. Non-core results do not influence the segment reference values as discussed above. Summary points for these results are

- 10-150 ppm $\mathrm{H}_{2} \mathrm{O}$. The best overall agreement with the core reference values occurs in this range. Segment differences show a wider range than core instruments, varying from about -100 to $+200 \%$ with most of the 


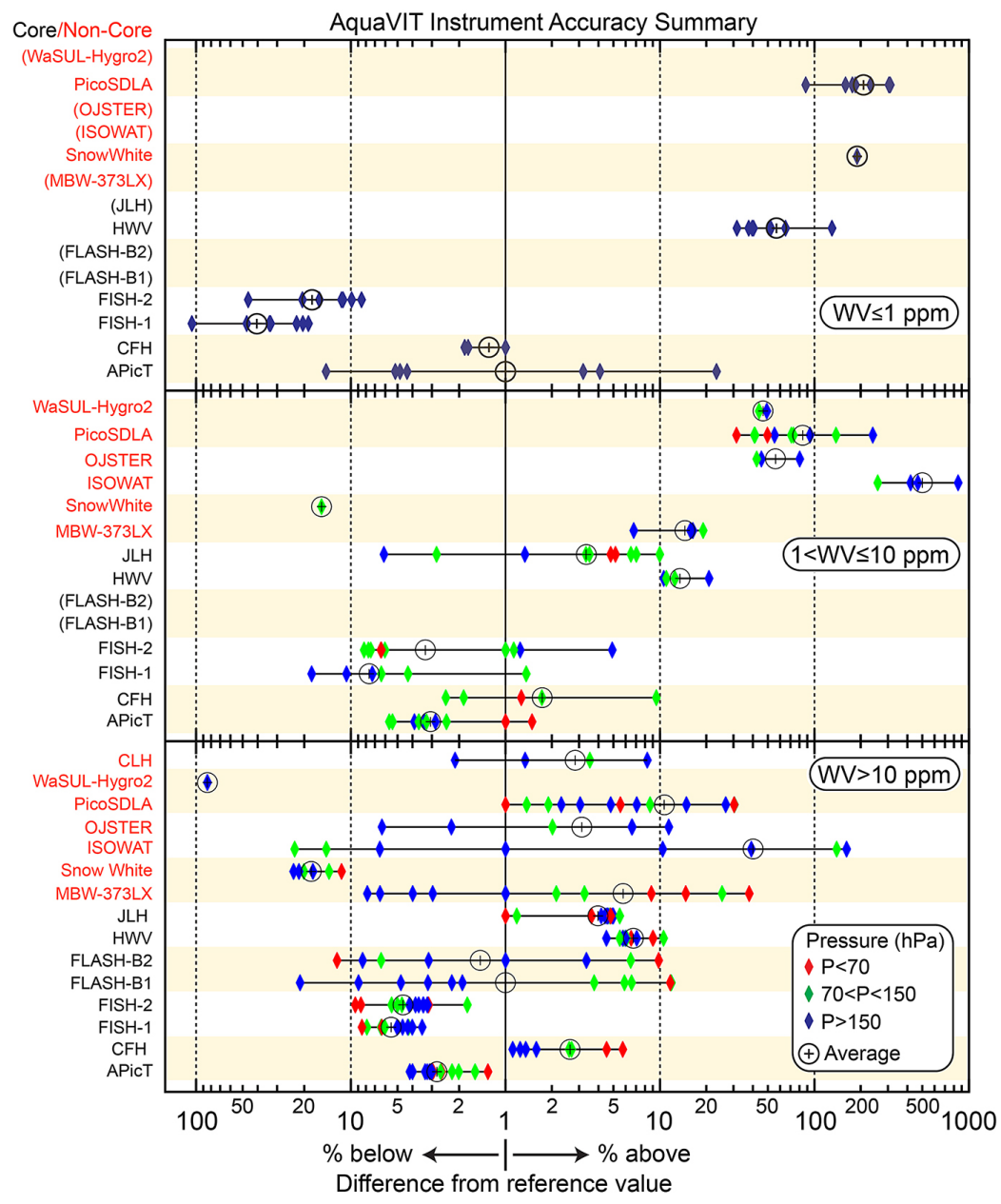

Figure 6. Summary plot of the core and non-core instrument intercomparison results for the five-day static experiment series. The instruments are identified on the left of each panel. Each panel is labeled by the range of reference water vapor mixing ratios. The chamber pressure range is indicated by the symbol color. The symbols represent the average difference within a segment from the reference water vapor value for that segment. Data from the FLASH instruments are not included in the reference value (see text). The segments varied from 900 to $3600 \mathrm{~s}$ in length, with most being $1800 \mathrm{~s}$ (Table 3). The differences are plotted on two separate log scales for values more than $1 \%$ above or below the reference value. Differences equal to or less than $1 \%$ are plotted at a value of $1 \%$. The average of all segments for an instrument is shown with the circle/plus symbol. Data are not available for all segments for each instrument, and some instruments have no data for the lower mixing ratio ranges. Instrument names in parentheses in a panel have no results in the associated mixing ratio range.

data falling within the -30 to $+50 \%$ range. Instrument averages also show a wider range, varying from about -90 to $+40 \%$.

$-1 \leq \mathrm{H}_{2} \mathrm{O} \leq 10 \mathrm{ppm}$. Poorer agreement with the core reference values occurs in this range. Segment differences show a much wider range than core instruments, varying from about -20 to $+1000 \%$ with most instruments significantly higher than the reference value.

$-0.2 \leq \mathrm{H}_{2} \mathrm{O} \leq 1 \mathrm{ppm}$. The poorest agreement with the core reference values occurs in this range as also found for the core instruments. Only two instruments submitted data for these low values. The results are 90-300\% higher than the reference value.

\subsection{Absolute reference values}

The ensemble average of the core instrument values was used as the reference value in the intercomparison in lieu of designating a single instrument as the reference. However, three AquaVIT-1 instruments have special merit in serving as absolute reference standards: the KIT MBW-373LX, APicT, and the German PTB water vapor permeation source (PTBWVPS). The first and last have direct links to international meteorological primary standards. APicT evaluations show that its values are very consistent with ice-saturation values expected in AIDA chamber ice cloud measurements. 


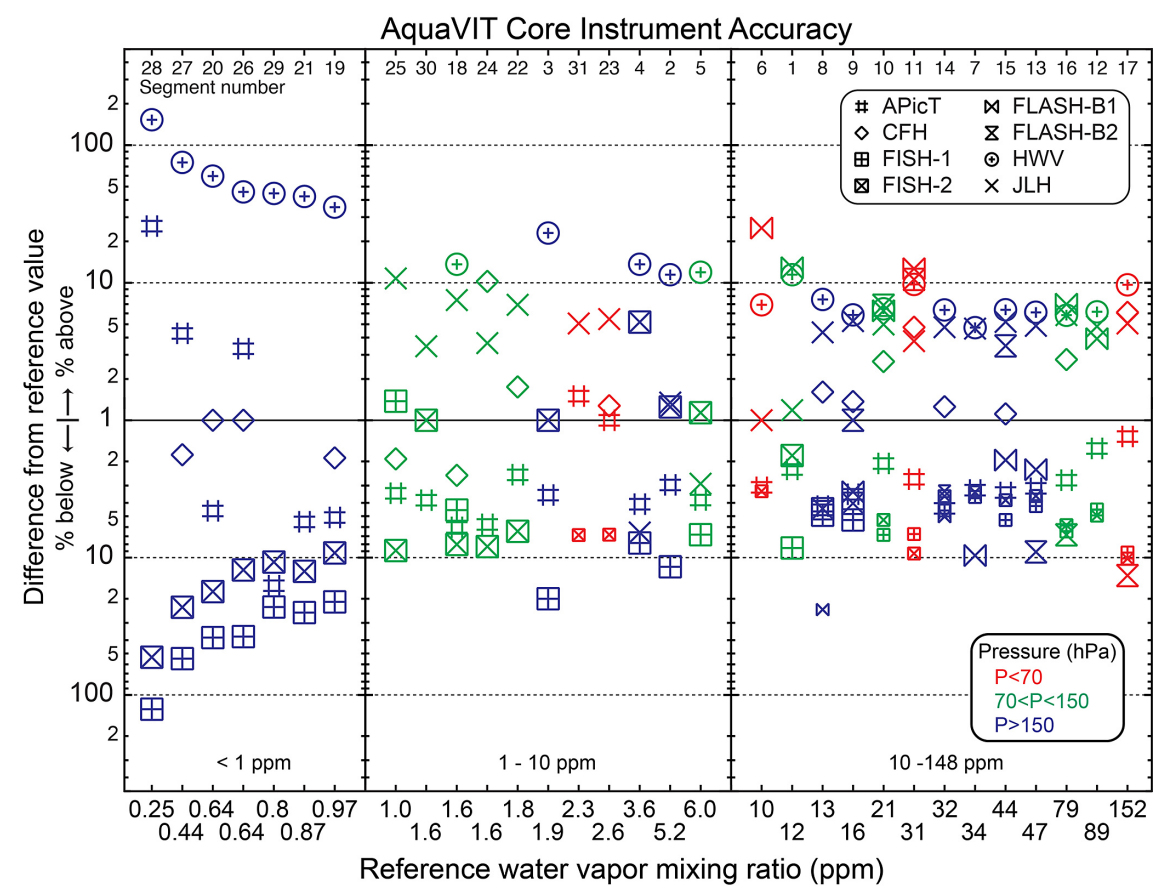

Figure 7. Summary plot of static experiment results for core instruments shown as the percent difference between values from the listed instruments and the corresponding reference values for three ranges of the reference values. Data from the FLASH instruments are not included in the reference value (see text). A symbol represents the result for the segment number noted near the top axis. The use of a small symbol size for a segment indicates that the accuracy and precision cannot be defined based on the relationships in Table 3. Segment details are provided in Table 4. Colors represent the AIDA chamber average pressure during the segment. Differences less than or equal to $1 \%$ are plotted as a $1 \%$ value.

The MBW-373LX is a chilled-mirror frost-point hygrometer from MBW Calibration Ltd. in Switzerland (http://www. mbw.ch) that is used regularly in the AIDA facility (Appendix A7). The unit has a frost-point accuracy of $\pm 0.1 \mathrm{~K}$ (corresponding to less than $\pm 2 \%$ in water vapor mixing ratio) according to the manufacturer's calibration, which is linked to international standards. The KIT MBW-373LX unfortunately was not configured to operate with sample line pressures less than $500 \mathrm{hPa}$ or sample flows below $0.2 \mathrm{~L} \mathrm{~min}^{-1}$ and thus could not be suitably intercompared in AquaVIT-1 for all conditions (Sect. A7). Near $1000 \mathrm{hPa}$, however, the KIT MBW hygrometer has intercompared well with the APicT in many previous AIDA experiments.

APicT values, derived from in situ absorption profiles, are only based on $\mathrm{H}_{2} \mathrm{O}$ spectral data (taken from the HITRAN 2008 (HIgh-resolution TRAnsmission molecular absorption) database and from PCI/KIT reference measurements (Hunsmann et al., 2006)) plus length, pressure, and gas temperature measurements. Hence, APicT performance in AquaVIT1 did not depend on a laboratory or in-field calibration procedures (i.e., a direct comparison to a reference $\mathrm{H}_{2} \mathrm{O}$ instrument or generator). As an absolute performance check, APicT water vapor mixing ratios were compared to equilibrium ice-saturation values during the AquaVIT-1 dynamic experiments. During these experiments, dense ice clouds were present in the AIDA chamber under almost constant pressure and temperature conditions. As a consequence, the water vapor mixing ratios inside the chamber can be assumed to be ice-saturation values at the respective gas temperatures. Within estimated uncertainty limits of about $5 \%$, APicT values agreed with the expected ice-saturation values (see Sect. A1.1), thereby validating APicT measurement accuracy.

The PTB-WVPS was provided to the AquaVIT-1 team during the experiment period by PTB (Brunswick, Germany; Appendix A14). The source was calibrated to the German national primary humidity standard (coloumetric) (Mackrodt, 2012; Brewer et al., 2011) over a mixing ratio range of 0.5 to $5 \mathrm{ppm}$. The total expanded relative uncertainty $(k=2)$ of the PTB-WVPS is $2 \%$. The source output flow was sampled by the CFH and MBW-373LX instruments, and the FISH MBW-DP30 unit, which all reported differences less than $\pm 5 \%$.

The combination of these additional intercomparisons adds substantial confidence that the core-ensemble reference value is accurate to $\pm 5 \%$. If the ensemble reference value is assumed to have an uncertainty of $\pm 5 \%$, then all of the core instrument segment values between 1 and $150 \mathrm{ppm}$ agree with the reference value within the combined uncertainties ( $\pm 5 \%$ plus uncertainties in Table 2 ). In contrast most of the 

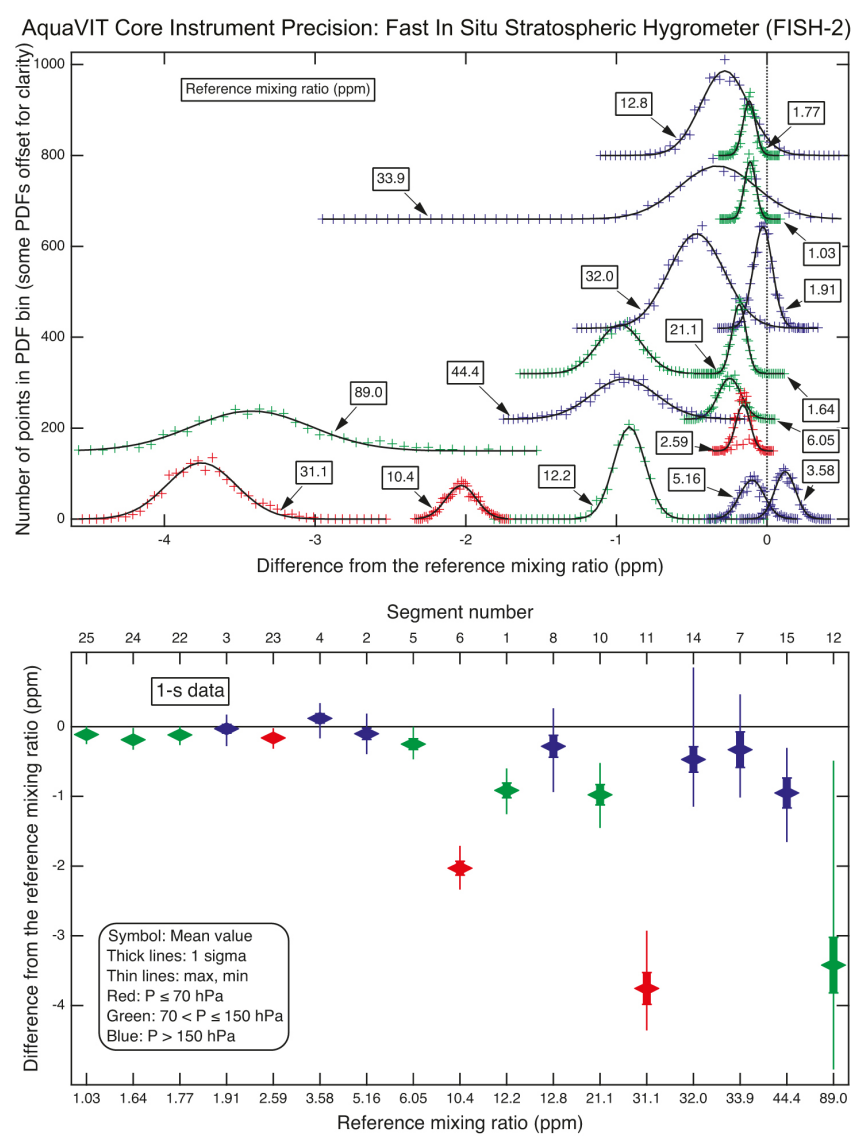

Figure 8. Example summary plot of measurement precision in the static experiments. The results shown are for the FISH-2 instrument. Top: Gaussian fits to the probability distribution functions (PDFs) of differences from the reference value function derived for each segment from the core instruments. The PDFs are derived from the $1 \mathrm{~s}$ time series data. Legend boxes indicate the reference water vapor value for each segment (see Table 3). The PDFs and fits are arbitrarily offset in the vertical for clarity. The baseline symmetry in the Gaussian fits for each instrument indicates that the mean slopes comprising the ensemble mean are similar and, hence, slope differences do not significantly affect the Gaussian widths. Bottom: plot of mean (symbols) and maximum and minimum differences from the reference values (thin vertical lines) and 1- $\sigma$ precision (thick vertical lines) as defined in the footnote in Table 4. Color indicates the chamber pressure range in both top and bottom panels.

non-core instrument segments do not agree with the reference value within combined uncertainties in the AquaVIT configuration.

\section{Atmospheric implications of the AquaVIT-1 static experiment results}

The AquaVIT-1 results have implications for atmospheric measurements of water vapor made by the core instruments in the UT-LS region. The experiment mixing ratio values spanned the range of $<1-150 \mathrm{ppm}$, which is highly relevant for the tropical UT-LS, where dehydration processes produce the lowest mixing ratios generally observed in the atmosphere. The core instrument results showed agreement in the key 1-10 ppm range within about $\pm 20 \%$. Part of the motivation for AquaVIT-1 was to provide an experimental basis to resolve the discrepancies observed when core instruments are operated in the UT-LS on the same or different moving platforms (Vömel, 2006, 2007a; Peter et al., 2006). In some cases, these discrepancies are large enough (50-100\%) to interfere with answering important scientific questions about water vapor in the UT-LS. An example of differences associated with core instruments is shown in Fig. 1. An important conclusion from AquaVIT-1 is that such differences as observed in the airborne field studies are significantly larger than those found for CFH and HWV in this laboratory study. However, the qualitative differences are similar, with CFH values less than HWV values. Hence, the AquaVIT-1 results alone do not resolve the water vapor discrepancies observed in the atmosphere on moving platforms. The uncertainties associated with the observational discrepancies will continue to limit our quantitative understanding of UT-LS water vapor (e.g., prevalence of supersaturation and understanding of dehydration process). It is hoped that the AquaVIT-1 campaign and results will help investigators improve the quality of new field instruments and future water vapor measurements and ultimately resolve or eliminate current discrepancies.

Caution must be taken in using these results to infer instrument performance on moving platforms (e.g., balloons and aircraft) because AquaVIT-1 did not fully reproduce UT-LS instrument or sampling conditions for the diverse set of instruments involved, nor could it be expected to. Some instruments were modified from their flight configuration in order to adapt to the laboratory setting (see Appendix A). For those instruments mounted outside the AIDA chamber, environmental pressures and/or temperatures were generally significantly higher than typically encountered in UT-LS flights. Similarly, sample flows internal to the instruments were in some cases significantly lower than in flight and were often at higher temperatures than those encountered in the UT-LS. A closer simulation of external and internal pressures and temperatures occurred for JLH and SnowWhite because both were located inside the chamber. However, sample-volume flow rates that occur in flight for these two instruments (aircraft and balloon, respectively) were not well simulated in the chamber tests because of the limited stirring of chamber air. There are potentially other factors that influence inflight performance in the UT-LS that did not influence the AquaVIT-1 experiments, such as rapid changes in mixing ratio, pressure, and temperature. These effects will need to be carefully evaluated to make appropriate and optimal use of the results presented here. 


\section{Summary of the AquaVIT-1 experiments}

The AquaVIT-1 results are summarized as follows:

- AquaVIT-1 successfully integrated a variety of instruments to measure water vapor in the AIDA chamber using extractive and non-extractive sampling methods. The scientific and technical participant group developed procedures and protocols to carry out the physical experiments and post-experiment data processing and analysis. For five days in October 2007, static experiments were conducted with chamber conditions covering a range of pressures $(50-500 \mathrm{hPa})$, temperatures $(185-243 \mathrm{~K})$, and water vapor mixing ratios $(<1-$ $150 \mathrm{ppm}$ ) in order to simulate conditions typically found in the UT-LS.

- The subset of the instruments examined here was divided into two categories: core and non-core instruments. Core instruments have been extensively used in field campaigns on moving platforms, and some participated in campaigns, particularly in the tropics, that revealed large systematic discrepancies in the UT-LS.

- Time series of water vapor mixing ratios from the core and non-core instrument were divided into 31 segments of 900-3600 s duration for analysis. The intercomparison was based on reference values derived for each segment using linear fits to the core instrument data.

- The core instrument values are in fair to good agreement in the 1-150 ppm $\mathrm{H}_{2} \mathrm{O}$ range, with instrument averages over all segments agreeing within about $\pm 20 \%$. For individual segments, agreement is generally found to be close or within the combined uncertainties for any instrument pair. Below $1 \mathrm{ppm} \mathrm{H}_{2} \mathrm{O}$, fewer instruments reported data and overall agreement is poorer.

- The non-core instrument group included mature instruments and newly developed prototypes. This group demonstrated generally poorer agreement with each other and with the core reference values than the core instruments.
- No conclusion can be made about the absolute accuracy of the instruments because no absolute reference instrument was available for the AquaVIT-1 experiments. However, each core instrument team independently and routinely calibrates (or validates) their respective instrument and links it to one or more absolute reference sources. Most pairs of core instruments agree within the respective combined uncertainties over the water vapor range of $1-150 \mathrm{ppm}$. Thus, it is highly likely that the correct water vapor value for each segment is between the maximum and minimum of the segment averages of the core instruments. This corresponds to within about $\pm 10-20 \%$ of the reference value for the $1-150 \mathrm{ppm}$ range. The APicT results from the dynamic experiments strengthen the conclusion that the correct water vapor values are bounded by the core instrument averages.

- Caution must be taken in using the AquaVIT-1 results to infer instrument performance on moving platforms (e.g., balloons and aircraft) because AquaVIT-1 could not fully reproduce operating and sampling conditions in the UT-LS for the diverse set of instruments involved. All flight instruments were modified or reconfigured for chamber operation. In some cases, adaptation to the laboratory environment introduced other sources of error or uncertainty. Furthermore, there are potentially other factors that influence in-flight performance that did not influence the AquaVIT-1 experiments. It is possible that these additional factors are responsible for the larger discrepancies observed in intercomparisons of some moving platform measurements.

- The AquaVIT-1 results alone do not resolve the water vapor discrepancies observed in the UT-LS. The uncertainties associated with the observational discrepancies will continue to limit our quantitative understanding of UT-LS water vapor.

- The success of AquaVIT-1 provides a template for future intercomparison efforts with water vapor or other species that are focused on improving the analytical quality of atmospheric measurements on moving platforms. 


\section{Appendix A: Instrument descriptions}

Instrument descriptions as provided by the respective instrument teams.

\section{A1 AIDA-PCI-in-cloud-TDL (APicT)}

The APicT (AIDA-PCI-in-cloud-TDL) spectrometer is a near-infrared, diode-laser-based, fiber-coupled, highspectral-resolution absorption spectrometer with an openpath absorption cell mounted on the inner surface of the walls of the AIDA vessel. This open-path configuration avoids any gas sampling and allows a selective detection of the interstitial water vapor inside clouds and a continuous determination of the absolute water vapor molar fraction inside the AIDA chamber. APicT was designed to investigate cloud formation within AIDA and thus can be used not only in particle-free conditions but also when clouds are formed within the APicT absorption path.

The main goal of the APicT design was - aside from high chemical selectivity and sensitivity, and sufficient temporal resolution - to achieve a highly accurate, absolute water vapor measurement by complete avoidance of gas sampling and gas treatment. Special attention was given to providing absolute $\mathrm{H}_{2} \mathrm{O}$ detection levels without the need for a regular calibration of the instrument response (i.e., by using water vapor generators). APicT's measurement volume is distributed equally over a central intersect through the AIDA chamber, which delivers representative, spatially averaged $\mathrm{H}_{2} \mathrm{O}$ concentrations over the respective AIDA cross section with very little influence from wall effects or gas sampling problems.

The APicT instrument (Giesemann, 2003; Giesemann et al., 2003; Ebert et al., 2004, 2005, 2008) is based on the extensive tunable diode laser absorption spectroscopy (TDLAS) experience of the Ebert group previously located at the Physical Chemistry Institute (PCI) at the University of Heidelberg (now at PTB and Technical University Darmstadt). Extensive knowledge - particularly from very robust, laser-based, open-path species diagnostics in largescale combustion processes (Schulz et al., 2007) as well as from a previously developed stratospheric, balloon-borne, open-multi-path instrument (CHILD) for simultaneous $\mathrm{H}_{2} \mathrm{O}$ and $\mathrm{CH}_{4}$ detection (Gurlit et al., 2005; Ebert, 2006) - has been combined for the development of the APicT spectrometer. APicT also takes advantage of knowledge of highly stable, open, White-type (White, 1942) multipath cells at AIDA developed by KIT (Wagner et al., 2008).

Since 2003, APicT has been used in more and more cloud formation studies at AIDA in order to determine absolute water vapor and super saturation values dynamics during cloud formation (Murray, 2010; Wagner et al., 2008; Möhler et al., 2008a, b, 2005; Mangold, 2005).

APicT uses direct absorption spectroscopy (Schulz et al., 2007; Ebert and Wolfrum, 2001) (instead of the more common $2 f$ wavelength modulation technique (Fernholz et al.,

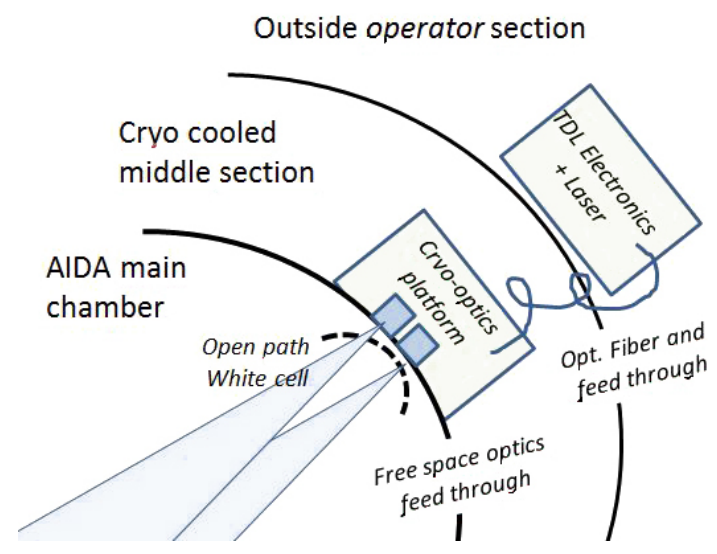

Figure A1. Schematic of the general setup of the APicT spectrometer: APicT consists of three parts placed in different segments of the AIDA chamber facility. The parts are connected either via fiber optic cables or free-space laser beams. The outer section - including most electronics, data acquisition components, and the diode laser can be directly operated by the user. The middle section contains a cryogenic transfer optic, including detectors and fiber optics, and is usually only serviced at sufficiently high temperatures (above about $-30^{\circ} \mathrm{C}$ ). The inner section is connected to the middle section via free-space optics and mainly encompasses the open-path White cell, with opto-mechanic components directly attached to the inner walls of the AIDA chamber (Wagner et al., 2008; Giesemann et al., 2003).

2002)) to avoid calibration, while simultaneously permitting an efficient disturbance correction (e.g., for the strong, spectrally broadband optical losses caused by the cloud particles). This technique has been derived from even more demanding measurements in extremely dust-laden combustion chambers (Dreier et al., 2011; Schulz et al., 2007; Awtry, 2006; Teichert et al., 2003; Ebert et al., 1998).

APict detects $\mathrm{H}_{2} \mathrm{O}$ vapor molecules via the (110-211) line $\left(7299 \mathrm{~cm}^{-1}\right)$ in the $v_{1}+v_{3}$ combination band (or for higher $\mathrm{H}_{2} \mathrm{O}$ concentrations via the (211-322) line in the $2 v_{1}$ overtone band) around $1.37 \mu \mathrm{m}$ (Giesemann, 2003; Ebert et al., 2004, 2005, 2006; Hunsmann, 2006).

APicT consist of three basic parts (Fig. A1) (Giesemann, 2003; Ebert et al., 2005):

- A.: the outer part, placed within the user accessible space outside the AIDA insulated chamber, contains a fiber-coupled, temperature-stabilized, distributedfeedback (DFB) diode laser module in an $\mathrm{N}_{2}$-purged container and all electronics (laser/Peltier driver, signal generator, detector preamplifiers, data acquisition, and computer).

- B.: the middle, opto-mechanical part is a cryogenic transfer optic (including two detectors for $\mathrm{I}$ and $\mathrm{I}_{0}$ ) directly attached to the outside wall of the AIDA chamber. Using the fiber from the laser module and a lens collimator, a free-space laser beam is formed, which is then focused through wedged $\mathrm{CaF}_{2}$ windows into the 
absorption cell in the inner chamber. Through a second identical window the laser light behind the measurement zone is collected and directed onto an uncooled InGaAs (indium gallium arsenide) detector (1 $\mathrm{mm}$ diam) using a $2.54 \mathrm{~cm}$ spherical mirror. In the middle section, which is at atmospheric pressure but at cryogenic AIDA chamber temperatures, the total path length of the freespace beam from the fiber end to the detector is $36 \mathrm{~cm}$.

- C.: the inner part is the cryogenic, open, White-type, multipath absorption cell with heated mirrors. The cell is permanently mounted onto the walls inside the AIDA chamber (3.74 $\mathrm{m}$ mirror separation) and enables path lengths of up to $250 \mathrm{~m}$. A path of $82 \mathrm{~m}$ was mostly used during AquaVIT-1.

For the measurements the laser is scanned across the target $\mathrm{H}_{2} \mathrm{O}$ line with a repetition frequency of $139.8 \mathrm{~Hz}$. The resulting absorption profiles are co-added up to 100 times to yield a 1-2 s time resolution. The averaged, in situ raw signal is corrected for spectrally broadband optical losses and electricoptical offsets, converted from time to frequency space, and evaluated via a proprietary Labview-based fitting software taking into account (i) the ideal gas law and an extended Beer-Lambert law (Giesemann, 2003; Schulz et al., 2007; Ebert and Wolfrum, 2001; Teichert et al., 2003; Ebert et al., 2005); (ii) a Voigt line-shape-based spectral model that is fitted to the raw data using a nonlinear Levenberg-Marquardt fitting algorithm, taking into account measured pressure, temperature and absorption path length inside AIDA; (iii) a highly precise characterization of the dynamic laser tuning (using a $10 \mathrm{~cm}$ air-spaced precision etalon); and (iv) $\mathrm{H}_{2} \mathrm{O}$ spectral data like our measured air-broadening coefficient ( $g_{\text {air }}=0.0981 \pm 0.0002 \mathrm{~cm}^{-1} \mathrm{~atm}^{-1}$ at $\left.296 \mathrm{~K}\right)$ and temperature coefficient ( $n=0.74 \pm 0.01$ ) (Hunsmann et al., 2006) and the tabulated $\mathrm{H}_{2} \mathrm{O}$ line strength from HITRAN 2004/8, which was independently verified within $\pm 3 \%$ uncertainty (Hunsmann et al., 2006) during earlier AIDA measurements. For very low $\mathrm{H}_{2} \mathrm{O}$ concentrations, parasitic absorption effects in the middle section of the spectrometer were also corrected for by using either a secondary detector channel on the cryotransfer optics board or the known ratio between the parasitic and the inner absorption path $(0.36 \mathrm{~m} / 82 \mathrm{~m})$. No calibration or scaling parameters are used in order to derive absolute water mixing ratios.

With that procedure, APicT can report absolute $\mathrm{H}_{2} \mathrm{O}$ molar fractions from above 10000 to below $1 \mathrm{ppm}$ at pressure/temperature ranges from 1000 to $1 \mathrm{hPa}$ and 300 to $180 \mathrm{~K}$ and achieve precision ( $1 \mathrm{~s}$ ) in the $20 \mathrm{ppb}$ range (Ebert et al., 2004, 2005, 2008; Ebert, 2006). The absolute accuracy estimated from an error budget is better than $5 \%$ and dominated by the line strength uncertainty $( \pm 3 \%)$. Optical losses by cloud particles of $99 \%$ have been handled without additional systematic errors (even higher losses of $99.99 \%$ have been compensated for in combustion applications using dedicated digital-signal-processing (DSP)-based electronics (Awtry et al., 2006)).

The instrument, parts thereof, as well as the principles behind the APicT software and absolute evaluation procedure were successfully validated in numerous cases in view of achieving absolute accuracy without a regular calibration. Tuning accuracy has been checked via retrieved Doppler line widths at AIDA (yielding $0.15 \%$ deviation). APicT water vapor values were compared at AIDA with the MBW373LX and FISH instruments during cloud-particle-free conditions yielding typically less than $3 \%$ deviation (Hunsmann et al., 2006). A similar open-path TDLAS spectrometer for $\mathrm{CH}_{4}$ was compared at atmospheric background levels of $\mathrm{CH}_{4}$ with a NOAA-calibrated extractive gas chromatograph and yielded $<1 \%$ average deviation over $36 \mathrm{~h}$ (Lauer et al., 2007).

Recently an improved, extractive version of our TDLAS hygrometer series (using the same data evaluation principles) was investigated in a smaller water vapor intercomparison at FZ Jülich (Buchholz et al., 2013) and yielded an average offset of $-3.9 \%$ with respect to a frost-point hygrometer and a Lyman- $\alpha$ absorption hygrometer. Particularly important is the direct validation of our extractive TDLAS spectrometer (named SEALDH) at the German primary national standard for humidity, which resulted in average relative absolute deviations of less than $1.5 \%$ (Buchholz et al., 2014)

During the AquaVIT-1 static experiments, however, APicT performance was hampered by a software problem that caused a sensitivity loss of nearly a factor of 10 , which should not have impaired measurement accuracy. This precision loss was compensated by reducing the instrument temporal response. During the dynamic experiments (second week) this error was corrected.

\section{A1.1 APicT ice-saturation experiments}

The second phase of AquaVIT-1 was focused on dynamic experiments characterized by almost constant average temperature conditions each day (22-26 October) in the chamber superimposed with quick variations of pressure, temperature, and humidity conditions. Dense ice clouds were generated during 10 segments (600 to 2400 s duration) with almost constant pressure and temperature. During these segments, the average relative humidity inside the chamber was maintained at ice-saturation conditions at the respective gas temperature. At constant pressure and temperature conditions, the variability of the gas temperatures measured throughout the chamber volume is typically less than $\pm 0.2^{\circ} \mathrm{C}$, which means that the variability of the water saturation pressure above the ice-crystal phase is less than about $\pm 3 \%$. The average values of water vapor and temperature in the icesaturated segments were in the range $0.01-40 \mathrm{~Pa}$ and $185-$ $243 \mathrm{~K}$, respectively. Figure A2 (top) shows the percentage differences between the APicT water vapor partial pressures and ice-saturation values (pwsat) derived from measured 


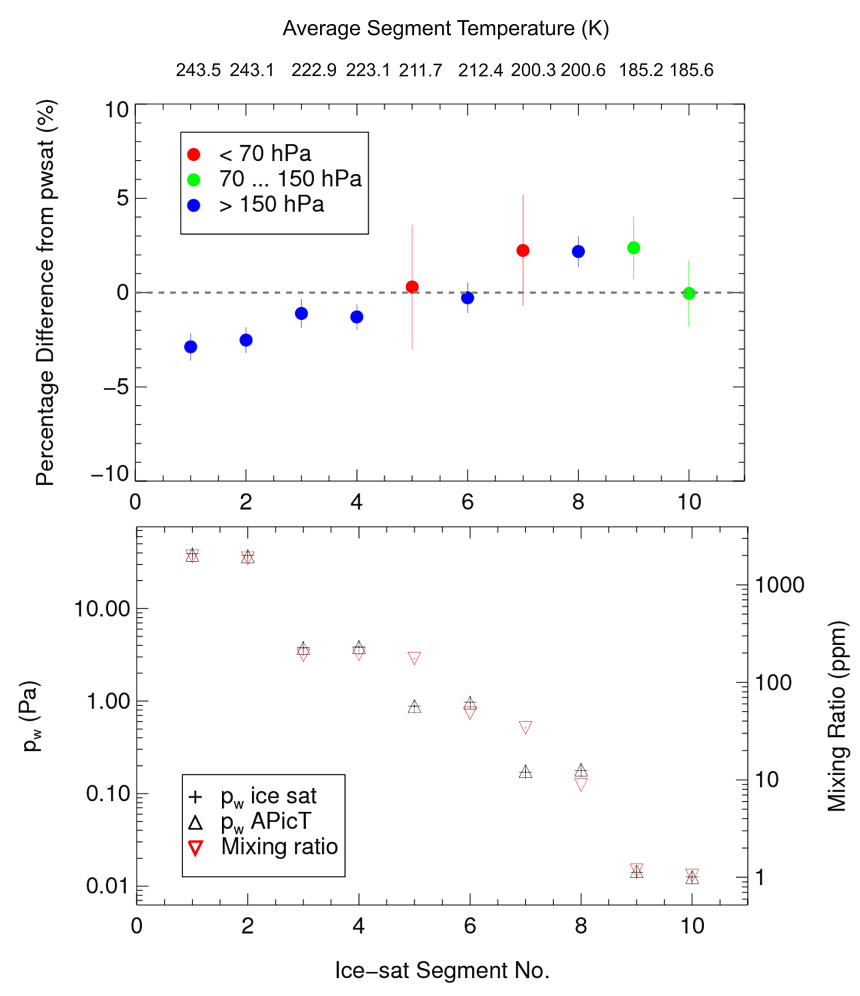

Figure A2. Top: differences between APicT water vapor partial pressures and those calculated from ice saturation at measured temperatures (top axis) for AquaVIT-1 dynamic experiment segments. Bottom: water vapor partial pressures versus dynamic segment number as calculated ( $p_{\mathrm{W}}$ ice sat) and as measured by APicT $\left(p_{\mathrm{w}} \mathrm{APicT}\right)$. Also shown are water vapor mixing ratios in the chamber (right-hand axis).

temperatures for segments in the dynamic AquaVIT-1 experiments (Table 1). Figure A2 (bottom) shows the water vapor partial pressures from APicT measurements $\left(p_{\mathrm{w}}\right.$ APicT) and ice-saturation calculations ( $p_{\mathrm{w}}$ ice sat), and the chamber water vapor mixing ratio for each segment. During the segments, the water vapor partial pressure measured in situ with the APicT instrument deviated by less than $\pm 3 \%$ from the ice-saturation pressures calculated from the laboratory vapor-pressure equation reported by Murphy and Koop (2005), which have an estimated uncertainty of $\pm 1 \%$. APicT water retrievals over a large range are insensitive to the presence of ice clouds under the experiment conditions. The error bars in the figure are derived from the widths of the Gaussian fits to the probability distribution functions of $1 \mathrm{~s}$ APicT and ice-saturation water vapor partial pressure data in each segment. Within its estimated uncertainty limits of about $\pm 5 \%$, APicT correctly measured the expected icesaturation conditions, with a slight tendency of a low bias at the higher water concentrations and higher temperatures, and a slight high bias at the lower water concentrations and lower temperatures (i.e., at high segment numbers).

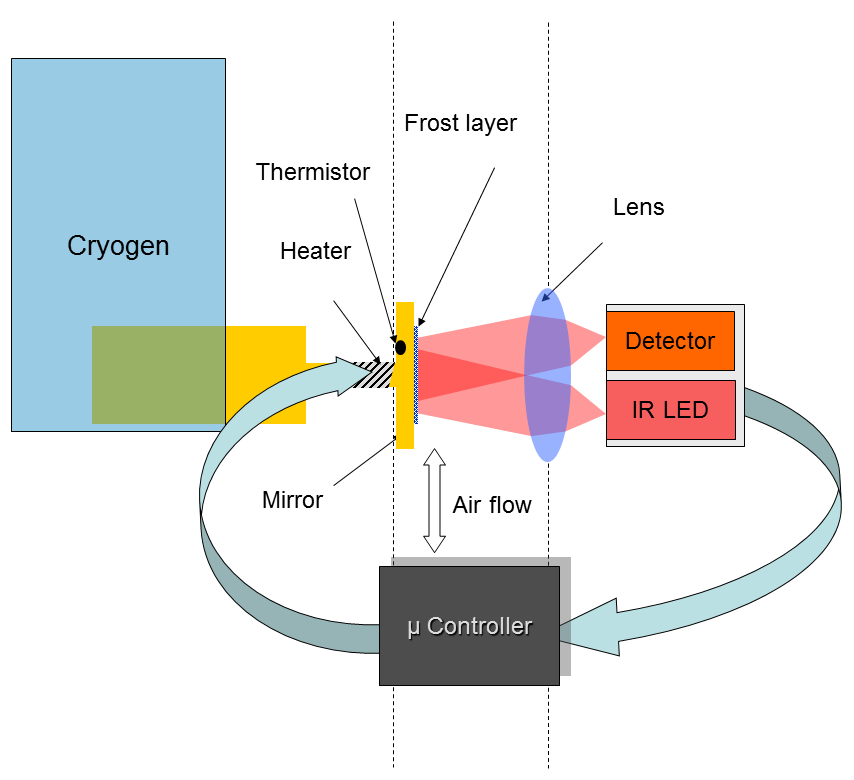

Figure A3. Schematic of the CFH sonde. The vertical dashed lines indicate the inlet and outlet tubes. The airflow inside the tubes is downward during balloon ascent and upward during descent. Only the lens and the mirror are exposed to the airflow inside the tube. The microprocessor controller regulates the mirror temperature such that the bulk reflectivity of the frost-covered mirror remains constant (Vömel et al., 2007a).

\section{A2 Cryogenic Frost-point Hygrometer (CFH)}

\section{A2.1 Instrument description}

The Crogenic Frost-point Hygrometer (CFH) is a small balloon-borne instrument that measures water vapor continuously between the surface and the middle stratosphere (Vömel et al., 2007a) (see Fig. A3 and Table A1). It is based on the chilled-mirror principle by measuring the temperature of a mirror carrying a thin dew or frost layer that is maintained in equilibrium with ambient water vapor. An optical phase-sensitive detector and light-emitting diode (LED) combination measures the bulk reflectivity of the mirror. A microprocessor feedback controller regulates the mirror temperature to maintain a constant bulk reflectivity and, hence, a constant condensate layer. Under this condition the condensate layer on the mirror is in thermal equilibrium with the water vapor in the ambient air passing over the mirror. The mirror temperature is then equal to the ambient dew-point or frost-point temperature, and the water vapor mixing ratio and relative humidity can be calculated from this temperature using a variation of the Clausius-Clapeyron equation and a measure of ambient pressure.

The CFH is currently flown with an electrochemical concentration cell (ECC) ozone sonde, Global Positioning System (GPS), and a radiosonde, which is also used as data transmitter. Therefore, in addition to water vapor mixing 
Table A1. CFH specifications.

\begin{tabular}{ll}
\hline Vertical measurement range & 0 to $\sim 28 \mathrm{~km}$ \\
\hline Dew-point or frost-point detection range & $>+25^{\circ} \mathrm{C}$ to $<-95^{\circ} \mathrm{C}$ \\
Mixing ratio detection range & $>25000 \mathrm{ppm}$ to $<0.8 \mathrm{ppm}$ \\
Dew-point or frost-point uncertainty & $0.5^{\circ} \mathrm{C}$ \\
Mixing ratio uncertainty & $\sim 3.5 \%$ (surface), $\sim 9 \%$ (tropopause), $\sim 11 \%(28 \mathrm{~km})$ \\
Vertical resolution & $<\sim 10 \mathrm{~m}$ (troposphere) to $<\sim 100 \mathrm{~m}($ stratosphere) \\
CFH instrument weight & $400 \mathrm{~g}$ \\
$\mathrm{CFH}+$ ECC + radiosonde payload launch weight & $1500 \mathrm{~g}$ \\
\hline
\end{tabular}

ratio, every $\mathrm{CFH}$ payload provides ozone mixing ratio and radiosonde pressure, temperature and humidity data, which are used to determine altitude, potential temperature and mixing ratio.

\section{A2.2 CFH configuration during AquaVIT-1}

\section{Laboratory instrument configuration}

During AquaVIT-1 a laboratory version of the balloon instrument was used because the latter cannot be operated at subambient pressures (i.e., is not vacuum sealed). A stainlesssteel sensor housing was built that has largely the same geometry as the balloon-borne instrument but allows the connection to a vacuum system and a separate pressure measurement near the sample volume. The optical path of the laboratory instrument is nearly identical to the balloon instrument, with the only difference being that the detector lens was slightly recessed to allow the addition of a sapphire window, which acted as a vacuum seal. The detector and electronics were taken from a balloon instrument. The mirror holder is made of a thin-walled stainless-steel tube, which was glued to the mirror disk and acted both as a vacuum seal and thermal insulator to the sensor housing. Unlike the balloon instrument, the mirror of the laboratory instrument was fitted with two identical thermistors, each of which was independently calibrated. The dimensions of the mirror, mirror stem and heater coil are identical to the balloon instrument, as is the location of the thermistors. This ensures that the thermal properties of the assembly are the same as those of the balloon instrument. The cold finger, which is the part of the mirror assembly that is immersed in the cryogen, was longer than that of the balloon instrument, since accessibility to the sensor housing required a larger separation between the cryogen container and sensor housing. The cooling rate of the instrument, however, is determined by the dimensions of the thin mirror stem, which remained unchanged. Thus the laboratory instrument differs from the balloon instrument largely in the use of different materials, which allowed the connection to a vacuum system. All key parameters of the laboratory version are identical to those in the balloon instrument.
The pressure was measured using a Baratron pressure sensor, which was attached to a separate fitting about $20 \mathrm{~cm}$ downstream of the mirror. The flow tube diameter was maintained at $2.54 \mathrm{~cm}$ through the $\mathrm{CFH}$, and hence no pressure gradient is expected for this configuration.

The new laboratory instrument allowed several additional features that are not implemented in the balloon instrument. The most important feature is the installation of a second optical detection axis. In the original configuration (see Fig. A3) the LED and photodetector are arranged such that mirror is lit with an incidence angle of about $85^{\circ}$. For the second optical detection axis, small vacuum-sealed windows were installed such that the LED and photodiode observed the same mirror at an incidence angle of about $45^{\circ}$. Rotationally offset by $90^{\circ}$ from this LED-detector axis, two whitelight LEDs were placed to illuminate the mirror and frost layer. This allowed a visual observation of the mirror and frost coverage through the main sapphire window. Since the $\mathrm{CFH}$ is insensitive to ambient light, the addition of the whitelight LEDs did not impact the detector operation. The relocation of the detector LED and photodiode from the specular axis resulted in some loss of signal, which is compensated for by referencing the frost coverage to the clear mirror signal. It did not impact the operation of the $\mathrm{CFH}$ or lead to a change in PID (proportional, integrating, differentiating) controller settings. Only one of the two detection axes at a time could drive the mirror temperature control.

\section{A2.3 CFH operation during AquaVIT-1}

\section{Cryogen}

The CFH during AquaVIT-1 was operated using liquid nitrogen. Since it is significantly colder than trifluoromethane $\left(\mathrm{CHF}_{3}\right)$, which is used in balloon soundings, a Teflon sleeve was placed over the cold finger to reduce the heat transfer into the cryogen. The Teflon sleeve nearly compensated for the lower temperature of liquid nitrogen since the mirror heater currents were comparable to those observed in flight. The cryogen container capacity was about twice that of the balloon instrument; liquid nitrogen was added more often (about every $2.5 \mathrm{~h}$ ) because the heat capacity of liquid nitrogen is less than that of trifluoromethane. 


\section{Mirror cleaning and clearing}

During the first week of operation the CFH remained connected to the AIDA chamber and was not opened, and the mirror was not cleaned during this set of experiments. A slight film deposit was observed on the fifth day of the first week, which prompted a mirror cleaning after the morning experiments. During the opening of the instrument, a vacuum fitting was damaged and had to be replaced. Therefore, no measurements could be performed during the afternoon of the fifth and last day of static experiments. Cleaning was done using cotton swabs and methanol, while monitoring the optics signal. This procedure is identical to the pre-launch instrument preparation for a balloon sounding. Cleaning was completed when the reflectivity signal was maximized.

In order to maintain a consistent frost layer, it was frequently cleared by heating the mirror to about $20^{\circ} \mathrm{C}$ and evaporating the condensate layer completely. A similar process occurs during balloon flights. The frost clears within one second. After mirror clearing the instrument resumes normal operation with a newly formed frost layer. However, during AquaVIT-1 when the chamber water vapor mixing ratio was low (frost-point temperatures typically less than $210 \mathrm{~K}$ ), the frost layer could not be reformed readily and some measurement intervals were incomplete. When this occurred, water vapor was added to the system through a leak valve, which allowed the CFH to create a frost layer at a higher water vapor concentration than was available from the chamber. Establishing control at the higher water vapor concentrations using the leak valve took about $1 \mathrm{~s}$. Closing the leak valve with continuous control took about $1 \mathrm{~min}$. Thus, it took about 2 to 3 min to clear the mirror to recondense the frost layer and to bring the $\mathrm{CFH}$ into stable control at the water vapor concentration during the days of the lowest frost-point temperatures. The times between mirror clears varied from several minutes to about $2 \mathrm{~h}$. The upper limit was set by the buffer overflow problem of the acquisition software. During a balloon sounding, which typically takes $90 \mathrm{~min}$ on ascent and 30 to $45 \mathrm{~min}$ on descent, two mirror clears happen. Thus the time between mirror clears during AquaVIT-1 was comparable to that of a balloon sounding.

\section{A2.4 CFH experiments in addition to the AquaVIT-1 program}

Since the CFH was significantly modified from its balloon configuration in being adapted to the AIDA chamber tests, several aspects of the $\mathrm{CFH}$ operation were examined in more detail to ensure that the CFH measurements were of expected high quality during the intercomparison campaign.

\section{Detector location and microscope observations}

During the second and third day of AquaVIT-1, both detection axes were used to study whether the reduced signal in the off-perpendicular detector configuration causes any negative impacts. No difference between these two configurations was observed. Starting on day four of AquaVIT-1 all experiments were run using the off-perpendicular detector configuration. This configuration allowed observing the mirror directly through the perpendicular detection port using a microscope. For nearly all measurements in this configuration visual images of the frost layer exist. These visual images can be used as an independent quantification of a stable frost layer.

\section{Controller settings}

During the first week of operation the PID parameters used to run the $\mathrm{CFH}$ were those used by the balloon instrument, which depend only on frost-point temperature. During the second week a number of experiments were performed with changed parameters to study whether the PID parameters could be optimized. All of these experiments remained inconclusive, and, aside from occasional controller instability, no changes in instrument performance were observed.

\section{Frost layer morphology}

The mirror clear capability was used to study the influence of different frost layer morphologies. These experiments showed that the frost layer morphology can have a significant influence on the performance of a frost-point hygrometer. However, all data submitted to the AquaVIT-1 archive used a frost layer consistent with one that would have formed during a routine $\mathrm{CFH}$ sounding.

\section{Liquid-ice transition}

The AquaVIT-1 experiment focused on low water vapor concentrations, which translated to low frost-point temperatures. However, in the atmosphere there exists a frost-point temperature range in which the phase of the mirror condensate is not uniquely defined and in which the measurement of reflectivity does not provide sufficient data to distinguish the condensate phase. The transition between liquid phase and solid phase of the condensate on the mirror was studied after the completion of one experiment day. These experiments clearly show that the liquid-to-ice transition for the mirror condensate may extend to mirror temperatures colder than $-30^{\circ} \mathrm{C}$. Without special precaution, the condensate on the mirror may remain liquid down to these temperatures. Spontaneous frost formation will then create a frost layer whose morphology is undetermined. The poorly defined frost layer morphology may negatively impact the controller stability at much colder temperatures. The control routines used in the $\mathrm{CFH}$ force the condensate layer to freeze at a predetermined temperature (usually $-15^{\circ} \mathrm{C}$ ) and always lead to a welldefined frost layer morphology. The same routine as used in flight was used in the AquaVIT-1 experiments, ensuring that 
the results of this experiment are transferable to the performance of the instrument in atmospheric soundings.

\section{Flow rate dependency}

The exhaust line of the lab CFH was connected to the vacuum system using a needle valve. Using this valve, the flow through the instrument could be varied to study any possible flow rate dependency of the measurement. No such dependency could be found. In fact, flow rate variations led to strong pressure variations in the instrument as well as to strong frost-point temperature variations. Measured frostpoint changes were as fast as pressure changes when the needle valve was either opened or closed. However, the changes in frost point perfectly canceled changes in pressure, leading to constant mixing ratios throughout these experiments. This was taken as confirmation that the instrument responds as it should to changes in partial pressure when measuring a constant mixing ratio.

\section{Comparison to PTB water vapor permeation source (PTB-WVPS)}

The PTB (Brunswick, Germany) provided a primary referenced water vapor permeation source, which was used as independent reference on day four of the second week of experiments. After $1 \mathrm{~h}$ of purging the combined flow systems, $\mathrm{CFH}$ water vapor values agreed with the permeation source to within $5 \%$ and after $2.5 \mathrm{~h}$ to within $2 \%$.

\section{A3 Fast In situ Stratospheric Hygrometer (FISH-1 \& FISH-2)}

\section{A3.1 Instrument description}

The FISH instruments, developed at the Forschungszentrum Jülich (Germany), are based on the Lyman- $\alpha$ photofragment fluorescence technique. FISH has been used in several balloon and aircraft campaigns and compared to many other hygrometers during atmospheric measurements.

The instrument is described in detail by Zöger et al. (1999). FISH consists of a closed, vacuum-tight fluorescence cell, a Lyman- $\alpha$ radiation source, a photomultiplier tube (PMT) in photon-counting mode, detectors to monitor the vacuum ultraviolet (VUV) radiation output of the Lyman$\alpha$ lamp, and a mirror drive that controls the measuring cycle: the determination of the fluorescence $\left(N_{g}\right)$ and background count rate $\left(N_{u}\right)$ and of the lamp intensity $\left(I_{0}\right)$. The water vapor mixing ratio is determined via $\left[\mathrm{H}_{2} \mathrm{O}\right]=c_{k} \cdot\left(N_{g}-f_{u}\right.$. $\left.N_{u}\right) / I_{0}$. The coefficients $c_{k}$ and $f_{u}$ are determined in the calibration procedure.

The calibration of FISH is done in regular intervals between the measurement deployments using a calibration bench, consisting of a humidity mixing system and a frostpoint hygrometer (MBW DP30) as a reference instrument (Zöger et al., 1999; Meyer et al., 2014). A calibration is done by varying the pressure (typically $80-500 \mathrm{hPa}$ ) and mixing ratio $(1-500 \mathrm{ppm})$ to cover the relevant range of the atmospheric measurements.

\section{A3.2 Performance during AquaVIT-1}

During AquaVIT-1, two instruments were operated: FISH-1, designed for and used on Learjet missions and here operated from the upper AIDA platform, and FISH-2, designed for and used on Geophysica and Falcon missions and here operated from the lower AIDA platform. Both instruments are almost identical concerning the core components. However, a problem arose during AquaVIT-1 of the Lyman- $\alpha$ lamp in FISH-1 not being able to be tuned to its optimum mode, resulting in a lower signal-to-noise ratio compared to FISH-2. This problem had not been observed previously in FISH-1, which has been replaced now by a new, updated Lyman- $\alpha$ instrument.

Both hygrometers worked nominally during all AquaVIT1 experiments except for 22 October, as the high $\mathrm{H}_{2} \mathrm{O}$ concentrations during that particular dynamic experiment caused optically thick conditions for FISH. Flow rates on the order of 10 standard liters per minute (SLM) could be achieved and are comparable to those during aircraft operations; only a few periods with flow rates below 5 SLM had to be removed from FISH-2 data when contamination could not be excluded.

Calibrations were carried out on 10, 15, 20, 21, 24, and 30 October. No significant drift of the calibration factors $c_{k}$ and $f_{u}$ could be detected over the AquaVIT- 1 period. The reproducibility of $c_{k}$ was better than $3 \%$ (FISH-2) and $4 \%$ (FISH-1) for individual calibrations (Meyer, 2008).

The MBW-DP30 reference hygrometer was calibrated by the manufacturer with traceability to National Physical Laboratory (NPL, Middlesex, UK) standards a few months before AquaVIT-1. During AquaVIT-1, this DP30 was also compared to the secondary PTB standard (PTB-WVPS in Sect. 6.5). From this comparison, the MBW-DP30 accuracy was determined to be $\pm 4 \%$ in volume mixing ratio (Meyer, 2008; Meyer et al., 2014).

\section{A3.3 Lessons learned during AquaVIT-1}

At high mixing ratios and low pressure, an unexpected low bias of FISH data compared to the 18 other AquaVIT-1 instruments occurred. Vice versa, at low mixing ratios and high pressure, a slight high bias of FISH data was found. In response, additional laboratory calibrations carried out over an extended pressure range in the home laboratory were conducted, and correction schemes based on these calibration procedures were developed (Meyer et al., 2014). The AquaVIT-1 data reported here have not been corrected. The airborne data of FISH, however, are not impacted by these biases since mixing ratios of several tens to hundreds of ppm at pressures below $100 \mathrm{hPa}$ and mixing ratios below $10 \mathrm{ppm}$ at several hundreds of $\mathrm{hPa}$ do not occur in the atmosphere. 


\section{A4 FLuorescent Advanced Stratospheric Hygrometer for Balloon (FLASH-B1 \& FLASH-B2)}

\section{A4.1 Instrument description}

The FLASH-B instruments are a compact lightweight sonde developed at the Central Aerological Observatory (CAO) (Russia) for balloon-borne water vapor measurements in the upper troposphere and stratosphere (Yushkov et al., 1998, 2001). The instrument is based on the Lyman- $\alpha$ fluorescence technique. The source of Lyman- $\alpha$ radiation $(\lambda=121.6 \mathrm{~nm})$ is a hydrogen discharge lamp, while the detector of $\mathrm{OH}$ fluorescence at 308-316 nm is a Hamamatsu R647-P photomultiplier run in photon-counting mode with a narrowband interference filter for selecting the fluorescence spectral region. The intensity of the fluorescent light sensed by the photomultiplier is directly proportional to the water vapor mixing ratio under stratospheric conditions $(30-150 \mathrm{hPa})$ with small oxygen absorption ( $3 \%$ at $50 \mathrm{hPa}$ ). The background signal caused by the night sky emissions in the absence of fluorescence light is detected using lamp modulation with a $1 \mathrm{kHz}$ square wave with $1 / 8$ duty cycle and synchronous demodulation of the received signal. The $\mathrm{H}_{2} \mathrm{O}$ measurement range is limited to below $400-500 \mathrm{hPa}$ due to strong Lyman- $\alpha$ absorption in the troposphere. FLASH-B uses the open layout (Khaplanov et al., 1992) with the optics looking directly into the outside air. This arrangement is suitable only for nighttime measurements.

The source of VUV radiation used in the FLASH-B instrument is a hydrogen glow-discharge lamp filled with a mixture of hydrogen and helium at the total pressure of $10 \mathrm{hPa}$. Unlike the more sophisticated hygrometers based on the fluorescence technique, FLASH-B does not have VUV photon flux control; however, this is compensated for by a very precise stabilization of the lamp's current, to which the emission intensity is directly proportional. The hydrogen glowdischarge lamps used in the FLASH-B instrument have been proven to have very stable intensity of the Lyman- $\alpha$ emission over both operation and storage time. The VUV light sources containing the mixture of hydrogen and helium are known to have stray helium line $(318 \mathrm{~nm})$ emission, which overrides the spectrum of hydroxyl fluorescence and thus may cause spurious signal from reflection (backscattering) of this emission. The FLASH-B lamp is equipped with a special $\mathrm{MgF}_{2}$ window filter for suppressing the $270-320 \mathrm{~nm}$ band emission.

The accuracy of the FLASH-B instrument is determined by the calibration error estimated as $4 \%$ in the $3-100 \mathrm{ppm}$ range. The measurement precision is $5.5 \%$ calculated for $4 \mathrm{~s}$ integration time at stratospheric conditions. The total uncertainty of the measurement is less than $10 \%$ at the stratospheric mixing ratios greater than $3 \mathrm{ppm}$ increasing to about $20 \%$ at mixing ratios less than $3 \mathrm{ppm}$. The total relative error of calibration amounts to $4 \%$. The calibration fit function is linear in the pressure range of $30-150 \mathrm{hPa}$ and water vapor mixing range of $1-300 \mathrm{ppm}$. At higher pressures the VUV absorption by oxygen and water vapor is taken into account. The lamp stray light backscattered from the chamber walls does not affect the calibration since the calibration coefficients are determined as the slope of a regression line.

FLASH-B has been successfully used in a number of balloon campaigns (e.g., LAUTLOS-WAVVAP, SCOUTAMMA, TC4, LAPBIAT-II, TRO-pico) that included simultaneous measurements of stratospheric water vapor by different measurement techniques. In particular, point-by-point comparison with the frost-point hygrometer from the NOAA Climate Monitoring Diagnostics Laboratory (Boulder, CO USA) showed a mean deviation of $2.4 \%$ with $3.1 \%$ standard deviation $(1 \sigma)$ (Vömel et al., 2007b), and comparison with $\mathrm{CFH}$ showed a mean deviation of $0.8 \%$ with $4 \%$ standard deviation (Khaykin et al., 2013). A number of unpublished field intercomparisons between FLASH-B and CFH flown simultaneously at various locations have provided similar results with discrepancies below $5 \%$ in the $1-10 \mathrm{ppm}$ mixing ratio range.

\section{A4.2 Performance during AquaVIT-1}

During AquaVIT-1 two FLASH-B instruments were operating independently: FLASH-B(1) was mounted onto the AIDA vessel and made in situ measurements directly in the vessel, and FLASH-B(2) ran in an external warm chamber connected to AIDA via heated tube. An important point, which has to be thoroughly considered when assessing FLASH-B performance during the AquaVIT-1 experiments, is the effect of stray light backscattering in both the AIDA vessel and FLASH-B2 external chamber. As mentioned above, the hydrogen lamp has a spurious emission line, overriding the fluorescence spectrum, and therefore the reflection of the lamp's emission from a surface would be treated by hygrometer as a water vapor signal. The latter is not an issue for the flight experiments, but does arise when the hygrometer is taking measurements inside a chamber.

During AquaVIT-1 the effect of stray light backscattering was observed for both FLASH-B1 and FLASH-B2 instruments. Attempts to estimate the contribution of stray light to the FLASH-B signal were performed for every static experiment by assuming a constant water vapor partial pressure. However, since the partial pressure was actually varying within every static experiment, the estimates of stray light contribution (SLC) turned out to be incorrect. It was found that the SLC varied slightly from one experiment to the other, introducing an additive of $7 \pm 2.5 \mathrm{ppm}$ to the value of water vapor mixing ratios from the fluorescence signal. Errors in estimation of SLC introduced a systematic offset into the FLASH-B1 water vapor data as described below.

For experiment 3 (15 October) SLC was overestimated by $20 \%$, resulting in a constant negative offset of about $1.4 \mathrm{ppm}$ with respect to APicT data for pressures above $100 \mathrm{hPa}$. At the lowest mixing ratio of $1.7 \mathrm{ppm}$ observed 


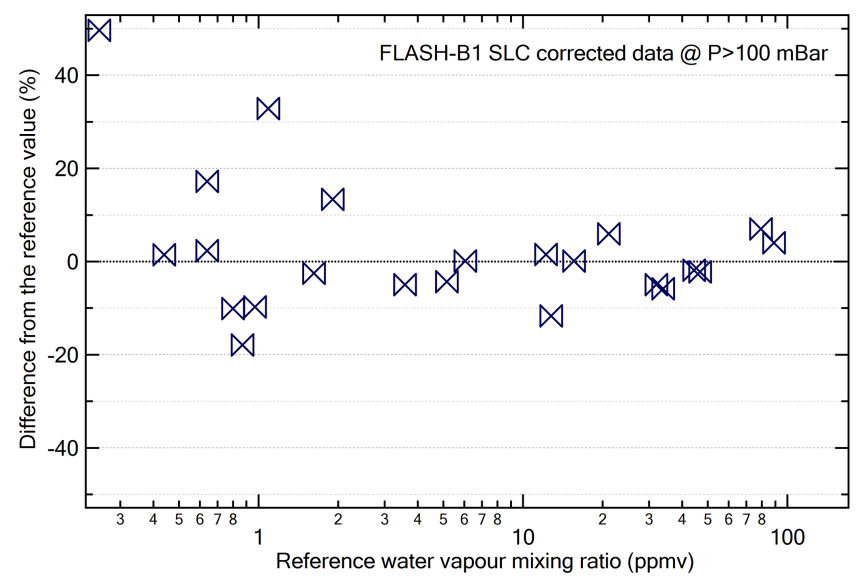

Figure A4. Summary plot of the static experiment results for FLASH-B1 data in the entire range of water vapor mixing ratios, with the data from experiments 3 and 7 recalculated using correct SLC values.

during experiment 3 (based on APicT data), this offset accounts for an $82 \%$ deviation from APicT. For experiment 7 (18 October) the $4 \%$ error in estimation of SLC resulted in a constant negative offset of about $0.35 \mathrm{ppm}$ and consequently a $54 \%$ deviation from APicT at $0.65 \mathrm{ppm}$. The stray light effect had a much larger contribution to the FLASHB2 measurements in a small chamber. The average value of SLC amounted to $230 \mathrm{ppm}$, and, due to some noisiness in the data, mixing ratios below $2 \mathrm{ppm}$ (i.e., less than $1 \%$ of the SLC value) could not be properly detected by the FLASHB2 instrument. Accordingly, the FLASH-B2 data from the experiments with low water vapor mixing ratios were not archived. The data of both FLASH-B1 and FLASH-B2 were not used for the formal intercomparison due to high relative error introduced by incorrect quantification of the stray light contribution.

Figure A4 shows the summary plot of the static experiment results for FLASH-B1 data in the entire range of water vapor mixing ratios with the data from experiments 3 and 7 recalculated using correct SLC values. The SLC values have been determined by fitting FLASH-B 1 data at $200 \mathrm{hPa}$ pressure to APicT data. While such a method does not comply with the rules of the AquaVIT-1 blind intercomparison, measuring a known amount of water vapor is the only way to determine SLC in a closed chamber. The results shown in Fig. A4 were obtained by comparing FLASH-B1 segment averages to the reference water vapor mixing ratios. Only the data obtained at pressures equal to or higher than $100 \mathrm{hPa}$ were used for the recomparison as the low-pressure measurements bore issues as described below.

The comparison between FLASH-B1 and APicT revealed positive deviations of FLASH-B1 data increasing at low chamber pressures, typically below $200 \mathrm{hPa}$. Importantly, this effect was not observed for FLASH-B2, which suggests that the low-pressure bias of FLASH-B1 is somehow related to the measurement configuration of FLASH-B1, with the analyzed volume located in a hollow of the chamber wall within a close vicinity $(<3 \mathrm{~cm})$ of the heated flange. Another effect observed at low pressure for FLASH-B1 was a dramatic increase of noise in the data, known from field experiments to be the consequence of water contamination due to outgassing from balloon or instrument surfaces. Although it is somewhat doubtful that the chamber wall could be a source of such water contamination, it is absolutely clear that the low-pressure effect is not an instrument-related issue.

During the AquaVIT-1 period, FLASH-B2 was calibrated twice using the MBW-DP30 hygrometer and the FISH calibration bench. No change of calibration factor was detected. Both FLASH-B1 and 2 instruments were calibrated at CAO after the AquaVIT-1 campaign and did not show any change in calibration factors, which proves at best the stability of FLASH-B calibrations.

\section{A4.3 Lessons learned during AquaVIT-1}

The experimental setup of the FLASH-B instruments in the AquaVIT-1 campaign resulted in major issues that were not properly identified before and during the experiments. FLASH-B is an open-cell Lyman- $\alpha$ hygrometer; therefore when operated in a closed chamber it receives reflected stray light that is not produced during balloon flights. The latter introduces a constant additive offset to the water vapor signal. In order to avoid this, the stray light has to be accurately determined for every particular chamber experiment. The only way of accurate stray light signal determination is to measure a known water vapor concentration in the chamber. For this, a single measurement point is enough because the sensitivity of the sensor is governed by the calibration factor, which proved to remain constant during the entire campaign. The procedure of stray light detection as described above was not performed during AquaVIT-1. Other attempts to determine or estimate stray light contribution either failed or turned out highly inaccurate, resulting in a constant bias in the FLASHB data.

The adaptation of the FLASH-B1 instrument to the AIDA chamber, in which FLASH-B-analyzed volume is located very close to the AIDA wall, caused boundary wall effects, becoming apparent at low pressures as a sign of water contamination. For future chamber experiments with FLASH-B the adaptation scheme and experimental setup have to be seriously reconsidered.

\section{A5 Harvard Water Vapor (HWV)}

\section{A5.1 Instrument description}

HWV is an aircraft-borne water vapor instrument that has flown on NASA's WB57F since 2001, successfully participating in the Clouds, Water Vapor and the Climate System mission (CWVCS); CRYSTAL FACE; the Middle-latitude 
Cirrus Experiment (MidCiX); Pre-AVE (Aura Validation Experiment); AVE; AVE-WIIF (Water Isotope Intercomparison Flights); CRAVE (Costa Rica AVE); and the Tropical Composition, Cloud, and Climate Coupling Experiment (TC4) missions prior to the AquaVIT-1 comparison (Weinstock et al., 2009). The instrument detection axis is a lightweight version of the one that has flown on the ER-2 aircraft since 1992 (Weinstock et al., 1994). The operating principle, optical configuration, and laboratory calibrations of these instruments are nearly equivalent, thus providing a self-consistent set of measurements of upper tropospheric and lower stratospheric water vapor from 1992 to 2007. The HWV instrument (as it flew until 2011) is shown on the left in Fig. A5 mounted in the WB57F left spearpod. On the right is a schematic representation of the flow through the instrument. The inner secondary duct picks up the laminar core of the ram-fed flow. Flow velocities to the detection axis are controlled by a throttle valve and are varied during flight from $\sim 40$ to $\sim 80 \mathrm{~m} \mathrm{~s}^{-1}$ to verify a "wall-less" flow system. This approach has been used for all our aircraft-borne water vapor measurements on the ER-2 and WB57F since 1992.

The HWV instrument, and its companion, Harvard Total Water, HTW, have been previously described in detail by Weinstock et al. (1994, 2006a, b). Briefly, as illustrated in the inset of Fig. A6, $121.6 \mathrm{~nm}($ Lyman- $\alpha)$ radiation from a sealed radio-frequency discharge lamp photo-dissociates water vapor in a $5 \mathrm{~cm} \times 5 \mathrm{~cm}$ square duct. A fraction of the resulting $\mathrm{OH}$ fragments are formed in their first excited electronic state $\left(A^{2} \Sigma^{+}\right)$, and the $\mathrm{OH}$ fluorescence at $\sim 315 \mathrm{~nm}$ is collected at right angles to both the Lyman- $\alpha$ beam and the airflow. The fluorescence passes through a filter assembly and is detected with a photomultiplier tube (not shown). Because the fluorescence is strongly quenched by collisions with $\mathrm{O}_{2}$ and $\mathrm{N}_{2}$ at a rate proportional to the air density, at altitudes of the upper troposphere and lower stratosphere the observed detector signal is effectively proportional to the water vapor mole fraction. Solar and lamp scatter near $315 \mathrm{~nm}$ are measured by using a quartz window to periodically block the Lyman$\alpha$ beam. This background measurement is typically executed for $2 \mathrm{~s}$ out of every $10 \mathrm{~s}$. Changes in lamp intensity monitored with a VUV photodiode opposite the lamp are used to normalize the fluorescence signal. The lamp intensity at the fluorescence detection volume is calculated by correcting for absorption by water vapor, and the pressure-dependent absorption of $121.6 \mathrm{~nm}$ light by molecular oxygen. A rearsurface coated $\mathrm{MgF}_{2}$ mirror adjacent to the VUV diode reflects some of the radiation back across the duct to a second VUV diode, permitting simultaneous measurements of water vapor by direct (Beer-Lambert) absorption at sufficiently high water vapor (mid- to upper troposphere) concentrations.

Empirically determined proportionality constants define the sensitivity of the instrument to water vapor detection. These calibration constants describe the pressure-dependent relationship between the net normalized fluorescence signal and the water vapor concentration in the duct. Extensive laboratory calibrations are run over a range of water vapor mixing ratios $(\sim 0.5$ to $\sim 500$ ppmv $)$, pressures $(\sim 30$ to $500 \mathrm{hPa}$ ), temperatures $\left(\geq-60^{\circ} \mathrm{C}\right)$, and flow rates, chosen to replicate the flight environment as closely as possible. Figure A6 shows a schematic of our laboratory calibration system. HWV is calibrated with two independent reference standards. A two-stage bubbler is used as both a water addition system and a primary standard. A small flow of air is brought to water vapor saturation by bubbling it through a glass frit immersed in distilled water in two stages; this flow is then combined with a main flow of dry air to produce air with known water vapor concentrations from 1 to 500 ppmv. The added water vapor concentration is known to within $5 \%$ based on the uncertainty in the temperature and pressure at the bubbler, the flow rates of the two flow controllers adding dry and saturated air, and achievement of $100 \%$ saturation of air after the bubbler. The delivered mixing ratio is independently confirmed via a direct absorption measurement of $121.6 \mathrm{~nm}$ light over a $\sim 1 \mathrm{~m}$ pathlength along the axis of the calibration duct. The absorption cross section has been accurately determined (Kley, 1984). The agreement between these two standards is typically within $5 \%$ and establishes the accuracy of the HWV calibration constants (Smith, 2012). HWV is capable of measuring water vapor mixing ratios (ppmv) in situ at $1 \mathrm{~Hz}$ with an accuracy of $5 \%(1 \sigma)$ and precision of $\sim 0.1 \mathrm{ppmv}$ for mixing ratios $<10 \mathrm{ppmv}$, and a precision of $\sim 1 \%$ for mixing ratios $>10 \mathrm{ppmv}$. The reliability and accuracy of the HWV system has been thoroughly documented (e.g., Weinstock, et al., 1994; Hintsa, et al., 1999; Weinstock, et al., 2006a, b, 2009).

Advances in recent years have increased confidence in the in-flight accuracy of HWV. The addition of the independent total water instrument in 2001, which uses a virtually identical detection axis as HWV, has provided a means of comparing water vapor measurements in clear air from two instruments operating under very different detection temperature and mass flow conditions. In flight, the HWV detection axis samples air at high flow velocities, $\sim 80 \mathrm{~m} \mathrm{~s}^{-1}$ $(\sim 1500 \mathrm{SLM}$ at $100 \mathrm{hPa})$, and with temperatures in the detection region measuring about $15 \mathrm{~K}$ above ambient. In sharp contrast, HTW, which is fitted with an isokinetic inlet and an upstream $600 \mathrm{~W}$ heater, has a flow velocity in the detection region of $\sim 5 \mathrm{~m} \mathrm{~s}^{-1}(\sim 70 \mathrm{SLM}$ at $100 \mathrm{hPa})$ and an air temperature of $\sim 25^{\circ} \mathrm{C}$. The HTW detection axis detects water vapor in flight under pressure, temperature, and flow conditions nearly identical to those encountered during laboratory calibrations. Accordingly, the documented agreement between HWV and HTW in the UT-LS demonstrates the robustness of these instruments to radically different environmental conditions.

\section{A5.2 HWV performance in AquaVIT-1}

During AquaVIT-1 the HWV instrument was set up with two detection axes in series, taken from the HWV and HTW 

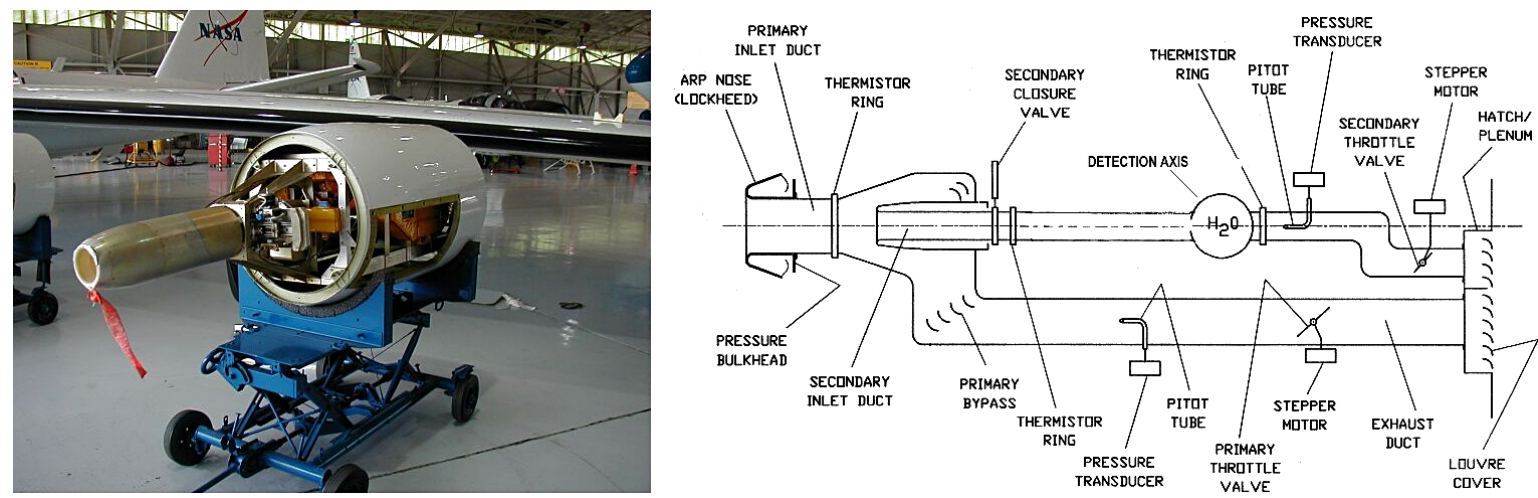

Figure A5. Left: the HWV instrument as it is mounted in the WB57F. Right: schematic illustrating the subsystems that control the flow of air through the instrument and acquire simultaneous measurements of temperature, pressure, and velocity in the duct.

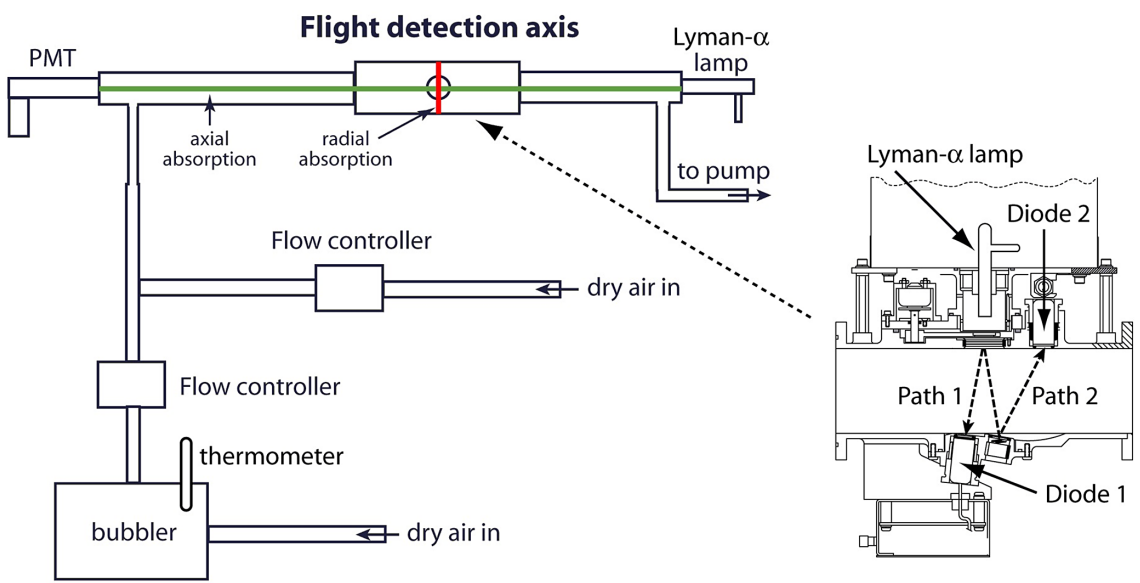

Figure A6. A schematic of the HWV calibration system and heart of the Lyman- $\alpha$ detection axis, with the components necessary for radial absorption labeled. The calibration system is routinely used in the laboratory and in the field. The bubbler serves as both a water vapor source and a primary standard. In the laboratory, axial absorption of $121.6 \mathrm{~nm}$ light down the $1 \mathrm{~m}$ length of the duct is a secondary reference standard. Radial absorption of $121.6 \mathrm{~nm}$ light provides independent verification of the fluorescence measurement accuracy in flight.

instruments, with an additional three-way valve inserted between our detection axes and the chamber to allow for laboratory calibrations without any instrument or ducting disassembly. Figure A7 shows calibration data for two days, 16 and 19 October, that were acquired immediately following AquaVIT-1 static experiments on those days. These calibration runs, in particular the one on 19 October, simulate the pressure and mixing ratio regimes of the chamber experiments (i.e., low water vapor mixing ratios and high pressures). Figure A7 (top) shows selected dilution steps from these two runs. The first calibration run explored mixing ratios from $\sim 1$ to $21 \mathrm{ppmv}$ in steps of 1 to $5 \mathrm{ppmv}$ and had a background mixing ratio of $\sim 1.1 \mathrm{ppmv}$. The second explored mixing ratios from $\sim 0.5$ to $3 \mathrm{ppmv}$ in steps of $\sim 0.5 \mathrm{ppmv}$ and had a stable background of $\sim 0.6 \mathrm{ppmv}$ when no water was added. Figure A7 (bottom) shows the inverse of the pressure-dependent calibration constant, $C$ [counts $\left./\left(\#_{\mathrm{H}_{2} \mathrm{O}} / \mathrm{cm}^{3}\right)\right]$, derived from the dilution step data, plotted as a function of the number density in the duct, $M$ $\left[\# / \mathrm{cm}^{3}\right]$. The solid black line represents the results of a linear fit to the complete set of calibration data acquired during the AquaVIT- 1 campaign, and the dashed lines denote the $\pm 5 \%$ range. The data from these two runs fall well within the $\pm 5 \%$ uncertainty envelope. These results demonstrate the linearity and robustness of the calibration over an order of magnitude in pressure and from a few tenths of a ppmv to tens of ppmv.

The laboratory environment at AquaVIT-1 introduced sources of systematic error that were substantially different from those encountered in flight, and that degraded the performance of HWV. The HWV instrument was plagued by a systematic bias and large uncertainties associated with a combination of leaks into the sample duct and outgassing from the walls upstream of the detection axis. Note that neither outgassing nor leaks are expected to impact either the determination of the instrument sensitivity (i.e., calibration) or the airborne HWV measurements. In flight there 

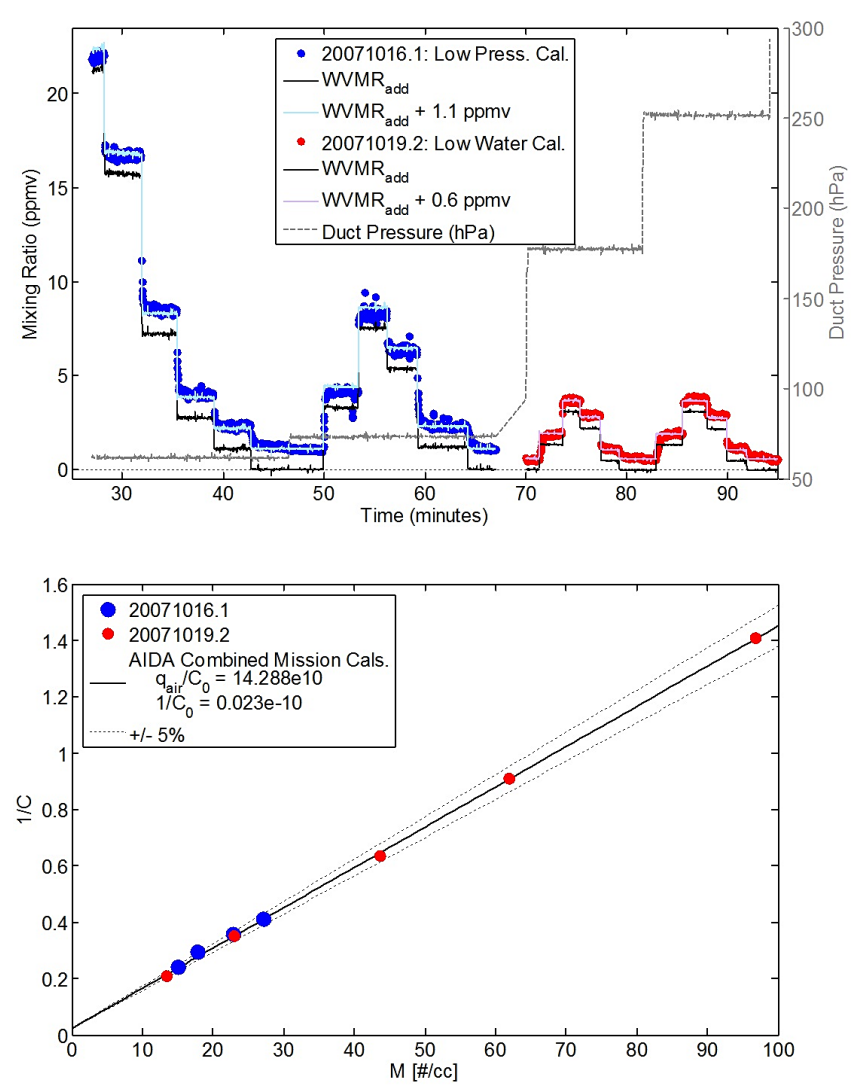

Figure A7. Linearity of the Lyman- $\alpha$ detection method over a range of pressures and mixing ratios representative of chamber conditions on 16 and 19 October. The top panel shows selected dilutions from calibrations executed at low pressures, $\sim 60$ to $120 \mathrm{hPa}$ (blue), and at low water vapor mixing ratios, 0 to $5 \mathrm{ppmv}$ (red). The fluorescence data, evaluated using calibration constants from a composite of four calibration runs, are plotted as the colored dots; added water vapor, $\mathrm{WVMR}_{\mathrm{add}}$, utilizing the bubbler reference standard, is plotted as the black line; and the colored lines show the bubbler plus a constant offset representative of the background mixing ratio in the carrier flow for each run. The bottom panel shows the calibration figures (i.e., $1 / C_{\mathrm{flr}}$ vs. $M$ ) with the data from both calibration runs. The solid black line represents the best fit to the full set of calibrations performed at the AIDA facility, and the dashed lines show the $\pm 5 \%$ uncertainty range.

is little pressure differential across the instrument duct; in fact pressures inside the duct are greater than ambient, often by $\sim 10 \mathrm{hPa}$. Furthermore, to achieve fast time response and minimize the impact of outgassing in flight, HWV was specifically designed for high flow velocities and correspondingly high mass flow rates. Mass flows in the instrument duct during flight are $>1000$ SLM, in contrast to the maximum achievable flow rate of 20 SLM at the lowest chamber pressures during AquaVIT-1.

During the week allotted to instrument setup, every attempt was made to provide our instrument with the maximum possible flow rate, and during the week of static runs the

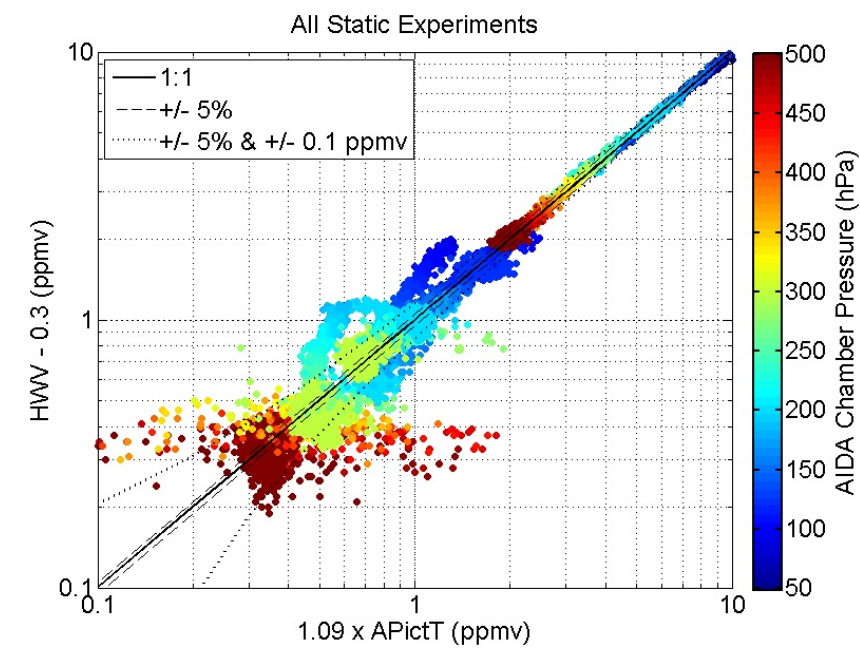

Figure A8. Comparison of HWV and APicT low water vapor data for static experiments. Color indicates chamber pressure. APicT data are multiplied by 1.09 to account for a calibration difference between these two instruments inferred from data acquired during the high water vapor experiments on 16 and 17 October. In addition, a constant offset of 0.3 ppmv has been subtracted from HWV. At mixing ratios lower than $\sim 2$ ppmv and chamber pressures less than $\sim 200 \mathrm{hPa}$, systematic uncertainties associated with low mass flows in the HWV instrument plagued the measurement.

instrument was repeatedly tested for its sensitivity to varying flow rates and duct pressures. Using these test results, an empirical model was constructed to determine the appropriate pressure and flow-dependent correction factor for the data. The large uncertainties associated with the correction, however, increased the uncertainty of the final measurement. At the highest pressures and faster flows, the combined contribution from leaks and outgassing was minimized, amounting to less than $\sim 0.05 \mathrm{ppmv}$. However, at lower pressures and/or slower flows these contributions exceeded $\sim 1.0 \mathrm{ppmv}$ and became a significant fraction of the water vapor signal measured by HWV. A full analysis of the test results, the development of the model, and an analysis of the uncertainties associated with the correction factor is explained in detail in Smith (2012). A brief description is given in the headers for the AquaVIT-1 data files. Data that required a correction of $30 \%$ or greater were not archived. Accordingly, for the low mixing ratio experiments on 18 and 19 October, data were not archived when chamber pressures were below $200 \mathrm{hPa}$. Figure A8 shows the relationship between APict and HWV for mixing ratios $<10 \mathrm{ppmv}$. The large deviations from the linear relationship are associated with insufficient flow in HWV at low chamber pressures.

Despite the difficulties enumerated above, HWV performed well during AquaVIT-1. The short-term precision was excellent, within $\sim 0.03 \mathrm{ppmv}$ for $5 \mathrm{~s}$ data for the lowest mixing ratios in the chamber (i.e., $<1.0 \mathrm{ppmv}$ ) and within $0.5 \%$ for chamber mixing ratios greater than $10 \mathrm{ppmv}$. The 
calibrations executed during the campaign exhibited excellent agreement over a representative range of pressures and water vapor mixing ratios, and, while the opportunity did not arise to cross-calibrate with the MBW-373 LX or the PTBWVPS during the campaign, comparisons of HWV with both JLH and CFH show agreement within the combined uncertainty of each instrument pair. For reasons that cannot be identified, agreement between HWV and both the APicT and FISH-2 fall just outside their combined uncertainty envelopes. However, these observed differences at the level of $10 \%$ cannot explain the larger systematic differences found in atmospheric observations as shown in Fig. 1.

\section{A6 JPL Laser Hygrometer (JLH)}

\section{A6.1 Instrument description}

The NASA Jet Propulsion Laboratory (JPL) Laser Hygrometer (JLH) instrument is a single-channel, near-infrared, openpath, tunable diode laser spectrometer for in situ measurements of atmospheric water vapor from aircraft platforms in the troposphere and stratosphere (May, 1998). Three laser hygrometers were developed at the Jet Propulsion Laboratory, California Institute of Technology, for the NASA ER2, WB-57, and DC-8 aircraft platforms and have participated in numerous NASA missions from 1997 to the present: POLARIS, CAMEX, ACCENT, SOLVE, CRYSTAL-FACE, AVE, AVE-WIIF, MidCiX, PUMA-A, Costa Rica AVE, and TC4

The light source for JLH is a near-infrared distributed feedback (DFB) tunable diode laser operated at $1370.0 \mathrm{~nm}$ wavelength. The laser beam passes through an aspheric lens and is focused at the midpoint of a multipass cell in the Herriott optical configuration (Altmann et al., 1981; Herriott et al., 1964). Both laser and detector are temperature-stabilized at $15^{\circ} \mathrm{C}$ on a thermoelectrically cooled aluminum mount inside an evacuated aluminum housing (the blue sampling enclosure in Fig. 3). The laser beam enters the Herriott cell through a hole in the mirror closest to the laser. The mirrors are Au-coated spherical mirrors made of Zerodur. The separation between the mirrors is maintained to within a tight tolerance by invar rods for optical stability over a wide range of temperatures (verified from 180 to $300 \mathrm{~K}$ ). The laser beam traverses 50 passes of the Herriott cell (corresponding to $1039.3 \mathrm{~cm}$ optical pathlength) and then returns through the same mirror hole to impinge on a detector. There is an additional $8.6 \mathrm{~cm}$ path through the air between the Herriott cell and the window to the evacuated laser/detector housing, yielding a total optical path of $1047.9 \mathrm{~cm}$. The virtual sampling volume is a $1.6 \mathrm{~L}$ hyperboloid between the two mirrors (plus the small path to the window).

JLH operates in two modes: harmonic wavelength modulation spectroscopy (May, 1998; May and Webster, 1993) and direct absorption spectroscopy. In harmonic spectroscopy, the laser is scanned at an $8 \mathrm{~Hz}$ repetition rate across the strong water absorption line at $1370.0 \mathrm{~nm}$ $\left(7299.43 \mathrm{~cm}^{-1}\right)$, and modulated at $f=64 \mathrm{kHz}$ for sensitive harmonic detection at $2 f$. All 10 scans are averaged to report data at $0.8 \mathrm{~Hz}(1.3 \mathrm{~s})$. The modulated $2 f$ peak-to-peak amplitude ("pp2f"), normalized by returned laser power, is used to calculate water mixing ratios as described in May (1998). The advantages of harmonic spectroscopy are fast response and high precision.

Every $24 \mathrm{~s}$, JLH switches to its second operational mode, namely direct absorption spectroscopy. The advantages of direct absorption measurements are high accuracy, detection of background water, signal specific to water, and more highly constrained results (i.e., the laser linewidth is constrained by fitting the absorption line). The volume mixing ratio of water vapor is calculated from the Beer-Lambert law using the known pathlength and spectroscopic parameters from the HITRAN 2004 database (Rothman et al., 2005), which did not change in the HITRAN 2006 update. One can tie the direct absorption calculation of water either to (1) the spectroscopic parameters in HITRAN and the measurements that were used to make the line list in the database or to (2) in situ calibration with a reference source, while varying the spectroscopic parameters accordingly.

For the AquaVIT-1 experiment, the JLH team assumed that the HITRAN 2004 parameters were correct and calculated water mixing ratios on that basis. In addition to pathlength and spectroscopic parameters, the absolute wavelength scale must be known. For JLH, the wavelength scale was characterized by measuring the spacing of seven weak methane absorption lines in the $7299 \mathrm{~cm}^{-1}$ region. The line center positions of these methane lines have been accurately measured (Brown, 2005) and bracket the targeted water line at $7299.43 \mathrm{~cm}^{-1}$. In the calibration experiments, the calibration chamber was back-filled with methane and trace water. The spectra of water and methane were measured simultaneously. The water line position and wavelength scale of the laser scan were accurately determined by interpolation between the methane lines.

The largest source of error in this direct absorption measurement is the uncertainty in the spectroscopic parameters in the HITRAN line list. A secondary source of error arises from assumptions made in fitting the absorption line (e.g., Skrotzki et al., 2013). The absorption line is fitted with a Voigt line shape, using occasional checks with a Galatry line shape to ensure that the Voigt fit does not introduce errors greater than $3 \%$. As an additional check on the validity of the spectroscopic parameters, the water vapor mixing ratios are compared with the known humidity output from a National Institute of Standards and Technology (NIST)traceable Thunder Scientific 3900 Low-Humidity Generator. JLH is placed inside a stainless-steel chamber with continuous gas flow from the humidity generator. The water vapor mixing ratio can be monitored at the input and/or output of the chamber by a mid-infrared direct absorption measurement at $5316 \mathrm{~cm}^{-1}$ (Troy, 2007). The final JLH data are 
the fast-response $(1.3 \mathrm{~s})$ harmonic measurements, scaled to match the 24 s direct absorption measurements for higher accuracy.

\section{A6.2 Performance during AquaVIT-1}

During the AquaVIT-1 static experiments (10-19 October 2007), the JLH laser, detector, and open-path optical cell were mounted inside the AIDA chamber. These components were mounted to a flat aluminum plate, offset by posts, and the plate was mounted $80 \mathrm{~cm}$ above the base of the AIDA vessel (Fig. 3). JLH experienced realistic UT-LS conditions of pressure, temperature, and water vapor mixing ratios in the open-path optical cell inside the chamber. These conditions are the same when JLH flies on research aircraft, except that the flow rates across the optical path are much faster on aircraft. In both AquaVIT-1 (outside the chamber) and aircraft field missions, the control electronics are maintained at $25^{\circ} \mathrm{C}$. For the data analysis, measured chamber pressure and temperature are used.

JLH performed well on every day of the static experiments. The laser modulation was optimized for the 100$200 \mathrm{hPa}$ pressure range, so this is where JLH had the greatest sensitivity and precision. In the range of 2-200 ppm, JLH agreed with APicT to within $10 \%$ on average. This accuracy is within the experimental uncertainty of JLH, but JLH is biased high relative to APicT. Since JLH and APicT use the same water absorption line $(1370.0 \mathrm{~nm})$, systematic differences can be narrowed down to four possibilities: misalignment of JLH optics at low temperature, and the accuracy of measuring laser properties and tuning rate; assumptions about spectroscopic parameters, line broadening, and line shape; and the method of fitting direct absorption lines.

JLH precision was not ideal during AquaVIT-1. JLH was installed with a $3 \mathrm{~m}$ long signal cable between the optics inside the chamber and the control electronics external to the chamber. The signal noise was an order of magnitude higher in the chamber than on aircraft. The long cable is suspected of picking up noise, making the precision worse. As a result, the JLH limit of detection in AquaVIT-1 was $0.15 \mathrm{ppm}$, and no data less than $1 \mathrm{ppm}$ were submitted to the archive. At higher mixing ratios, the precision did not adversely impact the comparisons.

\section{A6.3 Lessons learned}

Mounting the JLH laser, detector, and optical cell inside the chamber worked extremely well, and the JLH team recommends this approach for any open-path instrument. If this experiment is repeated, the precision could be improved by mounting the amplifier closer to the detector.

\section{A7 MBW-373LX}

The MBW-373LX is a chilled-mirror frost-point hygrometer that is used as a reference instrument for AIDA water vapor measurements. Briefly, the measurement accuracy given by the manufacturer for the frost point is $\pm 0.1 \mathrm{~K}$ (i.e., $\pm 0.13 \mathrm{ppm}$ at $10 \mathrm{ppm}$ ) with a precision of $0.05 \mathrm{~K}$ for operation at 2.5 bar with a sample flow between 0.5 and $1.0 \mathrm{~L} \mathrm{~min}^{-1}$. For a detailed description of this frost-point mirror hygrometer, see http://www.mbw.ch/product_373.php. For the calculation of water mixing ratios or partial pressures from the measured frost-point temperatures, the parameterization of the water vapor pressure given by Murphy and Koop (2005) is used.

The MBW-373LX instrument is located on level 3 outside the cold box around the AIDA chamber. It is connected to the chamber via $10 \mathrm{~mm}$ inner-diameter (ID) stainless-steel tubes ranging $40 \mathrm{~cm}$ into the chamber volume. With a threeway valve an inlet located either at level 2 or at level 3 of the AIDA cylinder can be selected. Both sampling tubes are heated to $30^{\circ} \mathrm{C}$ from the inlet to outside of the cold box. The remaining section of the tubing is at about $23^{\circ} \mathrm{C}$. During AquaVIT-1 typical flow rates through the instrument were 1.0 SLM, decreasing to about 0.3 SLM at a total chamber pressure of $100 \mathrm{hPa}$. For lower pressures the small flow rates lead to a very slow time response of the instrument. After the first week of measurements the mirror was cleaned and the instrument gained in response time and accuracy. Therefore it seems likely that there was some mirror contamination in the first week contributing to the unusually bad performance of the instrument compared to many previous AIDA experiments. For pressures less than $100 \mathrm{hPa}$ the MBW-373LX usually showed systematic deviations, and those values should not be used. At the lowest temperatures in the static experiments the MBW data should not be used because they were obviously too high. During the dynamic experiments the instrument showed a good agreement with the other measurements except for the last experiment $(185 \mathrm{~K})$, for which again too-high values and a slow time response were observed.

In all four calibration experiments $(20,21,24$, and 25 October) with higher sample pressures and flows, the instrument compared very well with another dew-point mirror (MBWDP30) and the FISH-1 instrument. Comparison of MBW373LX (1 atm, 1 SLM) with the PTB-WVPS directly after the AquaVIT-1 campaign (30 October) showed a systematic deviation of $-4.2 \pm 3.3 \%(2 \sigma)$ for the mixing ratios applied $(1.5-13.5 \mathrm{ppm})$. The reason for this systematic deviation to the water permeation source is not completely clear. Besides possible problems in the permeation source or the dew-point mirror instrument, the flow determination seems to be the largest source of uncertainty.

\section{A8 SnowWhite}

The night version of the Snow White frost-point hygrometer (Schmidlin, 1999; Fujiwara et al., 2003; Vömel et al., 2003; Vaughan et al., 2005; Miloshevich et al., 2006) manufactured by Meteolabor (Wetzikon, Switzerland) was installed inside the AIDA chamber. The entire radiosonde as set up to 
fly on meteorological balloons was mounted on a steel plate approximately $1 \mathrm{~m}$ above the vessel floor. For the two-week campaign duration the instrument was not accessible. Therefore, the following modifications with respect to the balloon configuration were made: the batteries allowing operation for $4 \mathrm{~h}$ flight time were replaced by an external supply located outside the chamber. Water bags that heat the instrument internally to temperatures close to $0^{\circ} \mathrm{C}$ during freezing were removed and replaced by heaters with thermostats. The radiosonde transmitter was not enabled: instrument data were read out by a remote computer through a serial RS-232 interface, which is normally used during pre-flight setup. Water vapor partial pressure was calculated from the frost-point temperature according to Murphy and Koop (2005). Meteolabor specifies $0.2^{\circ} \mathrm{C}$ for both frost-point temperature precision and accuracy, leading to a total error of about $\pm 5 \%$ (depending on temperature) in the water vapor mixing ratio.

Two major difficulties were encountered during the two weeks of operation. The heaters replacing the water bags caused periodic oscillation of the temperature inside the Styrofoam housing, with strong transients as compared to the gradual temperature change during flight conditions. The resulting temperature gradients in the instrument electronics lead to erroneous reading of the frost-point and ambient temperatures. Following advice from the manufacturer, this problem was solved during the second week by operating the heaters at a temperature below the thermostat switch-off level and manually adjusting their power such that the internal temperature remained in the range of 0 to $5^{\circ} \mathrm{C}$. Thus, conditions comparable to those during balloon flights were obtained on four days during the second week. During the remaining time without the improved heating, especially for the static experiments carried out in the first week, data quality was much poorer.

The second problem was caused by the small ventilation of the sensor due to slow flow conditions inside the chamber. Under flight conditions the ascent of the balloons results in an airflow velocity of $5 \mathrm{~m} \mathrm{~s}^{-1}$. In contrast, at the instrument position near the chamber walls the corresponding downward air movement induced by a mixing fan circulating the air upward along the chamber center line was estimated to be at least a factor of 10 less in magnitude. As a consequence, at low water vapor partial pressure corresponding to mixing ratios of $10 \mathrm{ppm}$ or less, mass exchange at the frost-point mirror was very limited, leading in general to a response too slow for the feedback loop to stabilize safely on the frost-point temperature. A further effect was that in the early phase of each experiment with mixing ratios less than $100 \mathrm{ppm}$ it took very long for the frost layer to build up. In the second week, however, it was always established during the first dynamic cloud experiment. This second problem could not be solved during the campaign. Therefore, low mixing ratio data in general have to be analyzed with care. This experience shows that for future applications inside a climate chamber adequate thermal control and airflow are prerequisites to achieve performance comparable to flight conditions.

For the above reasons it could be misleading to judge SnowWhite's general performance based on an analysis restricted to the first week of static experiments as summarized in Fig. 6. Consequently, cloud-free stationary segments defined by the referees for the second week of the intercomparison were consulted for additional data analysis. All segments in the second week in which SnowWhite delivered data (i.e., 17 out of 18 for the first four days) were subjected to the data treatment described in Sect. 6.2, with the APicT taken as a reference. (During the final day water vapor was below the SnowWhite detection limit.) Figure A9 shows the relative deviation of the SnowWhite with respect to the APicT on its abscissa with the ordinate indicating the water vapor mixing ratio measured by the APicT during the respective segment. For a water vapor level above $200 \mathrm{ppm}$ the agreement between the instruments is better than $2 \%$. Between 10 and 200 ppm mixing ratio the SnowWhite measurements exhibit a positive bias of typically not more than $5 \%$ with the exception of one analysis point located near $30 \mathrm{ppm}$ and $-60 \%$ relative deviation. This point represents the first segment of experiment number 11 and provides an example of the failure to freeze condensate onto the mirror at dry starting conditions. All other data points of that experiment day were obtained after an ice cloud event. Below a water vapor mixing ratio of $10 \mathrm{ppm}$, the limitation caused by the low flow conditions becomes obvious. It is interesting to note that in the 10-200 ppm range the SnowWhite positive bias with respect to the APicT is comparable to the APicT deviation below the reference value as shown in Fig. 6 .

While loss of frost condensate on the mirror, feedback loop instability, and inlet contamination are SnowWhitespecific problems that remain to be solved (Cirisan et al., 2013), the above analysis confirms the manufacturer's erroneous estimate of approximately $\pm 5 \%$ in mixing ratio for water vapor amounts above $10 \mathrm{ppm}$ when instrumental operation was reliable and comparable to balloon flight conditions.

\section{A9 ISOWAT}

The ISOWAT instrument is a compact TDL spectrometer that has been developed to measure water-isotopic ratios (in this case $\delta^{17} \mathrm{O}$ and $\delta^{18} \mathrm{O}$, later $\delta^{18} \mathrm{O}$ and $\delta \mathrm{D}$ (Dyroff et al., 2010)) in the upper troposphere and lower stratosphere. The instrument is designed for a $48 \mathrm{~cm}$ rack width with a height of $35 \mathrm{~cm}$.

The beam of a diode laser emitting at around $v=$ $3663 \mathrm{~cm}^{-1}$ is focused into an astigmatic Herriott-type multipass-absorption cell (MPC) as depicted in Fig. A10 (Dyroff, 2009). After 238 passes inside the MPC an absorption pathlength of $76 \mathrm{~m}$ is accumulated, and the exiting beam is focused onto the thermoelectrically cooled sample detector (SD). The gas pressure inside the MPC is maintained at 


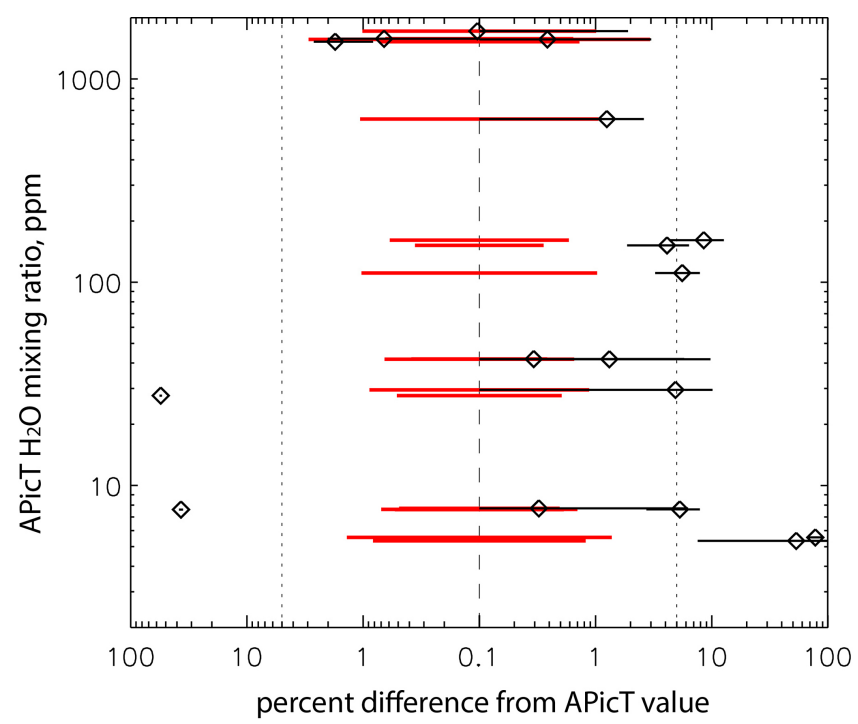

Figure A9. Comparison of SnowWhite and APicT during the stationary segments during the second week's dynamic experiments. Data analysis is as described in Sect. A8. The black symbols and error bars indicate segment averages and standard deviations. The red bars denote the APicT precision derived from the Gaussian fit. Dashed lines indicate the $\pm 5 \%$ error interval.

$70 \mathrm{hPa}$. Reference spectra due to absorption within a highconcentration reference cell are recorded by the reference detector (RD). These spectra are used for locking of the laser emission wavelength to the spectral scan window.

Wavelength modulation spectroscopy is used in combination with second-derivative detection in order to improve the signal-to-noise ratio as well as to minimize the contribution of absorption due to residual water inside the free optical paths.

In order to perform isotopic-ratio measurements it is necessary to probe absorption lines with relatively similar integrated line strengths. Due to the low abundance of the heavy isotopologues $\mathrm{H}_{2}{ }^{18} \mathrm{O}$ and $\mathrm{H}_{2}{ }^{17} \mathrm{O}$ it is therefore necessary to probe a relatively weak $\mathrm{H}_{2}{ }^{16} \mathrm{O}$ line. Although a good detection limit has been achieved in terms of optical density, the relatively low integrated line strength in turn leads to a somewhat reduced precision in the $\mathrm{H}_{2}{ }^{16} \mathrm{O}$ measurements.

For calibration purposes a calibration gas source was developed that produces a gas mixture of known isotopic composition by injecting small droplets of water $(\approx 30 \mu \mathrm{m}$ diameter) into a flow of dry $\mathrm{N}_{2}$. Since ISOWAT has been developed to measure water-isotopic ratios, all our efforts were focused to achieve stable isotopic ratios rather than water mixing ratios of ultimate stability. This calibration source has a calibration uncertainty of around $\pm 50 \mathrm{ppm}$. However, it is important to stress that this uncertainty does not lead to uncertainties in the isotopic ratios.

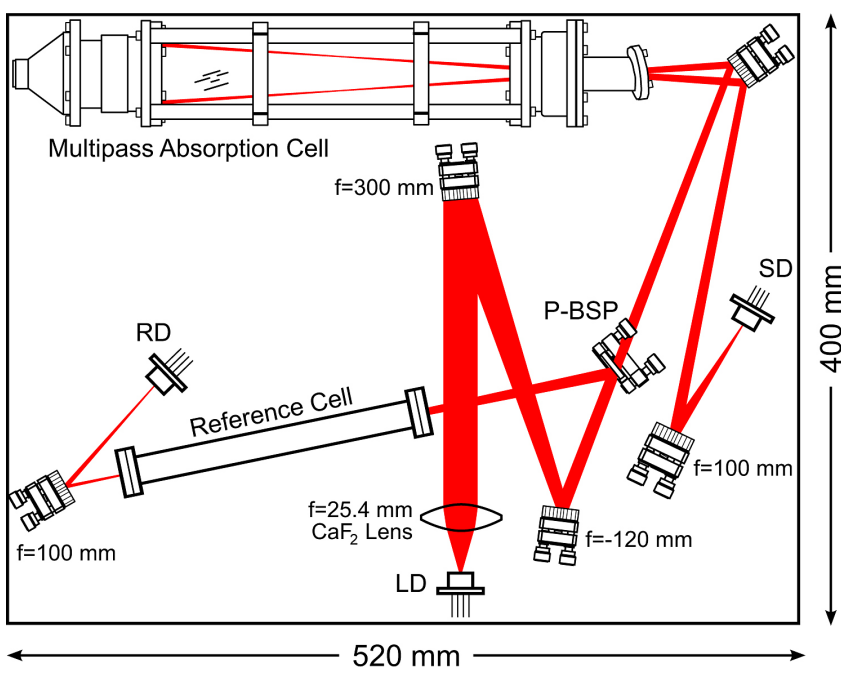

Figure A10. ISOWAT schematic. The beam of a tunable diode laser (LD) is focused into a multipass-absorption cell to achieve $76 \mathrm{~m}$ absorption pathlength. The sample detector (SD) records the multipass cell signal. A high-concentration reference cell in combination with the reference detector (RD) is used for laser wavelength stabilization.

ISOWAT was connected to the chamber via heated stainless-steel tubing to an extractive port. A flow of around 1.25 SLM through the MPC was established by a membrane pump downstream of the instrument. The pressure inside the MPC was controlled by a proportional valve located upstream of the cell.

During AquaVIT-1 the first prototype of ISOWAT was tested, which was finalized just prior to the campaign. During the campaign relatively large drift was observed in the mixing ratios (not in the isotopic ratios) that could later be linked to thermally induced changes in the optical alignment of the instrument. Since the campaign this issue has been largely eliminated. Furthermore, the sensitivity of ISOWAT was increased by careful investigation and elimination of noise sources. The current performance of ISOWAT can be found in Dyroff et al. (2010). ISOWAT has been deployed since April 2010 aboard the CARIBIC A340-600 passenger aircraft (Brenninkmeijer et al., 2007), where it provides monthly measurements of $\delta^{18} \mathrm{O}$ and $\delta \mathrm{D}$ in the upper troposphere.

\section{A10 Open-path Jülich Stratospheric TDL Experiment (OJSTER)}

\section{A10.1 Instrument description}

OJSTER (Open-path Jülich Stratospheric TDL Experiment) is an open-path cell diode laser experiment manufactured by MayComm Inc. (California, USA). The open-path Herriott multipath cell allows for absorption lengths of $4 \mathrm{~m}$. The $1.37 \mu \mathrm{m}$ diode laser can be tuned over a $\mathrm{H}_{2} \mathrm{O}$ absorption 
line, and analyzed both in direct absorption or the $2 f$ mode. The instrument is similar to the ER-2 instrument described in May (1998), which originally used the matrix method to compensate for pressure and temperature dependence. This calibration matrix is provided by the manufacturer and is derived from measurements made in a climate chamber against an EdgeTech DewPrime 2000 Chilled Mirror system. This calibration has been re-evaluated in the Jülich laboratories against the MBW-DP30 frost-point hygrometer, which also serves as a reference hygrometer for FISH calibrations. First aircraft measurements and characterization of OJSTER in the laboratory are given in Schlicht (2006).

\section{A10.2 Performance during AquaVIT-1}

During AquaVIT-1, the open-path cell of OJSTER was mounted in a stainless-steel container with a volume of a few liters in the cold space outside the chamber walls (Fig. 2). Chamber air was extracted with a pump via stainless-steel tubes (Fig. 3). This experimental setup had two major disadvantages: first, the outgassing of the OJSTER cell components was very slow; even after several cycles of purging with dry warm air, a background $\mathrm{H}_{2} \mathrm{O}$ contamination of up to $20 \mathrm{ppm}$ was detected. Secondly, the container leaked at the lowest temperatures; therefore, no measurements at all were obtained on AquaVIT-1 days with the lowest temperatures. OJSTER data during AquaVIT-1, therefore, cannot be used for a quantitative comparison with other hygrometers.

\section{A11 PicoSDLA}

PicoSDLA is a tunable diode laser spectrometer that measures in situ $\mathrm{H}_{2} \mathrm{O}$ by absorption spectroscopy at $2.63 \mathrm{mi}-$ crometer wavelength. The beam emitted by an antimonide laser diode is propagated in the open atmosphere over a $1 \mathrm{~m}$ distance, and in situ spectra are recorded with an InAs detector at $1 \mathrm{~s}$ intervals. The sensor is designed to be operated from stratospheric balloons. At the time of the AquaVIT-1 experiment, PicoSDLA was still under development, and it had just been tested in flight three months before the beginning of the campaign. For a detailed description of the laser hygrometer, see Durry et al. (2008).

For the calculation of water vapor mixing ratios, a nonlinear least-square fit was applied to the full molecular line shape using a molecular model based on the Beer-Lambert law in conjunction with pressure and temperature measurements yielded by onboard sensors. The detection technique is a standard direct-differential method. With all the sources of errors taken into account (baseline determination, spectroscopy, nonlinearities in the laser spectral emission, achieved signal-to-noise ratio in the spectra, uncertainties in pressure and temperature determinations), the expected precision in the water vapor mixing-ratio retrievals ranges between 5 and $10 \%$ for UT-LS conditions.
PicoSDLA was installed outside the AIDA chamber but inside the chamber thermal enclosure. The laser hygrometer was integrated into a $150 \mathrm{~mm}$ diameter cylinder with a length of $1.5 \mathrm{~m}$. This cylinder was located at the bottom of the chamber enclosure (Fig. 2). The chamber inlet line was connected to the cylinder with a flexible connection (Tombac, DN40mm). The output of the cylinder was connected to a vacuum pump and to a flow rate regulator. Electric wires were passed through special vacuum connectors capable of operation at very low temperatures (down to $-90^{\circ} \mathrm{C}$ ). The flow rate was adjusted during the calibration campaign with a regulator in the AIDA control room. This regulator was set between 10 and $30 \mathrm{Lmin}^{-1}$ (at very low pressure, the real flow rate was less than $10 \mathrm{~L} \mathrm{~min}^{-1}$ ). During AquaVIT1, typical flow rates through the instrument were 1.0 SLM, decreasing to about $0.3 \mathrm{SLM}$ at a total chamber pressure of $100 \mathrm{hPa}$. At lower pressures, the small flow rates led to a very slow effective time response of the instrument.

Once installed in the cylinder, PicoSDLA was operated continuously with no intervention during the full campaign. The behavior of the laser hygrometer installed in the cylinder was really satisfying in terms of laser stability and quality of the absorption spectra despite the low temperature encountered (down to $-90^{\circ} \mathrm{C}$ ) and the duration of the measurement (10 days for $8 \mathrm{~h}$ per day, as compared to the $3 \mathrm{~h}$ duration of a standard stratospheric flight).

PicoSDLA is not designed for operation in a closed cell like in the AquaVIT-1 configuration. It is typically operated in an open-path configuration suspended from a stratospheric balloon. This means that the air sample between the laser and detector is renewed every second based on a descent speed of the balloon of $2-3 \mathrm{~m} \mathrm{~s}^{-1}$ and a cell length of $1 \mathrm{~m}$. The equivalent flow rate is more than 30 SLM. The effect seen during AquaVIT-1 calibrations is that, for medium $\mathrm{H}_{2} \mathrm{O}$ concentrations and with sufficient flow rates, PicoSDLA gives a result in agreement with the reference data (see discussions in previous chapters). Nevertheless, one critical issue for PicoSDLA in the present configuration is the contamination by water vapor outgassing from the instrument itself or from the cylinder; this effect could even be enhanced by the fact that flat heaters were used at different places in the instrument to maintain proper operation of the laser, detector, and electronics. It could explain the disagreement with reference values observed at very low water vapor concentrations. In retrospect, after looking at the PicoSDLA data, it would have been perhaps more appropriate to locate the laser sensor in the main chamber with other core instruments. The relation between flow rate, heater operations, and potential $\mathrm{H}_{2} \mathrm{O}$ outgassing effect in the cylinder is still unclear to us.

\section{A12 WaSul-Hygro2}

During the campaign a prototype of the photoacousticspectroscopy-based WaSul-Hygro (Bozóki et al., 2003) was operated fully automatically without being supervised by 
the Hungarian group. Only after the campaign, during data evaluation, did it became clear that the WaSul-Hygro1 and WaSul-Hygro2 instruments were almost always operated under overload conditions caused by excessive acoustical noise inside the gas handling system, which ruined most of the measured data. Based on this experience, the WaSulHygro instruments are now equipped with additional noisecanceling acoustic buffer volumes, and there is also an overload detection algorithm implemented into its electronics.

\section{A13 Closed-path Laser Hygrometer (CLH)}

The University of Colorado Closed-path Laser Hygrometer (CLH) is a tunable diode laser spectrometer designed to measure tropospheric water vapor and particulate water. This sensor is virtually identical, except for its internal absorption cell, to open-path instruments (JLH) flown by the JPL group (R. May and R. Herman) on the NASA ER-2, DC-8, and WB-57 during past missions. These water vapor spectrometers use near-infrared $\left(1.37 \mu \mathrm{m}, 7306 \mathrm{~cm}^{-1}\right)$ TDL sources that provide about $5 \mathrm{~mW}$ of single-mode output. In addition to their small size and dependability, these lasers are attractive because they operate near room temperature, eliminating the need for cryogens. Instead, a thermoelectric element is used to stabilize the laser temperature to about $15^{\circ} \mathrm{C}$. The infrared detector - a standard InGaAs sensor - also does not require cryogens but is mounted to a thermostated base plate to maintain a stable operating temperature.

The absorption path is defined by the length of the internal sample cell, a $6 \mathrm{~mm}$ ID stainless-steel tube, which is capped at both ends with anti-reflection-coated quartz windows. The path length is $27.62 \mathrm{~cm}$, with a single pass between the laser and detector, which is sufficient for tropospheric water (the original intent) but is limited to mixing ratios above about $10 \mathrm{ppm}$ in the upper troposphere and lower stratosphere for $1 \mathrm{~s}$ integrations.

On aircraft, the CLH measures behind a forward-facing, heated inlet. The sample flow velocity within the instrument is fixed at less than $5 \mathrm{~m} \mathrm{~s}^{-1}$ using a mass flow controller, considerably slowing the flow compared to the free-stream velocity. This subisokinetic condition enhances sampling of particulates relative to the gas phase. The particles are evaporated primarily by ram heating, and the resulting water vapor is measured by absorption. The inlet has been designed such that the instrument is sensitive to particles larger than about $5 \mu \mathrm{m}$ in diameter. Details of the CLH instrument and its performance on research aircraft can be found in Davis et al. (2007a, b).

At the AIDA facility, the CLH was operated in conditions quite different from the normal flight configuration. The instrument sat on a table at ambient pressure and temperature, and was connected to the chamber via a long, heated stainless-steel line. The internal mass flow controller was bypassed for most of the experiments, and air was pulled through the instrument by attaching to the general vacuum system via an external flow controller. When available, a low delta-P flow controller was used to allow for the highest flow rates possible.

\section{A13.1 Performance during AquaVIT}

The CLH experienced a number of problems during the AquaVIT-1 experiments that limited the ability to participate in several of the experiments, especially during the static experiments. Three separate issues affected the instrument performance and the amount of data collected: (1) a small $\left(\sim 1\right.$ standard $\left.\mathrm{cm}^{3} \mathrm{~min}^{-1}(\mathrm{sccm})\right)$ leak of ambient air into the instrument, (2) an instrument computer failure, and (3) undermodulation of the laser frequency. The instrument computer was replaced, but a day of data collection was lost in the process. To address the leak, a set of tests was performed to assess the impact on the measured water vapor. As a result, only data with a total instrument flow rate greater than 1 SLM were used; under these conditions the leak contributed less water to the system than detectable within the precision of the instrument. Undermodulation of the laser frequency was corrected in data post-processing but, because the correction relies on spectral line parameters, resulted in a somewhat larger uncertainty in the overall data than original expected. Additionally, some amount of aliasing in the spectra could not be removed, resulting in degraded signal-to-noise ratio and worse-than-normal precision.

Despite the problems encountered, CLH gathered usable data during three of the static and three of the dynamic experiments. As a result of its short pathlength, CLH cannot retrieve usable spectra at mixing ratios less than $10 \mathrm{ppm}$, so no data are provided for a number of experiments.

\section{A13.2 Lessons learned}

The AquaVIT-1 experiment provided a wealth of data for assessing the performance of the CLH under conditions previously inaccessible in laboratory calibrations, especially at very low mixing ratios and low pressures. With these data, we were able to firmly establish the instrument's detection threshold.

\section{A14 PTB water vapor permeation source (PTB-WVPS)}

PTB provided the PTB-WVPS that was used for intercomparison with the CFH, MBW-DP30 (used to calibrate FISH$1 / 2$ instruments), and MBW-373LX instruments. The humidity reference source was calibrated with the national trace humidity standard of Germany (Mackrodt, 2012; Brewer et al., 2011) at PTB using a chilled-mirror hygrometer as the transfer standard. The humidity source consists of three permeation tubes made from different lengths of PTFE and located in a thermostatic bath filled with purified water. The tubes are flushed constantly with dry synthetic air. The water vapor content can be varied by changing the temperature in the thermostatic bath or the airflow over the tubes. The 
temperature controls the permeation rates, and the airflow determines the dilution rate. The WVPS covers a range of 0.5 to 5 ppmv with an expanded relative uncertainty $(k=2)$ of $2 \%$. The main contribution to the measurement uncertainty is that of the calibration of the flow meter used to control the airflow ( $1 \%$ relative uncertainty). Due to the nonlinearity of the mass flow controller calibration, the flow is corrected by a third-order polynomial. Using the full range of the flow meter and bath temperatures of 30 to $60^{\circ} \mathrm{C}$, the humidity range can be extended from $250 \mathrm{ppbv}$ to $50 \mathrm{ppmv}$. 


\section{Dedication}

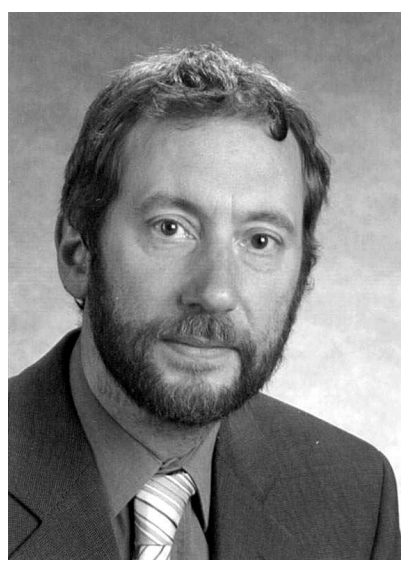

This work is dedicated to our dear colleague and driving force in AquaVIT-1 activity, the excellent and enthusiastic scientist Dr. Cornelius Schiller. He died much too soon at the age of 50 years on 3 March 2012. Starting in 1986 he built a group to measure atmospheric water vapor at the Forschungszentrum Jülich and became one of the world's leading scientists in this research area. He was chairman and member of several international scientific bodies. His research resulted in numerous highly relevant publications on the distribution and the changes in the global water vapor budget of the upper troposphere and stratosphere. With his passing we lose a colleague with the highest personal regard, a mentor for young researchers, and a paragon for all colleagues.

Acknowledgements. In ordering the authors, the first eight include the referees (D. W. Fahey, R.-S. Gao, O. Möhler), the organizers (H. Saathoff, C. Schiller 4, V. Ebert), and those who helped conceive and initiate the intercomparison (M. Krämer, T. Peter). The remaining authors from individual participating teams are in alphabetical order.

The success of the AquaVIT-1 campaign derived significantly from the excellent support of the staff scientists and technicians at the AIDA facility led by O. Möhler and H. Saathoff. R. Bauer of Forschungszentrum Jülich, Jülich, Germany, provided support for the AquaVIT-1 wiki page. Travel support for the referees (D. W. Fahey and R. S. Gao) and some investigator groups was provided by the EU project EUROCHAMP; by SPARC - a core project of the world climate research program; and by the Institute for Meteorology and Climate Research of Karlsruhe, Germany. The NASA Upper Atmospheric Research Program also provided travel support for some USA participants. Elliot Weinstock is gratefully acknowledged for his valuable assistance with the HWV measurements. Ulrich Krieger and Martin Brabec are gratefully acknowledged for their help with SnowWhite. Z. Bozóki was partially supported by the OTKA Foundation from the Hungarian Research and Technology Innovation Fund (project number: NN109679).

This research and participation of JLH in AquaVIT-1 were supported by the NASA Atmospheric Composition Focus. The research described here was carried out by the Jet Propulsion
Laboratory, California Institute of Technology, under a contract with NASA. (Copyright 2009 California Institute of Technology. Government sponsorship acknowledged.)

Edited by: H. Schlager

\section{References}

Altmann, J., Baumgart, R., and Weitkamp, C.: Two-mirror multipass absorption cell, Appl. Optics, 20, 995-999, 1981.

Awtry, A. R., Fisher, B. T., Moffatt, R. A., Ebert, V., and Fleming, J. W.: Simultaneous diode laser based in situ quantification of oxygen, carbon monoxide, water vapor, and liquid water in a dense water mist environment, Proceedings of the Combustion Institute, 31, 799-806, 2006.

Bozóki, Z., Szakáll, M., Mohácsi, Á., Szabó, G., and Bor, Z.: Diode laser based photoacoustic humidity sensors, Sensor. Actuat. BChem., 91, 219-226, 2003.

Brenninkmeijer, C. A. M., Crutzen, P., Boumard, F., Dauer, T., Dix, B., Ebinghaus, R., Filippi, D., Fischer, H., Franke, H., Frieß, U., Heintzenberg, J., Helleis, F., Hermann, M., Kock, H. H., Koeppel, C., Lelieveld, J., Leuenberger, M., Martinsson, B. G., Miemczyk, S., Moret, H. P., Nguyen, H. N., Nyfeler, P., Oram, D., O’Sullivan, D., Penkett, S., Platt, U., Pupek, M., Ramonet, M., Randa, B., Reichelt, M., Rhee, T. S., Rohwer, J., Rosenfeld, K., Scharffe, D., Schlager, H., Schumann, U., Slemr, F., Sprung, D., Stock, P., Thaler, R., Valentino, F., van Velthoven, P., Waibel, A., Wandel, A., Waschitschek, K., Wiedensohler, A., Xueref-Remy, I., Zahn, A., Zech, U., and Ziereis, H.: Civil Aircraft for the regular investigation of the atmosphere based on an instrumented container: The new CARIBIC system, Atmos. Chem. Phys., 7, 4953-4976, doi:10.5194/acp-7-4953-2007, 2007.

Brewer, P. J., Milton, M. J. T., Harris, P. M., Bell, S. A., Stevens, M., Scace, G., Abe, H., and Mackrodt, P.: EURAMET1002: international comparability in measurements of trace water vapour, NPL REPORT AS, 59, ISSN: 1754-2928, 2011.

Brown, L. R.: Empirical line parameters of methane from 1.1 to 2.1 micrometers, J. Quant. Spectrosc. Ra., 96, 251-270, 2005.

Buchholz, B., Kühnreich, B., Smit, H. G. J., and Ebert, V.: Validation of an extractive, airborne, compact TDL spectrometer for atmospheric humidity sensing by blind intercomparison, Appl. Phys. B., 110, 249-262, 2013.

Buchholz, B., Böse, N., and Ebert, V.: Absolute validation of a diode laser hygrometer via intercomparison with the german national primary water vapor standard, Appl. Phys. B., 1-17, doi:10.1007/s00340-014-5775-4, 2014.

Cirisan, A., P. Luo, B., Engel, I., Wienhold, F. G., K. Krieger, U., Weers, U., Romanens, G., Levrat, G., Jeannet, P., Ruffieux, D., Philipona, R., Calpini, B., Spichtinger, P., and

Peter, T.: Balloon-borne match measurements of mid-latitude cirrus clouds, Atmos. Chem. Phys. Discuss., 13, 25417-25479, doi:10.5194/acpd-13-25417-2013, 2013.

Davis, S. M., Hallar, A. G., Avallone, L. M., and Engblom, W.: Measurements of ice water content with a tunable diode laser hygrometer: calibration procedure and inlet analysis, J. Atmos. Ocean. Tech., 24, 463, doi:10.1175/JTECH1975.1, 2007a.

Davis, S. M., Avallone, L. M., Weinstock, E. M., Twohy, C. H., Smith, J. B., and Kok, G. L.: Comparisons of in situ measure- 
ments of cirrus cloud ice water content, J. Geophys. Res., 112, D10212, doi:10.1029/2006JD008214, 2007b.

Dessler, A. E.: Observations of climate feedbacks over 2000-10 and comparisons to climate models, J. Climate, 26, 333-342, doi:10.1175/JCLI-D-11-00640.1, 2013.

Dreier, T., Ebert, V., and Schulz, C.: Laser-based Combustion Diagnostics in Encyclopedia of Analytical Chemistry, 2nd edn., edited by: Meyers, R. A., John Wiley, Chichester, ISBN 978-0470-97333-2, 2011.

Durry, G., Amarouche, N., Joly, L., Liu, X., Zéninari, V., and Parvitte, B.: Laser diode spectroscopy of $\mathrm{H}_{2} \mathrm{O}$ at 2.63 micron for atmospheric applications, Appl. Phys. B., 90, 573-580, 2008.

Dyroff, C.: Tunable diode-laser absorption spectroscopy for trace-gas measurements with high sensitivity and low drift, Ph.D. thesis, University of Karlsruhe, ISBN: 978-3-86644328-0, available at: http://digbib.ubka.uni-karlsruhe.de/volltexte/ 1000010030 (last access: 20 March 2014), 2009.

Dyroff, C., Fütterer, D., and Zahn, A.: Compact diode-laser spectrometer ISOWAT for highly sensitive airborne measurements of water-isotope ratios, Appl. Phys. B., 98, 537-548, doi:10.1007/s00340-009-3775-6, 2010.

Ebert, V.: In situ Absorption Spectrometers using near-IR diode lasers and rugged multi-path-optics for environmental field measurements, in: Laser Applications to Chemical and Environmental Analysis, OSA Technical Digest, paper WB1, Optical Society of America, Washington DC, 2006.

Ebert, V. and Wolfrum, J.: Absorption spectroscopy, in: Optical Measurements-Techniques and Applications, 2nd corr. edn, edited by: Mayinger, F. and Feldmann, O., Heat and Mass Transfer, Springer Verlag, Heidelberg, München, 227-265, 2001.

Ebert, V., Fitzer, J., Gerstenberg, I., Pleban, K.-U., Pitz, H., Wolfrum, J., Jochem, M., and Martin, J.: Simultaneous laser-based in-situ-detection of oxygen and water in a waste Incinerator for active combustion control purposes, Proceedings of the Combustion Institute, 27, 1301-1308, 1998.

Ebert, V., Teichert, H., Giesemann, C., Saathoff, H., and Schurath, U.: Fiber-coupled in situ-laser absorption spectrometer for the selective detection of water vapor traces down to the ppblevel, VDI Berichte 1863, VDI Verl., Düsseldorf, 197-208, 2004.

Ebert, V., Teichert, H., Giesemann, C., Saathoff, H., and Schurath, U.: Fiber-coupled in situ-laser absorption spectrometer for the selective detection of water vapor traces down to the ppblevel, Tech. Mess., 72, 23-30, 2005.

Ebert, V., Saathoff, H., Lauer, C., Hunsmann, S., and Wagner, S.: Simultaneous, absolute gas-phase and total water detection during cloud formation studies in the AIDA chamber using a dual $1.37 \mu \mathrm{m}$ TDL-Spectrometer, European Geosciences Union - General Assembly 2008, Vienna, Austria, 13-18 April, EGU2008-A-10066, 2008.

Fernholz, T., Teichert, H., and Ebert, V.: Digital, phase-sensitive detection for in situ diode laser spectroscopy under rapidly changing transmission conditions, Appl. Phys. B., 75, 229-236, 2002.

Fujiwara, M., Shiotani, M., Hasebe, F., Vömel, H., Oltmans, S., Ruppert, P., and Horinouchi, T. T. T.: Performance of the meteolabor "Snow White" chilled-mirror hygrometer in the tropical troposphere: comparisons with the Vaisala RS80 A/H-humicap sensors, J. Atmos. Ocean. Tech., 20, 1534-1542, 2003.

Giesemann, C.: Entwicklung und Einsatz eines Diodenlaserspektrometers zum quantitativen In-situ-Nachweis von Methan und
Wasser in der Stratosphäre,Ph.D. thesis, Fakultät für Chemie und Geowissenschaften, Universität Heidelberg, 2003.

Giesemann, C., Teichert, H., Saathoff, H., Schurath, U., and Ebert, V.: Fiber-coupled near-infrared diode laser based in situ hygrometer for the detection of water traces in cryogenic aerosol clouds, 4th International Conference on Tunable Diode Laser Spectroscopy, Zermatt, CH, 14-18 July, 2003.

Gurlit, W., Burrows, J. P., Zimmermann, R., Platt, U., Giesemann, C., Wolfrum, J., and Ebert, V.: Light-weight diode laser spectrometer for balloon-borne measurements of water vapor and methane, Appl. Optics, 44, 91-102, 2005.

Herriott, D. R., Kogelnik, H., and Kompfner, R.: Off-axis paths in spherical mirror interferometers, Appl. Optics, 3, 523-526, 1964.

Hintsa, E. J., Weinstock, E. M., Anderson, J. G., and May, R. D.: On the accuracy of in situ water vapor measurements in the troposphere and lower stratosphere with the Harvard Lyman- $\alpha$ hygrometer, J. Geophys. Res., 104, 8183-8189, 1999.

Hunsmann, S., Wagner, S., Saathoff, H., Möhler, O., Schurath, U., and Ebert, V.: Measurement of the temperature dependence of line strength and pressure broadening coefficients of water absorption lines in the $1.4 \mu \mathrm{m}$-Band, VDI Berichte 1959, VDI Verl., Düsseldorf, 149-164, 2006.

Jensen, E. J., Smith, J. B., Pfister, L., Pittman, J. V., Weinstock, E. M., Sayres, D. S., Herman, R. L., Troy, R. F., Rosenlof, K., Thompson, T. L., Fridlind, A. M., Hudson, P. K., Cziczo, D. J., Heymsfield, A. J., Schmitt, C., and Wilson, J. C.: Ice supersaturations exceeding $100 \%$ at the cold tropical tropopause: implications for cirrus formation and dehydration, Atmos. Chem. Phys., 5, 851-862, doi:10.5194/acp-5-851-2005, 2005.

Jensen, E. J., Pfister, L., Bui, T. V., Lawson, P., Baker, B., Mo, Q., Baumgardner, D., Weinstock, E. M., Smith, J. B., Moyer, E. J., Hanisco, T. F., Sayres, D. S., Clair, J. M. St., Alexander, M. J., Toon, O. B., and Smith, J. A.: Formation of large $(\sim 100 \mu \mathrm{m})$ ice crystals near the tropical tropopause, Atmos. Chem. Phys., 8, 1621-1633, doi:10.5194/acp-8-1621-2008, 2008.

Khaplanov, M., Astakhov, V., Lukjanov, A., Kretova, M., and Yushkov, V.: Fluorescent hygrometer for middle atmosphere measurements, Proc. 19th Annual European Meeting on Atmospheric Studies by Optical Methods, 540-545, 1992.

Khaykin, S. M., Engel, I., Vömel, H., Formanyuk, I. M., Kivi, R., Korshunov, L. I., Krämer, M., Lykov, A. D., Meier, S., Naebert, T., Pitts, M. C., Santee, M. L., Spelten, N., Wienhold, F. G., Yushkov, V. A., and Peter, T.: Arctic stratospheric dehydration - Part 1: Unprecedented observation of vertical redistribution of water, Atmos. Chem. Phys., 13, 11503-11517, doi:10.5194/acp13-11503-2013, 2013.

Kley, D.: $\mathrm{Ly}(\alpha)$ absorption cross-section of $\mathrm{H}_{2} \mathrm{O}$ and $\mathrm{O}_{2}$, J. Atmos. Chem., 2, 203-210, 1984.

Krämer, M., Schiller, C., Afchine, A., Bauer, R., Gensch, I., Mangold, A., Schlicht, S., Spelten, N., Sitnikov, N., Borrmann, S., de Reus, M., and Spichtinger, P.: Ice supersaturations and cirrus cloud crystal numbers, Atmos. Chem. Phys., 9, 3505-3522, doi:10.5194/acp-9-3505-2009, 2009.

Lauer, C., Weber, D., Wagner, S., and Ebert, V.: Calibration free measurement of atmospheric methane background via tunable diode laser absorption spectroscopy at $1.6 \mu \mathrm{m}$, Laser Applications to Chemical, Security and Environmental Analysis (LACSEA), St. Petersburg, Florida, USA, 17-20 March 2008, Paper 
no. LMA2 and Dresdner Beiträge zur Sensorik, Hrsg. G. Gerlach, and P. Hauptmann, Band 29, ISBN 978-3-940046-45-1, 710, 2007.

Mackrodt, P.: A new attempt on a coulometric trace humidity generator, Int. J. Thermophys., 33, 1520-1535, 2012.

Mangold, A., Wagner, R., Saathoff, H., Schurath, U., Giesemann, C., Ebert, V., Krämer, M., and Möhler, O.: Experimental investigation of ice nucleation by different types of aerosols in the aerosol chamber AIDA: implications to microphysics of cirrus clouds, Meteorol. Z., 14, 485-497, 2005.

May, R. D.: Open-path, near-infrared tunable diode laser spectrometer for atmospheric measurements of $\mathrm{H}_{2} \mathrm{O}$, J. Geophys. Res., 103, 19161-19172, 1998.

May, R. D. and Webster, C. R.: Data processing and calibration for tunable diode laser harmonic absorption spectrometers, J. Quant. Spectrosc. Ra., 49, 335-347, 1993.

Meyer, J.: Vergleich und Charakterisierung stratosphärisch messender in-situ Hygrometer, Diploma thesis, University Aachen, 2008 (in German).

Meyer, J., et al.: Calibration of a fluorescence hygrometer at low water mixing ratios, in preparation, Atmos. Meas. Tech. Discuss., in preparation, 2014.

Miloshevich, L., Vömel, H., Whiteman, D., Lesht, B., Schmidlin, F., and Russo, F.: Absolute accuracy of water vapor measurements from six operational radiosonde types launched during AWEXG, and implications for AIRS validation, J. Geophys. Res., 111, doi:10.1029/2005JD006083, 2006.

Möhler, O., Stetzer, O., Schaefers, S., Linke, C., Schnaiter, M., Tiede, R., Saathoff, H., Krämer, M., Mangold, A., Budz, P., Zink, P., Schreiner, J., Mauersberger, K., Haag, W., Kärcher, B., and Schurath, U.: Experimental investigation of homogeneous freezing of sulphuric acid particles in the aerosol chamber AIDA, Atmos. Chem. Phys., 3, 211-223, doi:10.5194/acp-3-211-2003, 2003.

Möhler, O., Büttner, S., Linke, C., Schnaiter, M., Saathoff, H., Stetzer, O., Wagner, R., Krämer, M., Mangold, A., Ebert, V., and Schurath, U.: Effect of sulfuric acid coating on heterogeneous ice nucleation by soot aerosol particles, J. Geophys. Res., 110, D11210, doi:10.1029/2004JD005169, 2005.

Möhler, O., Benz, S., Saathoff, H., Schnaiter, M., Wagner, R., Schneider, J., Walter, S., Ebert, V., and Wagner, S.: The effect of organic coating on the heterogeneous ice nucleation efficiency of mineral dust aerosol, Environ. Res. Lett., 3, 025007 , doi:10.1088/1748-9326/3/2/025007, 2008a.

Möhler, O., Georgakopoulos, D. G., Morris, C. E., Benz, S., Ebert, V., Hunsmann, S., Saathoff, H., Schnaiter, M., and Wagner, R.: Heterogeneous ice nucleation activity of bacteria: new laboratory experiments at simulated cloud conditions, Biogeosciences, 5, 1425-1435, doi:10.5194/bg-5-1425-2008, 2008b.

Murphy, D. M. and Koop, T.: Review of the vapour pressures of ice and supercooled water for atmospheric applications, Q. J. Roy. Meteorol. Soc., 131, 1539-1565, 2005.

Murray, B. J., Wilson, T. W., Dobbie, S., Cui, Z., Möhler, O., Schnaiter, M., Wagner, R., Benz, S., Niemand, M., Saathoff, H., Ebert, V., and Kärcher, B.: Glassy aerosol modify cirrus cloud properties, Nat. Geosci., 3, 233-237, 2010.

Peter, T., Marcolli, C., Spichtinger, P., Corti, T., Baker, M. B., Koop, T.: When dry air is too humid, Science, 314, 1399-1402, doi:10.1126/science.1135199, 2006.
Peter, T., Krämer, M., and Möhler, O.: ETH, Upper Tropospheric Humidity: a Report on an International Workshop, Karlsruhe, Germany, 12-15 June 2007, SPARC Newsletter No. 30., available at: http://www.sparc-climate.org/publications/ newsletter/ (last access: 20 March 2014), 2008.

Rollins, A. W., Thornberry, T. D., Gao, R. S., Smith, J. B., Sayres, D. S., Sargent, M. R., Schiller, C., Krämer, M., Spelten, N., Hurst, D. F., Jordan, A. F., Hall, E. G., Vömel, H., Diskin, G. S., Podolske, J. R., Christensen, L. E., Rosenlof, K. H., Jensen, E. J., and Fahey, D. W.: Evaluation of UT/LS hygrometer accuracy by intercomparison during the NASA MACPEX mission, J. Geophys. Res., doi:10.1002/2013JD020817, 2014.

Rothman, L. S., Jacquemart, D., Barbe, A., Chris Benner, D., Birk, M., Brown, L. R., Carleer, M. R., Chackerian, C., Chance, K., Coudert, L. H., Dana, V., Devi, V. M., Flaud, J.-M., Gamache, R. R., Goldman, A., Hartmann, J.-M., Jucks, K. W., Maki, A. G., Mandin, J.-Y., Massie, S. T., Orphal, J., Perrin, A., Rinsland, C. P., Smith, M. A. H., Tennyson, J., Tolchenov, R. N., Toth, R. A., Vander Auwera, J., Varanasi, P., and Wagner, G.: The HITRAN 2004 molecular spectroscopic database, J. Quant. Spectrosc. Ra., 96, 139-204, 2005.

Sayres, D. S., Moyer, E. J., Hanisco, T. F., St. Clair, J. M., Keutsch, F. N., O'Brien, A., Allen, N. T., Lapson, L., Demusz, J. N., Rivero, M., Martin, T., Greenberg, M., Tuozzolo, C., Engel, G. S., Kroll, J. H., Paul, J. B., and Anderson, J. G.: A new cavity based absorption instrument for detection of water isotopologues in the upper troposphere and lower stratosphere, Rev. Sci. Instrum., 80, 044102, doi:10.1063/1.3117349, 2009.

Schlicht, S.: Untersuchungen zur Wasserpartitionierung in Wolken, Ph.D. thesis, University of Aachen, Germany, 2006 (in German).

Schmidlin, F.: Relative humidity measurements from a chilledmirror technique flown on low cost radiosonde, American Meteorological Society meeting, American Meteorological Society, Dallas, 1999.

Schulz, C., Dreizler, A., Ebert, V., and Wolfrum, J.: Combustion diagnostics, in: Springer Handbook of Experimental Fluid Dynamics, edited by: Tropea, C., Foss, J., and Yarin, A., 1241-1316, 2007.

Skrotzki, J., Habig, J. C., and Ebert, V.: Integrative fitting of absorption line profiles with high accuracy, robustness, and speed, Appl. Phys. B, doi:10.1007/s00340-013-5706-9, 2013.

Smith, J. B.: The sources and significance of stratospheric water vapor: mechanistic studies from equator to pole, Ph.D. thesis, Harvard University, Cambridge, MA, 2012.

Solomon, S., Rosenlof, K. H., Portmann, R. W., Daniel, J. S., Davis, S. M., Sanford, T. J., and Plattner, G.-K.: Contributions of stratospheric water vapor to decadal changes in the rate of global warming, Science, 327, 1219-1223, 2010.

SPARC Assessment of Upper Tropospheric and Stratospheric Water Vapour, edited by: Kley, D., Russell III, J. M., and Phillips, C., World Climate Research Programme, WCRP-113, available at: http://www.atmosp.physics.utoronto.ca/SPARC/ WAVASFINAL_000206/WWW_wavas/Cover.html (last access: 20 March 2014), 2000.

Teichert, H., Fernholz, T., and Ebert, V.: In situ measurement of CO, $\mathrm{H}_{2} \mathrm{O}$ and gas temperature in a lignite-fired power-plant, Appl. Optics, 42, 2043-2051, 2003.

Trenberth, K. E., Jones, P. D., Ambenje, P., Bojariu, R., Easterling, D., Klein Tank, A., Parker, D., Rahimzadeh, F., Renwick, J. A., 
Rusticucci, M., Soden, B., and Zhai, P.: Observations: Surface and Atmospheric Climate Change, in: Climate Change 2007: The Physical Science Basis. Contribution of Working Group I to the Fourth Assessment Report of the Intergovernmental Panel on Climate Change, edited by: Solomon, S., Qin, D., Manning, M., Chen, Z., Marquis, M., Averyt, K. B., Tignor, M., and Miller, H. L., Cambridge University Press, Cambridge, United Kingdom and New York, NY, USA, 2007.

Troy, R. F.: Field studies of ice supersaturations in the tropical tropopause layer, Ph.D. thesis, University of California at Los Angeles, Los Angeles, CA, 177 pp., 2007.

Vaughan, G., Cambridge, C., Dean, L., and Phillips, A. W.: Water vapour and ozone profiles in the midlatitude upper troposphere, Atmos. Chem. Phys., 5, 963-971, doi:10.5194/acp-5-963-2005, 2005.

Vömel, H.: Report from the NDACC Meeting on Atmospheric Water Vapour Measurement, edited by: Braathen, G., University of Bern, Bern, Switzerland, available at: www.iapmw.unibe.ch/ research/collaboration/ndsc-microwave/workshop/2006 (last access: 20 March 2014), 2006.

Vömel, H., Fujiwara, M., Shirotami, M., Hasebe, F., Oltmans, S., and Barnes, J.: The behavior of Snow White chilled-mirror hygrometer in extremely dry conditions, J. Atmos. Ocean. Tech., 20, 1560-1567, 2003.

Vömel, H., David, D. E., and Smith, K.: Accuracy of tropospheric and stratospheric water vapor measurements by the cryogenic frost point hygrometer: instrumental details and observations, J. Geophys. Res., 112, D08305, doi:10.1029/2006JD007224, 2007a.

Vömel, H., Yushkov, V., Khaykin, S., Korshunov, L., Kyrö, E., and Kivi, R.: Intercomparisons of stratospheric water vapour sensors: FLASH-B and NOAA/CMDL frost-point hygrometer, J. Atmos. Ocean. Tech., 24, 941-952, 2007b.

Wagner, R., Benz, S., Bunz, H., Möhler, O., Saathoff, H., Schnaiter, M., Leisner, T., and Ebert, V.: Infrared optical constants of highly diluted sulfuric acid solution droplets at cirrus temperatures, J. Phys. Chem. A, 112, 11661-11676, doi:10.1021/jp8066102, 2008.

Webster, C. R., May, R. D., Trimble, C. A., Chave, R. G., and Kendall, J.: Aircraft (ER-2) laser infrared absorption spectrometer (ALIAS) for in-situ stratospheric measurements of $\mathrm{HCl}, \mathrm{N}_{2} \mathrm{O}$, $\mathrm{CH}_{4}, \mathrm{NO}_{2}$, and $\mathrm{HNO}_{3}$, Appl. Optics, 33, 454-472, 1994.
Weinstock, E. M., Hintsa, E. J., Dessler, A. E., Oliver, J. F., Hazen, N. L., Demusz, J. N., Allen, N. T., Lapson, L. B., and Anderson, J. G.: New fast response photofragment fluorescence hygrometer for use on the NASA ER-2 and the Perseus remotely piloted aircraft, Rev. Sci. Instrum., 65, 3544-3554, 1994.

Weinstock, E. M., Smith, J. B., Sayres, D., Spackman, J. R., Pittman, J. V., Allen, N., Demusz, J., Greenberg, M., Rivero, M., Solomon, L., and Anderson, J. G.: Measurements of the total water content of cirrus clouds, Part I: Instrument details and calibration, J. Atmos. Ocean. Tech., 23, 1397-1409, doi:10.1175/JTECH1928.1, 2006a.

Weinstock, E. M., Smith, J. B., Sayres, D., Pittman, J. V., Allen, N., and Anderson, J. G.: Measurements of the total water content of cirrus clouds, Part II: Instrument performance and validation, J. Atmos. Ocean. Tech., 23, 1410-1421, doi:10.1175/JTECH1929.1, 2006b.

Weinstock, E. M., Smith, J. B., Sayres, D. S., Pittman, J. V., Spackman, J. R., Hintsa, E. J., Hanisco, T. F., Moyer, E. J., St. Clair, J. M., Sargent, M. R., and Anderson, J. G.: Validation of the Harvard Lyman-a in situ water vapor instrument: implications for the mechanisms that control stratospheric water vapor, J. Geophys. Res., 114, D23301, doi:10.1029/2009JD012427, 2009.

White, J. U.: Long optical path of large aperture, J. Opt. Soc. Am., 32, 285-288, 1942.

Yushkov, V., Merkulov, S., and Astakhov, V.: Optical balloon hygrometer for upper stratosphere and stratosphere water vapour measurements, in optical remote sensing of the atmosphere and clouds, edited by: Wang, J., Wu, B., Ogawa, T., Guans, Z.-H., Proc. SPIE, 3501, 439-445, 1998.

Yushkov, V., Sitnikov, N., Zaitcev, I., Pommereau, J.-P., and Garnier, A.: Stratospheric water vapor measurements in the winter arctic with optical fluorescence hygrometer on short and long duration balloons, in: Proceedings of the 15th ESA Symposium on European Rocket and Balloon programmes and Related Research, Biarritz, France, ESA SP-471, 28-31, edited by: Warmbein, B., ESA, 263-268, 2001.

Zöger, M., Afchine, A., Eicke, N., Gerhards, M.-T., Klein, E., McKenna, D. S., Mörschel, U., Schmidt, U., Tan, V., Tuitjer, F., Woyke, T., Schiller, C.: Fast in situ stratospheric hygrometers: a new family of balloonborne and airborne Lyman- $\alpha$ photofragment fluorescence hygrometers, J. Geophys. Res., 104, 18071816, 1999. 